Report Title:

\title{
Reforming of Liquid Hydrocarbons in a Novel Hydrogen-Selective Membrane-Based Fuel Processor
}

Report Type: Final Technical Report

Reporting Period Start Date: 09/30/2001 End Date: 09/29/2005

Principal Author(s): Shamsuddin Ilias

Report Issue Date: March 10, 2006 DOE Award No.: DE-FG26-01NT41361

Name and Address of Submitting Organization:

North Carolina A\&T State University

Department of Mechanical and Chemical Engineering

Greensboro, NC 27411

E-mail: ilias@ncat.edu

Tel: (336) 334-7564 ext 317 Fax: (336) 334-7417 


\section{DISCLAIMER}

This report was prepared as an account of work sponsored by an agency of the United States Government. Neither the United States Government nor any agency thereof, nor any of their employees, makes any warranty, express or implied, or assumes any legal liability or responsibility for the accuracy, completeness, or usefulness of any information, apparatus, product, or process disclosed, or represents that its use would not infringe privately owned rights. Reference herein to any specific commercial product, process, or service by trade name, trademark, manufacturer, or otherwise does not necessarily constitute or imply its endorsement, recommendation, or favoring by the United States Government or any agency thereof. The views and opinions of authors expressed herein do not necessarily state or reflect those of the United States Government or any agency thereof. 


\begin{abstract}
In this work, asymmetric dense $\mathrm{Pd}$ /porous stainless steel composite membranes were fabricated by depositing palladium on the outer surface of the tubular support. The electroless plating method combined with an osmotic pressure field was used to deposit the palladium film. Surface morphology and microstructure of the composite membranes were characterized by SEM and EDX. The SEM and EDX analyses revealed strong adhesion of the plated pure palladium film on the substrate and dense coalescence of the Pd film. Membranes were further characterized by conducting permeability experiments with pure hydrogen, nitrogen, and helium gases at temperatures from 325 to $450{ }^{\circ} \mathrm{C}$ and transmembrane pressure differences from 5 to 45 psi. The permeation results showed that the fabricated membranes have both high hydrogen permeability and selectivity. For example, the hydrogen permeability for a composite membrane with a $20 \mu \mathrm{m}$ Pd film was $3.02 \times 10^{-5}$ moles $/ \mathrm{m}^{2} . \mathrm{s} . \mathrm{Pa}^{0.765}$ at $450{ }^{\circ} \mathrm{C}$. Hydrogen/nitrogen selectivity for this composite membrane was 1000 at $450^{\circ} \mathrm{C}$ with a transmembrane pressure difference of 14.7 psi.

Steam reforming of methane is one of the most important chemical processes in hydrogen and syngas production. To investigate the usefulness of palladium-based composite membranes in membrane-reactor configuration for simultaneous production and separation of hydrogen, steam reforming of methane by equilibrium shift was studied. The steam reforming of methane using a packed-bed inert membrane tubular reactor (PBIMTR) was simulated. A two-dimensional pseudo-homogeneous reactor model with parallel flow configuration was developed for steam reforming of methane. The shell volume was taken as the feed and sweep gas was fed to the inside of the membrane tube. Radial diffusion was taken into account for concentration gradient in the radial direction due to hydrogen permeation through the membrane. With appropriate reaction rate expressions, a set of partial differential equations was derived using the continuity equation for the reaction system and then solved by finite difference method with appropriate boundary and initial conditions. An iterative scheme was used to obtain a converged solution. Membrane reactor performance was compared to that in a traditional non-membrane packed-bed reactor (PBR). Their performances were also compared with thermodynamic equilibrium values achievable in a conventional non-membrane reactor. Numerical results of the models show that the methane conversions in the PBIMTR are always higher than that in the PBR, as well as thermodynamic equilibrium conversions. For instance, at a reaction pressure of $6 \mathrm{~atm}$, a temperature of $650^{\circ} \mathrm{C}$, a space velocity of $900 / 16.0 \mathrm{SCCM} / \mathrm{gm}_{\text {cat }}$, a steam to methane molar feed ratio of 3.0 , a sweep ratio of 0.15 , the conversion in the membrane reactor is about $86.5 \%$, while the conversion in the non-membrane reactor is about $50.8 \%$. The corresponding equilibrium conversion is about $56.4 \%$. The effects on the degree of conversion and hydrogen yield were analyzed for different parameters such as temperature, reactor pressure, feed and sweep flow rate, feed molar ratio, and space time. From the analysis of the model results, it is obvious that the membrane reactor operation can be optimized for conversion or yield through the choice of proper operating and design parameters. Comparisons with available literature data for both membrane and non-membrane reactors showed a good agreement.
\end{abstract}




\section{TABLE OF CONTENTS}

Title page..........................................................................................................................................................

Disclaimer ...............................................................................................................................................ii

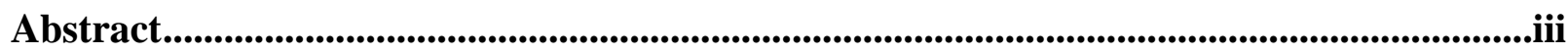

Table of Contents ............................................................................................................................................

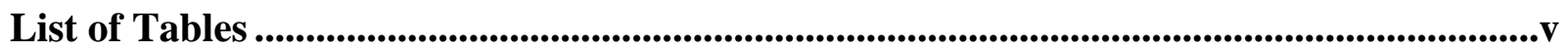

List of Figures...........................................................................................................................................vi

Executive Summary …..................................................................................................................................

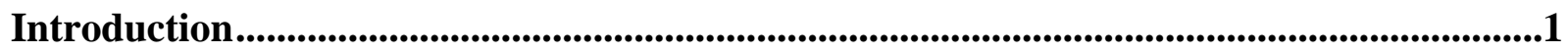

Research Objectives...................................................................................................................2

Materials and Methods.......................................................................................................................2

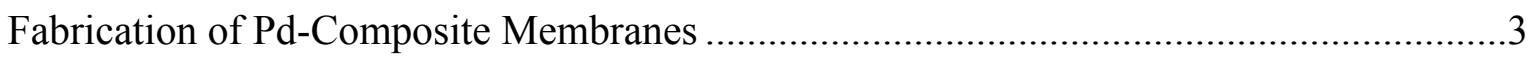

Characterization and Gas Permeation Testing ..............................................................

Membrane Reactor Model Development........................................................................................9

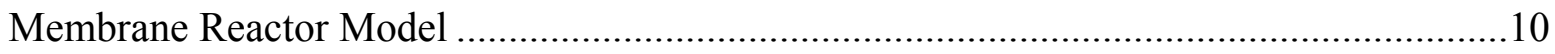

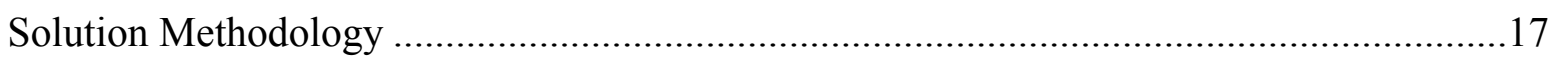

Results and Discussion....................................................................................................................19

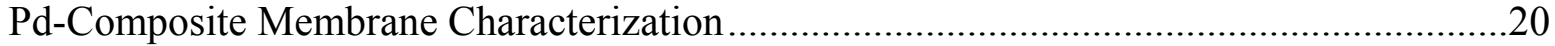

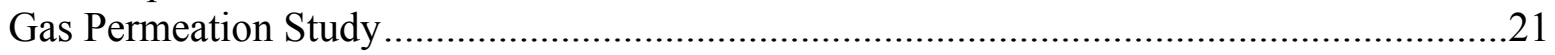

Membrane Reactor Model Simulation and Validation ......................................................22

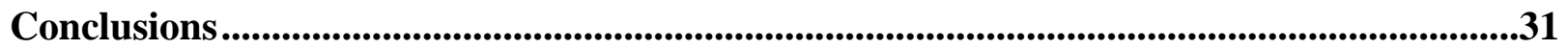

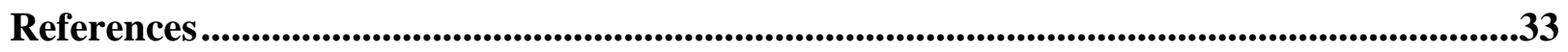

Acknowledgments ...........................................................................................................................33 


\section{LIST OF TABLES}

Table 1. Composition of sensitization and activation Solutions

Table 2. Typical Pd-electroless plating bath composition

Table 3. Kinetic parameters used to calculate rates of three reactions involved in steam methane reforming process

Table 4. Parameters used to calculate adsorption constants of the species involved in the steam methane reforming process

Table 5. Hydrogen permeabilities and regression coefficient values for the composite membrane $(\mathrm{H}=20 \mu \mathrm{m})$ for $\mathrm{n}=0.765$ 


\section{LIST OF FIGURES}

Figure 1. Experimental setup for electroless plating with osmotic pressure field 36

Figure 2. Experimental setup for permeability study 37

$\begin{array}{lll}\text { Figure 3. Permeator/Reactor setup } & 38\end{array}$

Figure 4. Schematic diagram of the membrane reactor configuration 39

Figure 5. Various radial dimensions of the reactor used during problem formulation 39 (not drawn to scale)

Figure 6. SEM and EDX analysis of Pd-film on $0.2 \mu \mathrm{m}$ microporous ceramic substrate: (a) SEM of Pd-film surface; (b) Penetration of Pd-film across the thickness; and (c) EDX analysis of Pd-film.

Figure 7. SEM and EDX analysis of Pd-film on $0.2 \mu \mathrm{m}$ microporous ceramic substrate: (a) SEM of Pd-film surface; (b) Penetration of Pd-film across the thickness (film separated from the support); and (c) EDX analysis of Pd-film.

Figure 8. SEM Micrographs of 0.2 micron pore size stainless steel tube:

(a) Substrate surface at 1000 magnification; (b) Pd-film at 100 magnification; (c) Pd-film at 400 magnification and (d) Pd-film at 2000 magnification.

Figure 9. Scanning electron micrograph of deposited $\mathrm{Pd}$ on the porous SS substrate at 1000 times magnification

Figure 10. SEM of the cross-section of Pd-SS composite membrane showing a uniform deposition on the substrate

Figure 11. Hydrogen flux through Pd-SS composite membrane as a function of indexed pressure difference. Temperature was decreased from $450{ }^{\circ} \mathrm{C}$ to $325^{\circ} \mathrm{C}$.

Figure 12. Arrhenius plot of the hydrogen permeance of the $20 \mu \mathrm{m}$ thick Pd-SS composite membrane as a function of inverse of absolute temperature.

Figure 13. Plot of Hydrogen/Nitrogen $\left(\mathrm{H}_{2} / \mathrm{N}_{2}\right)$ selectivity coefficient as a function of transmembrane pressure difference at various temperatures (20 $\mu \mathrm{m}$ thick Pd-SS composite membrane). 
Figure $14 . \mathrm{He} / \mathrm{N}_{2}$ selectivity coefficient as a function of transmembrane pressure difference at $450{ }^{\circ} \mathrm{C}(20 \mu \mathrm{m}$ thick Pd-SS composite membrane).

Figure15. Comparison of conversions in a PBIMTR as a function of the operating temperature with that in a conventional PBR, as well as thermodynamic equilibrium conversion achievable in a closed system at 2 atm (Space velocity $=900 / 16 \mathrm{SCCM} / \mathrm{gm}_{\text {cat }}$, Steam to methane molar ratio $=3.0$, and Sweep ratio $=1.25$ ).

Figure 16. Comparison of the performance of the PBR with thermodynamic equilibrium conversion as a function of the operating temperature at 2 atm (Space velocity $=900 / 16 \mathrm{SCCM} / \mathrm{gm}_{\text {cat }}$, and Steam to methane molar ratio $=3.0$ ).

Figure 17. Comparison of the performance of PBIMTR with PBR as a function of operating temperature at $2 \mathrm{~atm}$ (Space velocity $=900 / 16$, $\mathrm{SCCM} / \mathrm{gm}_{\text {cat }}$, Steam to methane molar ratio $=3.0$, and Sweep ratio $=1.25$ ).

Figure 18. Effect of pressure on conversion in the PBR compared with the equilibrium conversion at $500{ }^{\circ} \mathrm{C}\left(\right.$ Space velocity $=900 / 16 \mathrm{SCCM} / \mathrm{gm}_{\text {cat }}$, Steam to methane molar ratio $=3.0$, and Sweep ratio $=1.25)$.

Figure 19. Influence of pressure on methane and steam conversions at $500{ }^{\circ} \mathrm{C}$ (Space velocity $=900 / 16 \mathrm{SCCM} / \mathrm{gm}_{\text {cat }}$, Steam to methane molar ratio $=3.0$, and Sweep ratio $=0.28$ ).

Figure 20. Effect of reactor pressure on conversion in the PBIMTR at $400{ }^{\circ} \mathrm{C}$ (Space velocity $=900 / 16 \mathrm{SCCM} / \mathrm{gm}_{\text {cat }}$, Steam to methane molar ratio $=3.0$, and Sweep ratio $=1.25$ ).

Figure 21. Comparison of conversion in the PBIMTR with conventional PBR (Space velocity $=900 / 16 \mathrm{SCCM} / \mathrm{gm}_{\text {cat }}$, Steam to methane molar ratio $=3.0$, and Sweep ratio $=0.08$ ).

Figure 22. Influence on temperature on yield of hydrogen with respect to methane feed rate for $2 \mathrm{~atm}$ (Space velocity $=900 / 16 \mathrm{SCCM} / \mathrm{gm}_{\text {cat }}$, and Sweep ratio $=1.25)$.

Figure 23. Effect of total pressure on the yield of hydrogen with respect to methane feed rate at $500{ }^{\circ} \mathrm{C}$ (Space velocity $=900 / 16 \mathrm{SCCM} / \mathrm{gm}_{\text {cat }}$, Steam to methane molar ratio $=3.0$, and Sweep ratio $=0.28$ ).

Figure 24. Effect of temperature on the yield of hydrogen with respect to feed ratio of methane in the PBIMTR for different sweep ratio at 3 atm (Space velocity $=900 / 16 \mathrm{SCCM} / \mathrm{gm}_{\text {cat }}$, and Steam to methane molar ratio = 3.0). 
Figure 25. Predicted yield of hydrogen with respect to methane reacted in the PBIMTR as a function of reaction temperature with total reactor pressure as a parameter (Space velocity $=900 / 16 \mathrm{SCCM} / \mathrm{gm}_{\text {cat }}$, Sweep ratio $=0.25$, and Steam to methane molar ratio $=3.0$ ).

Figure 26. Effect of steam to methane molar feed ratio on the methane and steam conversion at $350{ }^{\circ} \mathrm{C}$ and $2 \mathrm{~atm}$ (Space velocity $=900 / 16 \mathrm{SCCM} / \mathrm{gm}_{\text {cat }}$, and Sweep ratio $=0.75$ ).

Figure 27. Effect of steam to methane molar feed ration on methane partial pressure at various locations along the length of the reactor and hydrogen removal rate in the PBIMTR (Space velocity $=900 / 16$ $\mathrm{SCCM} / \mathrm{gm}_{\text {cat }}$, and Sweep ratio $\left.=0.75\right)$.

Figure 28. Influence of space time on the overall methane conversion at $300{ }^{\circ} \mathrm{C}$ and $2 \mathrm{~atm}$ (Steam to methane molar ratio $=3.0, \mathrm{Ni} / \mathrm{Al}_{2} \mathrm{O}_{3}$ catalyst loading $=16 \mathrm{gm}$, and Sweep ratio $=1.0$ ).

Figure 29. Effect of reaction pressure on hydrogen permeation rate in the PBIMTR with reaction temperature as a parameter (Space velocity $=900 / 16 \mathrm{SCCM} / \mathrm{gm}_{\text {cat }}$, Steam to methane molar feed ratio $=3.0$, and Sweep ratio $=0.75$ ).

Figure 30. Effect of sweep ratio on the overall methane conversion in PBIMTR with reaction temperature as a parameter at 3 atm (Space velocity $=900 / 16 \mathrm{SCCM} / \mathrm{gm}_{\text {cat }}$, and Steam to methane molar feed ratio = 3.0).

Figure 31. Effect of sweep ratio on hydrogen permeation rate in the PBIMTR with reaction temperature as a parameter (Space velocity $=900 / 16$ $\mathrm{SCCM} / \mathrm{gm}_{\text {cat }}$, and Steam to methane molar feed ratio $=3.0$ ).

Figure 32. Partial pressure profiles along the length of the PBIMTR at $450{ }^{\circ} \mathrm{C}$ and $2 \mathrm{~atm}$ (Space velocity $=900 / 16 \mathrm{SCCM} / \mathrm{gm}_{\text {cat }}$, Steam to methane molar feed ratio $=3.0$, and Sweep ratio $=0.75)$.

Figure 33. Hydrogen partial pressure radial profiles on both permeate and reaction sides at different axial positions in the reactor at 350 ${ }^{\circ} \mathrm{C}$ and 2 atm (Space velocity $=900 / 16 \mathrm{SCCM} / \mathrm{gm}_{\text {cat }}$, Steam to methane molar feed ratio $=3.0$, and Sweep ratio $=0.3$ ).

Figure 34. Methane partial pressure radial profiles on the reaction side at different axial positions at $450{ }^{\circ} \mathrm{C}$ and 2 atm (Space velocity $=900 / 16 \mathrm{SCCM} / \mathrm{gm}_{\text {cat }}$, Steam to methane molar feed ratio $=3.0$, and Sweep ratio $=0.15$ ). 
Figure 35. Total conversion of methane in the conventional PBR as a function of temperature at $136 \mathrm{kPa}$ (Space velocity $=162 / 11 \mathrm{SCCM} / \mathrm{gm}_{\text {cat }}$, and Steam to methane molar feed ratio $=3.0$ ).

Figure 36. Total conversion of methane in the membrane reactor as a function of temperature at $136 \mathrm{kPa}$ (Space velocity $=162 / 11 \mathrm{SCCM} / \mathrm{gm}_{\text {cat }}$, Sweep flow rate $=40 \mathrm{SCCM}$, and Steam to methane molar feed ratio $=3.0$ ).

Figure 37. Pressure effect on methane conversion in the non-membrane PBR at $500{ }^{\circ} \mathrm{C}$ (Space velocity $=162 / 11 \mathrm{SCCM} / \mathrm{gm}_{\text {cat }}$, and Steam to methane molar feed ratio $=3.0)$.

Figure 38. Effect of purge flow rate on total methane conversion in the membrane reactor at $500{ }^{\circ} \mathrm{C}$ and $136 \mathrm{kPa}$ (Space velocity $=162 / 11 \mathrm{SCCM} / \mathrm{gm}_{\text {cat }}$, and Steam to methane molar feed ratio $=3.0$ ). 


\section{EXECUTIVE SUMMARY}

To develop, defect free hydrogen-selective metal-metal composite membrane, we have used osmotic pressure field induced electroless plating to deposit Pd-film on microporous stainless steel tube. In our previous report we presented $\mathrm{H}_{2}$-perm selectivity data. The new membrane appears to be robust and defect free. From limited permeability tests, it was found that the new membrane has excellent selectivity for hydrogen. Both the permeability and selectivity increase with increasing temperature. This property makes the new membrane attractive for high temperature $\mathrm{H}_{2}$-separation applications. The ultimate objective of this work is to use this new membrane in membrane-reactor-separator configuration for reforming of liquid hydrocarbons and methanol for production and separation of high purity hydrogen for fuel cell application. To better understand the performance of membrane reactor for reforming hydrocarbons, we used steam methane reaction for modeling membrane reactor. Model simulation results are discussed in this report. Numerical results of the models show that the methane conversions in the membrane reactor are always higher than that in the conventional packed-bed reactor, as well as thermodynamic equilibrium conversions. 


\section{INTRODUCTION}

The major focus on PEMFC (Proton Exchange Membrane Fuel Cell) technology is to develop fuel cell system for transportation applications, which require development of low cost cell components and reliable, high-purity $\mathrm{H}_{2}$-fuel source. The PEMFC technology is attractive because of its low operating temperature and ease of start-up. Reformed methanol and liquid hydrocarbons are expected to be major fuel source in PEMFCs for terrestrial transportation application as envisioned in Vision 21 for the 21st century. The poisoning of the expensive electrocatalysts by $\mathrm{CO}$ in the reformed fuel is a major concern. Crossover of methanol in direct methanol PEMFC is also problematic. Thus, there is a need for developing technology for reforming of methane, methanol and liquid hydrocarbons as a source of hydrogen to the fuel cells (Hirschenhofer et al., 1999; Collins \& Way, 1993). From economical and practical considerations, hydrocarbon reforming and hydrogen purification processes for an integrated fuel cell system need to meet several key criteria: (i) produce high-purity hydrogen, (ii) modular compact unit in size and weight, (iii) have low parasitic power requirements, (iv) be economic, affordable, and (v) exhibit rapid-load-following capability. In this context, membrane-based technology as fuel processor appears very attractive.

Inorganic membrane reactors offer the possibility of combining reaction and separation in a single operation at high temperatures to overcome the equilibrium limitations experienced in conventional reactor configurations. Such attractive features can be advantageously utilized in a number of potential commercial opportunities, which include dehydrogenation, hydrogenation, oxidative dehydrogenation, oxidation and catalytic decomposition reactions. However, to be cost effective, significant technological advances and improvements will be required to solve several key issues which include: (a) perm-selective thin solid film, (b) thermal, chemical and mechanical stability of the film at high temperatures, and (c) reactor engineering and module development in relation to the development of effective seals at high temperature and high pressure.

We propose to develop an inorganic metal-metal composite membrane to study reforming of methane, liquid hydrocarbons and methanol by equilibrium shift in membrane-reactor configuration, viewed as fuel processor. This approach will have several technological advantages over other hydrogen production and purification methods, that includes: (a) 
Reforming reaction is not limited by the thermodynamic chemical equilibrium, as soon as hydrogen is formed hydrogen is transported across the membrane; (b) Reforming and separation is carried out in a single unit, eliminating the need of hydrogen separation and recovery units, and (c) Membrane reactor-separator is modular and compact in size (Hsieh, 1996).

Based on our current understanding and experience in the Pd-ceramic composite membrane (Ilias, et al., 1997), we propose to further develop this membrane to a palladium-silver alloy membrane on microporous stainless steel support to provide structural reliability from distortion due to thermal cycling and hydrogen embrittlement. Because of the metal-metal composite structure, we believe that the associated end-seal problem in the Pd-ceramic composite membrane in tubular configuration would not be an issue at all. The major objective of this research is to further develop these materials and to test them for reforming liquid hydrocarbons and methanol for simultaneous production and separation of high-purity hydrogen for PEM fuel cell applications.

\section{RESEARCH OJECTIVES}

The objectives of this research are to:

1. Design and fabrication of membrane reactor using thin film $\mathrm{Pd}$ and $\mathrm{Pd}-\mathrm{Ag}$ alloy composite membrane in tubular configuration on porous stainless steel substrate.

2. Conduct steam reforming of methane experiments to study the equilibrium shifts and permeation characteristics.

3. Model the membrane reactor for methane reforming by equilibrium shift and validate the performance of the reactor.

\section{MATERIALS AND METHODS}

The Pd composite membranes were prepared by the electroless plating method combined with osmotic pressure field. A thin Pd film was deposited on the outer surface of a commercially available porous stainless steel tube. Electroless plating was chosen because it provides uniform 
and hard dense coatings on both conducting and non-conducting surfaces. The fabricated membranes were then characterized by conducting pure hydrogen and nitrogen permeation experiments at high temperatures and pressures.

\section{Fabrication of Pd-Composite Membranes}

Several different types of microporous tubes are commercially available to use as a substrate. Porous substrate for the Pd composite membrane was selected based on pore structure and size, porosity, mechanical and thermal stability, and surface smoothness of the substrate. Pore size and smoothness of the substrate mainly determine the quality of the composite membranes. The surface pore size should be neither too large to support a thin film nor too small to allow the free flow of gas. Similarly, the surface should be neither too coarse to form a thin film successfully nor too smooth to prevent adherence of the film with the substrate. Porous stainless steel was selected as the substrate to fabricate a Pd composite membrane because of its weld-ability into a steel module since sealing is still a problem for any ceramic composite membrane. Its high mechanical and thermal stabilities allow the membrane reactor to operate at high temperatures and high trans-membrane pressure differences. Palladium was deposited onto the outside surface of asymmetric microporous stainless steel (SS) tubes purchased form Mott Metallurgical Corporation by the electroless plating method. The inside and outside diameters of the SS tubes are $1 / 4$ and $3 / 8$ inch, respectively. The average pore size of the tube is $0.2 \mu \mathrm{m}$. SS tubes purchased in lengths of 12 inches were first cut to the desired length of 2.5-4.0 inches using a diamond saw. During the membrane preparation, substrate tubes were treated after the following three steps: pretreatment of the substrate, sensitization and activation, and electroless plating.

\section{Pretreatment of the Substrate}

Prior to deposition, the substrate was first cleaned through the following sequential steps to remove organic contaminants and dirt:

1. The porous SS tube was immersed in boiling water for 10 minutes. After that the tube was cleaned by bubbling air through the tube in an ultrasonic bath using a commercial cleaner supplied by LIQUINOX. One end of the tube was connected to an air supply line with an on/off valve to bubble air through the tube, and the other end of the tube was sealed. Lowpressure air was blown through the tube by switching the on/off valve in an on position 
several times for a period of 2-3 seconds during this cleaning step to help the fluid wash through the pores.

2. The tube was cleaned in the ultrasonic bath with deionized water to wash off the detergent.

3. The substrate was dried at $120^{\circ} \mathrm{C}$ for about an hour.

4. The substrate was washed ultrasonically with carbon tetrachloride supplied by Aldrich Chemicals for an hour, followed by drying at $120^{\circ} \mathrm{C}$ for 1 hour.

\section{$\underline{\text { Sensitization and Activation }}$}

Stainless steel substrate is not active enough to initiate autocatalytic palladium deposition and thus needs to be activated with a suitable catalytic species. In the case of palladium deposition, following the cleaning steps, the substrate surface was pre-seeded with Pd nuclei that initiate the plating process. For this purpose the substrate was successively immersed at ambient temperature in an acidic stannous chloride solution followed by an acidic palladium chloride solution with gentle rinsing in deionized water between baths. In general, the first bath is referred to as the sensitizer solution while the second is the activator. The immersion sequence was generally repeated 10-15 times, depending on the intensity of the activation to obtain a uniform activated membrane surface. A perfectly activated layer has a uniform dark-brown color smooth surface. The typical composition of the activation bath is given in Table 1. Measures were taken to prevent the activation of the inside tube surface. Surface activation is a key step because defects in the palladium film usually occur when the substrate surface is not uniformly activated prior to electroless plating. Sensitization is the adsorption of a reducing agent on the substrate surface, and activation occurs when the catalytic material is adsorbed on the substrate. The oxidation/reduction mechanism for this step is:

$$
\mathrm{Sn}^{2+}+\mathrm{Pd}^{2+} \rightarrow \mathrm{Sn}^{4+}+\mathrm{Pd}^{0}
$$

The adsorbed $\mathrm{Sn}^{2+}$ exists in a precipitated hydrolytic form on the substrate surface after the rinsing steps, and is further replaced by $P d^{0}$ via the redox step as given by equation, Eqn. (1). Once the surface was activated, the activated surface was kept in demonized water before dipping into the plating solution in order to prevent further reaction of the $S n$-oxides present on the substrate surface. 


\section{Electroless Plating}

The activated substrate surface was then coated with thin palladium film by the electroless plating method. Electroless plating is defined as the deposition of a metallic coating by a controlled autocatalytic chemical reduction that is catalyzed by the metal or alloy being deposited. The electroless-plating bath is a complex electrolyte solution containing a palladiumamine complex as palladium source, hydrazine as reducer and EDTA as complexing agent. Table 2 shows typical plating bath composition and conditions. The amount of hydrazine added to the bath was critical and was calculated based on the stoichiometric requirement of the reaction. It has been found that hydrazine less than $90 \%$ of the stoichiometric requirements gives more stable bath. The electroless plating deposition rate was controlled by controlling the temperature, $\mathrm{pH}$, and metal ion/reducer concentration in the bath. EDTA, a complexing agent acts as a buffer to help control $\mathrm{pH}$ and maintain control over the free metal ions available in the solution. A high concentration of $\mathrm{NH}_{4} \mathrm{OH}$ was used to improve the bath stability and to maintain the $\mathrm{pH}$ of the solution. $\mathrm{NH}_{4} \mathrm{OH}$ also used as the solvent for the autocatalytic reaction. Low concentration of $\mathrm{NH}_{4} \mathrm{OH}$ in the plating bath keeps the bath stable for a long time while a high concentration has a higher deposition rate of $\mathrm{Pd}$ metal which quickly leads to bath decomposition.

In electroless plating, metal ions are reduced to metal by the action of a chemical reducing agent, which is simply the electron donor. The metal ions are electron acceptors, which react with electron donors. The catalyst is the metal surface, which accelerates the electroless chemical reaction allowing oxidation of the reducing agent. Palladium deposition occurs according to the following two simultaneous reactions:

Anodic Reaction:

$$
\mathrm{N}_{2} \mathrm{H}_{4}+4 \mathrm{OH}^{-} \rightarrow \mathrm{N}_{2}+4 \mathrm{H}_{2} \mathrm{O}+4 e^{-}
$$

Cathodic Raction:

$$
2 P d^{2+}+4 e^{-} \rightarrow 2 P d^{0}
$$

Overall Autocatalytic Reaction:

$$
2 \mathrm{PdCl}_{2}+\mathrm{N}_{2} \mathrm{H}_{4}+4 \mathrm{NH}_{4} \mathrm{OH} \rightarrow 2 \mathrm{Pd}+\mathrm{N}_{2}+4 \mathrm{NH}_{4} \mathrm{Cl}+4 \mathrm{H}_{2} \mathrm{O}
$$


or,

$$
2 \mathrm{Pd}^{2+}+\mathrm{N}_{2} \mathrm{H}_{4}+4 \mathrm{OH}^{-} \rightarrow 2 \mathrm{Pd}+\mathrm{N}_{2}+4 \mathrm{H}_{2} \mathrm{O}
$$

The cathodic deposition of palladium catalyzes the anodic oxidation of hydrazine, thus resulting in an autocatalytic process. Pre-seeded palladium nuclei on the substrate at the sensitization/activation step reduce the induction period of the autocatalytic process at the beginning of the deposition.

The plating was carried out at $60^{\circ} \mathrm{C}$ and the constant temperature of the plating solution was maintained by a water bath. Once the temperature had stabilized, hydrazine was added, with stirring, along with the substrate tube into the plating bath solution. The plating was allowed to proceed without further stirring. Cheng and Yeung (2001) proposed that a higher plating efficiency (amount of Pd deposited on the substrate divided by the initial amount of Pd present in the plating solution) could be obtained from the same amount of hydrazine by simply dividing the hydrazine into two equal portions. Taking this into consideration, the first half portion of hydrazine was added at the beginning of the plating and the second half portion was added midway through the plating.

In order to improve the plating process for metal substrates, the conventional plating method was coupled with an osmotic pressure field. This new technique allows for uniform and deep coating of Pd on the substrate surface. Yeung, et al., (1995) demonstrated that the initial stages of plating in the presence of osmotic pressure field play a critical role in the formation of films with finer, more uniform and denser microstructure. The osmotic solution used for this experiment is a high molecular weight polyethylene glycol (PEG) solution. PEG was supplied by Fluka Chemicals and has a molecular weight of 17,500. A concentration of $1.20 \times 10^{-4} \mathrm{M}$ solution of PEG was used as an osmotic solution to allow the osmotic flux to pass through the pores of the tube from the plating solution into the osmotic solution. The electroless plating bath set-up is shown in Figure 1.

Each dipping in plating bath lasted for 5 hours. After each 5-hour dipping, the membrane was removed from the plating bath, rinsed with deionized water, and then put into a fresh bath. The plating process was continued until a desired film thickness was obtained. Under the conditions described here, it has been found that the plating rate is around 0.70 to $0.85 \mu \mathrm{m} / \mathrm{hr}$. The 5-hour 
plating period was chosen because the plating rate was significantly reduced after 5 hours. Although it has a lower plating rate, a high stable bath was formulated under these conditions. After 5 hours, the deposition efficiency calculated form the weight gain of the substrate was found to be about $56 \%$ of the Pd initially present in the plating solution. Membranes were rinsed in deionized water and then dried at 110 to $120^{\circ} \mathrm{C}$ for several hours after plating.

The average thickness of the deposited palladium film was calculated by dividing the weight difference in the plated and unplated membranes by the plated surface area and the pure palladium density of $11.93 \mathrm{gm} / \mathrm{cm}^{3}$. In this case it is assumed that the coating coverage is uniform on the substrate.

\section{Characterization And Gas Permeation Testing}

Membrane characterization includes identification of the physical properties of the membrane and measurement of membrane performance through hydrogen permeability and selectivity measurements. The surface morphology of the electrolessly deposited palladium films on the porous SS tubes were studied using a Scanning Electron Microscope (SEM), equipped with an Energy Dispersive X-ray (EDX) analyzer. EDX shows the elemental composition of the film that has been coated on the substrate surface.

\section{$\underline{\text { Heat Treatment }}$}

Before the as-deposited membranes are tested for permeation or separation, the membranes should be stabilized at elevated temperature. In this work, the membranes were treated and activated in a hydrogen atmosphere with a transmembrane pressure difference of 14.7 psi for $3 \mathrm{~h}$ at $450{ }^{\circ} \mathrm{C}$. Since the $\mathrm{Pd}$ film formed by the electroless plating technique is built up by packing palladium particles deposited from the plating solution through the autocatalytic decomposition of a palladium complex, the presence of boundaries or interfaces among the Pd particles is inevitable ( $\mathrm{Li}$ et al., 1998). The size of the palladium particles from this electroless plating technique varies from several nanometers to several hundred nanometers (Shu et al., 1994), depending on the concentration and conditions of the plating solution. Consequently, there are a great number of boundaries or interfaces between palladium particles of different sizes. These boundaries or interfaces constitute the barrier or resistance to hydrogen permeation. Treatment of the as-deposited $\mathrm{Pd}$ composite membrane by heating to above $336^{\circ} \mathrm{C}$ can eliminate these 
interparticle boundaries by causing the particles to coalesce. This treatment time was reduced in the presence of hydrogen. Initially, it had been found that at $450{ }^{\circ} \mathrm{C}$ and a transmembrane pressure difference of $14.7 \mathrm{psi}$ the permeation rate of hydrogen through the fabricated dense membrane was very low. After some time, the hydrogen permeation flux increased gradually to a steady value. It could be possible by gradual disappearance of boundaries or interfaces and therefore the resistance to hydrogen permeation through the Pd-film with the time of heat treatment.

\section{Permeability Experiments}

The fabricated $\mathrm{Pd} /$ porous stainless steel membranes were initially checked for leaks with nitrogen at room temperature by insertion into the permeator/reactor set-up. At room temperature and a transmembrane pressure of $14.7 \mathrm{psi}$, no nitrogen flux through the membrane was observed. This implied that the composite membrane was dense and defect-free. The permeation measurements were conducted with pure hydrogen and pure nitrogen. The temperature was varied between 350 and $450{ }^{\circ} \mathrm{C}$, and the transmembrane pressure difference was taken up to 45 psi. Below $300{ }^{\circ} \mathrm{C}$ both sides of the membrane were kept under a nitrogen or helium

atmosphere to avoid hydrogen embrittlement of the Pd composite membranes. All heating and cooling of the fabricated membrane during start-up or shutdown and in between all testing temperatures was accompanied in a nitrogen atmosphere. The heating or cooling rate was controlled at $1{ }^{\circ} \mathrm{C} / \mathrm{min}$.

\section{Experimental Set-up to study Permeation Behavior}

A schematic diagram of the experimental set-up for the studies of hydrogen permeation and separation is shown in Figure 2. A more detailed drawing of the membrane module is shown in Figure 3. The apparatus consists of a gas delivery system, gas flow rate measuring system, a double-pipe stainless steel permeator and a heating system. The membrane reactor has a doublepipe configuration. For hydrogen permeation study, palladium was deposited on the outer surface of a porous SS tube with an outside diameter of $3 / 8$ inch and a length of about 4.0 inches. The 4.0-inch length was convenient for both the electroless plating operation and permeation experiments. The porous SS tubes were plated to a length of 4 inches and finally dropped down to a size of 3.35 inches after preparation by cutting off the unplated ends. Ends were covered up 
to a certain distance with $1 / 4$-inch I.D. tygon tubing, filled with osmotic solution, during plating time. Both ends of the membrane tube were then connected to a dense $1 / 4$-inch (O.D.) stainless steel tube by reducing unions. The outer shell was an ordinary stainless steel pipe of 1 inch inside diameter and 16 inches in length. Feed gas flowed through the shell side of the permeator and the permeated gases were collected in the tube side, which was open to the atmosphere. No sweep gas was used throughout the experiment. However, if desired, a sweep gas could also be used on the tube side. The gases $\left(\mathrm{H}_{2}, \mathrm{~N}_{2}\right.$, etc.) were fed from gas cylinders and the flow rates were controlled and measured with a digital mass flow controller. Three digital mass flow controllers from Aalborg, model DFC 3600, were used in three different inlet lines and all were calibrated with respect to nitrogen for a maximum flow of $2.0 \mathrm{slpm}$. Mass flow controllers were connected to a personal computer through a RS485 converter. The permeate flow rate was measured with a mass flow transducer (Matheson, model 8143) for flow rates greater than $1000 \mathrm{~cm}^{3} / \mathrm{min}$. Further, a digital soap-bubble flow meter (J\&W Model ADM2000) was used for flow rates 0.1$1000 \mathrm{~cm}^{3} / \mathrm{min}$. An Omega CN 77333 temperature controller was used to maintain a constant temperature of the membrane reactor. A K-type thermocouple was placed at the membrane reactor to measure the reactor temperature. A heating tape $(420 \mathrm{~W}, 120 \mathrm{~V}$ and $8 \mathrm{ft}$ long) connected to output-1 of the temperature controller was used around the permeator to maintain a constant temperature of the permeator. Another similar heating tape connected to the output-2 of the temperature controller was used to preheat the inlet gas stream. Digital pressure gauges were used to measure the feed side and permeate side pressures. The composition of the outlet stream from permeate side can be analyzed by a Gas Chromatography (Model HP 6460 series) during the permeation and separation experiments with mixed gases.

\section{MEMBRANE REACTOR MODEL DEVELOPMENT}

The membrane reactor considered for simulation study is a packed-bed inert membrane tubular reactor. By inert membrane it means that the membrane acts as a separator not a catalyst. The reactants are fed to the shell side of the reactor where the $\mathrm{Ni} / \mathrm{Al}_{2} \mathrm{O}_{3}$ catalyst is packed. Hydrogen produced by the SMR permeates through the membrane into the tube side. Argon is used as a sweep gas in the tube side to remove the permeated hydrogen. The sweep gas flows co-currently with the reactant gas. 


\section{MEMbrane REACTOR MODEL}

The catalytic steam methane reforming process involves several elementary reactions; however, a kinetic study of SMR reaction over Ni-based catalysts (Xu and Froment, 1989) showed that the reaction rate might consider the following three reversible reactions:

$$
\begin{array}{ll}
\mathrm{CH}_{4}+\mathrm{H}_{2} \mathrm{O} \rightleftarrows \mathrm{CO}+3 \mathrm{H}_{2} & \left(\Delta H_{r 1}=206 \frac{\mathrm{kJ}}{\mathrm{mol}}\right) \\
\mathrm{CO}+\mathrm{H}_{2} \mathrm{O} \rightleftarrows \mathrm{CO}_{2}+\mathrm{H}_{2} & \left(\Delta H_{r 2}=-41 \frac{\mathrm{kJ}}{\mathrm{mol}}\right) \\
\mathrm{CH}_{4}+2 \mathrm{H}_{2} \mathrm{O} \rightleftarrows \mathrm{CO}_{2}+4 \mathrm{H}_{2} & \left(\Delta H_{r 3}=165 \frac{\mathrm{kJ}}{\mathrm{mol}}\right)
\end{array}
$$

High temperature and low pressure thermodynamically favor the endothermic reforming reaction, Eqn. (6). The second reaction, which is known as water-gas shift reaction, does not depend on pressure and is favored by low temperature because of being exothermic in nature. The overall reaction, Eqn. (8) is highly endothermic. Therefore, in order to gain high methane conversion, the SMR reaction is carried out at high temperatures.

The concentration of hydrogen near the membrane wall is depleted due to permeation. Hence, a concentration gradient occurs in the radial direction. A two-dimensional model is suitable to describe the transport mechanism through the catalyst bed. A two-dimensional heterogeneous model requires knowledge of effectiveness factors. For a first-order reaction it can be evaluated easily. Steam-methane reforming is a complex reaction and defining the effectiveness factor is complicated. In order to avoid this complexity, a two-dimensional pseudo-homogeneous model was assumed to describe the transport mechanism through the catalyst bed. In this study, the transport equations for the membrane layer are not taken under consideration because the membrane is not catalytic. The model membrane reactor is shown in Figure 4. The following assumptions were made for the formulation of the mathematical model developed in the present work:

- Isothermal and isobaric conditions throughout the whole reactor are considered.

- Operation is steady-state. 
- Co-current flow condition is assumed.

- Radial velocity is negligible compared to axial velocity. Because of the change in number of moles due to reaction, it is assumed that velocity varies along the length of the reactor.

- Ideal gas law is applicable.

- The partial pressure gradient of hydrogen in the radial direction, caused by the permeation of hydrogen through the membrane, is taken into account.

- The permeation of hydrogen through the Pd/SS membrane follows Sievert's law, that is, the driving force is proportional to the difference in the square roots of the feed and permeate pressures.

- Effective dispersion of mass in the axial direction is insignificant compared to the convective transport term.

- The reaction is predominantly taking place on the spherical catalyst pellet surface. The membrane is catalytically inert, that is, no reaction takes place in the membrane or membrane/support matrix.

- Interfacial mass transfer resistance is negligible.

- The permeability of hydrogen in mixture is the same as the pure gas value.

Based on the above assumptions, the continuity equation for each of the components, argon (A), methane (M), steam (S), carbon monoxide (C), carbon dioxide (D), and hydrogen (H) can be written as:

$$
v_{z} \frac{\partial C_{i}}{\partial z}=\left(D_{e r}\right)_{i} \frac{1}{r} \frac{\partial}{\partial r}\left(r \frac{\partial C_{i}}{\partial r}\right)+R_{i}
$$

where $i=A, M, S, C, D, H$ and since argon is non-reactive, $R_{A}=0$.

The appropriate boundary conditions are stated as follows:

BC 1: at $r=r_{2}+t$ (membrane wall) and $0 \leq \mathrm{z} \leq l_{o}$ :

$$
\frac{\partial C_{i}}{\partial r}=0 ; \quad i=A, M, S, C, D
$$


and

$$
\left(D_{e r}\right)_{H} \frac{\partial C_{H}}{\partial r}=\frac{Q_{H}}{t}\left(P_{H}^{n}-p_{H}^{n}\right)
$$

BC 2: at the shell wall, at $r=r_{3}$ and $0 \leq z \leq l_{o}$

$$
\frac{\partial C_{i}}{\partial r}=0 ; \quad i=A, M, S, C, D, H
$$

IC 1: Inlet conditions for reaction side:

At $z=0$ and $r_{2}+t \leq r \leq r_{3}$,

$$
\begin{aligned}
& C_{i}=C_{i}^{o} ; \quad i=A, M, S \\
& \mathrm{C}_{\mathrm{i}}=0 ; \quad i=H, C, D
\end{aligned}
$$

IC 2: Inlet condition for separation side:

For co-current configuration, at $\mathrm{z}=0$ and $\mathrm{r}_{2} \leq r \leq r_{3}$,

$$
c_{\mathrm{A}}=c_{\mathrm{A}}^{\mathrm{o}} \text { and } c_{\mathrm{H}}=0
$$

First by using the ideal gas law the concentration of the species in equations, Eqns. (9-14) is expressed in terms of their partial pressures. Then the both governing equations and the boundary and initial conditions were normalized using the following dimensionless variables:

$$
\begin{array}{lll}
\bar{Z}=\frac{Z}{l_{o}}, & V=\frac{v}{v_{o}}, \quad \bar{R}=\frac{r}{R\left(=r_{3}\right)} \\
\kappa=\frac{r_{2}+t}{r_{3}(=R)}, \quad \zeta=\frac{r_{2}}{r_{3}(=R)}, & \xi=\frac{r_{1}}{r_{3}(=R)} \\
\Phi_{i}=\frac{P_{i}}{P_{o}}=\frac{X_{i} P_{r}}{P_{o}}, & \text { and } \quad \phi_{i}=\frac{p_{i}}{p_{o}}=\frac{x_{i} p_{s}}{p_{o}}
\end{array}
$$

Here, $P_{o}$, and $p_{o}$ are the reference pressures of $1 \mathrm{~atm}$. If the system pressure is 1 atmosphere, then $\Phi_{i}$ and $\phi_{i}$ are nothing but mole fractions in the reaction and separation side, respectively. The radial dimensions of the reactor used in dimensionless variables are shown in Figure 5. The normalized governing equations and the boundary and initial conditions are as follows: 


$$
\frac{\partial\left(V \Phi_{i}\right)}{\partial \bar{Z}}=\frac{d_{p} l_{o}}{\left(P e_{r}\right)_{i} R^{2}}\left(\frac{1}{\bar{R}} \frac{\partial \Phi_{i}}{\partial \bar{R}}+\frac{\partial^{2} \Phi_{i}}{\partial \bar{R}^{2}}\right)+\varphi_{i}
$$

where $i=A, M, S, C, D, H,(P e)_{j}=v_{o} d_{p} /\left(D_{e r}\right)_{j}$ and $\varphi_{i}=R_{g} T l_{d} /\left(v_{o} P_{o}\right) R_{i}$

Boundary conditions:

BC $1:$ at $\bar{R}=1$ and $0 \leq \bar{Z} \leq 1$,

$$
\frac{\partial \Phi_{i}}{\partial \bar{R}}=0 ; \quad i=A, M, S, C, D, H
$$

BC 2: at $\bar{R}=\kappa$ and $0 \leq \bar{Z} \leq 1$,

$$
\frac{\partial \Phi_{i}}{\partial \bar{R}}=0 ; \quad i=A, M, S, C, D
$$

and for hydrogen from equation, Eqn. (16)

$$
\frac{\partial \Phi_{H}}{\partial r}=\frac{Q_{H} R_{g} T}{t\left(D_{e r}\right)_{H}} P_{o}^{n-1}\left(\Phi_{H}^{n}-\phi_{H}^{n}\right)
$$

Therefore,

$$
\frac{\partial \Phi_{H}}{\partial \bar{R}}=\beta\left(\Phi_{H}^{n}-\phi_{H}^{n}\right)
$$

where,

$$
\beta=\frac{R}{t} \frac{Q_{H} R_{g} T}{\left(D_{e r}\right)_{H} P_{o}^{1-n}}=\frac{1}{\kappa-\xi} \frac{Q_{H} R_{g} T}{\left(D_{e r}\right)_{H} P_{o}^{1-n}}
$$

Inlet conditions:

IC 1: at $\bar{Z}=0$ and $\kappa \leq \bar{R} \leq 1$,

$$
\begin{aligned}
& \Phi_{i}=\Phi_{i}^{o} ; \quad i=A, M, S \\
& \Phi_{i}=0 ; \quad i=C, D, H
\end{aligned}
$$

IC 2: at $\bar{Z}=0$ and $0 \leq \bar{R} \leq \xi$,

$$
\phi_{A}=\phi_{A}^{o} \text { and } \phi_{H}=0
$$


Therefore, the developed model here consists of six partial differential equations (Eqns. 21-26) with appropriate initial conditions (Eqns. 32 and 33) and boundary conditions (Eqns. 27, 28 and 30). This problem now can be solved by finite difference approximation method.

\section{$\underline{\text { Reaction Rates }}$}

A number of kinetic rate expressions have appeared in the literature to describe the steam methane reforming reaction. These rate expressions vary from empirical expressions to ones based on fundamentals. In this work, Kinetic parameters are taken from the work of $\mathrm{Xu}$ and Froment (1989) where they studied steam methane reforming over nickel catalyst supported on magnesium pellets in a tubular reactor. Xu and Froment's rate expression has been chosen due to its ability to describe the behavior of the reforming over a wide range of reactor operating conditions compared to previous models available in the literature, namely, Elnashaie et al. (1990). The reaction rate expressions for three main reactions, Eqns. (6-8) are given as:

$$
\begin{aligned}
& r_{1}=\frac{\frac{k_{1}}{p_{H}^{2.5}}\left(p_{M} p_{S}-\frac{p_{H}^{3} p_{C}}{K_{1}}\right)}{D E N^{2}} \\
& r_{2}=\frac{\frac{k_{2}}{p_{H}}\left(p_{C} p_{S}-\frac{p_{H} p_{D}}{K_{2}}\right)}{D E N^{2}} \\
& r_{3}=\frac{\frac{k_{3}}{p_{H}^{3.5}}\left(p_{M} p_{S}^{2}-\frac{p_{H}^{4} p_{D}}{K_{3}}\right)}{D E N^{2}}
\end{aligned}
$$

where the quantity in the denominator of the equations, Eqns. (34) - (36), DEN is defined as,

$$
D E N=1+K_{C} p_{C}+K_{H} p_{H}+K_{M} p_{M}+K_{S} \frac{p_{S}}{p_{H}}
$$

Here $k_{1}, k_{2}$, and $k_{3}$ are the rate constants for three reactions and corresponding equilibrium constants are denoted by $K_{1}, K_{2}$, and $K_{3}$, respectively. The adsorption equilibrium constants of the species are denoted as $K_{j}$, where the subscript $j=M$ for methane, $S$ for steam, $C$ for carbon monoxide, $D$ for carbon dioxide, and $H$ for hydrogen. 
The depletion rates of $M$ and $S$ are given as follows:

$$
\begin{aligned}
& r_{M}=r_{1}+r_{3} \\
& r_{S}=r_{1}+r_{2}+2 r_{3}
\end{aligned}
$$

And the production rate of $C, D$, and $H$ are given as follows:

$$
\begin{aligned}
& r_{C}=r_{1}-r_{2} \\
& r_{D}=r_{2}+r_{3} \\
& r_{H}=3 r_{1}+r_{2}+4 r_{3}
\end{aligned}
$$

Reaction rate constants and adsorption constants are assumed to obey Arrhenius temperature dependencies. The model parameters obtained by $\mathrm{Xu}$ and Froment (1998) are taken in the present study, as listed in Table 3 and Table 4 . The rate and adsorption parameters are calculated according to equations, Eqns. (43) and (44), with the reference temperature $T_{r}=648 \mathrm{~K}$ for the $k_{i}, K_{C}$ and $K_{H}$; and $823 \mathrm{~K}$ for $K_{M}$ and $K_{S}$.

$$
\begin{aligned}
& k_{i}=k_{i, T_{r}} \exp \left[-\frac{E_{i}}{R}\left(\frac{1}{T}-\frac{1}{T_{r}}\right)\right], i=1,2,3 \\
& K_{j}=K_{j, T_{r}} \exp \left[-\frac{\Delta H_{j}}{R}\left(\frac{1}{T}-\frac{1}{T_{r}}\right)\right] j=C, H, M, S
\end{aligned}
$$

\section{Permeation of Hydrogen through Palladium}

The transport mechanism of hydrogen through palladium/porous stainless steel composite membrane is the solution-diffusion type. According to Barrer (1951), hydrogen permeation through metals (such as Pd) involves three complex processes (Hsieh, 1996): (1) dissociative chemisorption of hydrogen on the membrane surface followed by dissolution of the atomic hydrogen on the membrane surface followed by dissolution of the atomic hydrogen in the structural lattice of the metal; (2) diffusion of the dissolved hydrogen through the membrane from the high pressure side to the low pressure side; (3) desorption of combined hydrogen atoms as molecules. The driving force for the diffusion across the dense palladium membrane is the 
concentration difference of the dissolved hydrogen in the atomic form. The permeation of hydrogen through the membrane can be described by a solution-diffusion type model in terms of Sievert's law as:

$$
N_{H}=\frac{Q_{H}}{t}\left(P_{H}^{n}-p_{H}^{n}\right)
$$

where $P_{H}$ and $p_{H}$ are the hydrogen partial pressures of feed side and permeate side, $Q_{H}$ is the permeability and $t$ is the membrane thickness. The value for $n$ varies from 0.5 to 1 . The value of 0.5 implies that the transport of hydrogen through the bulk of metal is rate determining and that equilibrium is established at the surface, that is, equilibrium between hydrogen molecules in gas phase and hydrogen atoms dissolved in the metal. A value of $n$ equal to 1 implies a slow, rate determining surface reaction of hydrogen with palladium. The hydrogen transport through a dense palladium film is an activated process. Under the assumption that the hydrogen pressure exponent, $\mathrm{n}$ does not depend on temperature, the relationship between the hydrogen permeability and the temperature can be described by an Arrhenius law as follows:

$$
Q_{H}=Q_{H O} \exp \left(-\frac{E_{A}}{R T}\right)
$$

\section{$\underline{\text { Effective Radial Diffusion Coefficient }}$}

Effective radial diffusion coefficient in the packed bed, $D_{e r}$, which appeared in the dimensionless number, Peclet number $\left(P e_{r}=v_{0} d_{p} / D_{e r}\right)$ in the model equations, is calculated from the empirical correlation originally developed by Wen and Fan (1975). Recently, Itoh (1994) carried out a study on the radial diffusion of hydrogen in a packed-bed type of palladium membrane reactor under non-reactive conditions. A binary mixture of hydrogen and argon was considered in the packed bed. They found that the obtained values of the Peclet group obeyed the following extended correlation proposed by Wen and Fan (1975):

$$
\begin{aligned}
& \frac{1}{P e_{r}}=\frac{0.4}{(\operatorname{Re} S c)^{0.8}}+\frac{0.09}{1+\frac{10}{\operatorname{Re} S c}} \\
& \text { for } \quad 0.4<\operatorname{Re}<500, \quad 0.77<S c<1.2
\end{aligned}
$$


Even though the ranges of Re and Sc were 0.1-1.45 and 0.357, respectively, Eqn. (47) may be still applicable.

\section{$\underline{\text { Gas Mixture Properties }}$}

For binary mixture, Sato (1953) proposed an equation to estimate the Schmidt number. Itoh (1994) used that expression to estimate the Schmidt number for binary mixture. In the present study, a multi-component mixture of six components is considered. No equation is available to estimate the Schmidt number for such a mixture. Hence, Schmidt number is taken as unity for the present analysis.Viscosity of the gas mixture was estimated by a semi-empirical formula of Wilke (Wilke, 1950).

\section{SOLUTION METHODOLOGY}

The model equations developed for PBIMTR cannot be solved analytically. The finite difference method is used to solve these equations. The second term of the right hand side of the differential equations, Eqns. (21-26), except the equation for argon, is the reaction term and this is a source term. This term is highly non-linear and complex in form. It is not possible to linearize this term. It has been treated as a constant evaluated at a previous grid. Forward finite difference approximations for axial derivatives and central finite difference approximations for radial derivatives are used.

\section{Computational Procedure}

Partial pressure of hydrogen is a critical parameter in Xu and Froment's model, because if the feed does not contain any hydrogen, then the initial rate of reactions, Eqns. (34-36) becomes infinite. To overcome this problem, the idea of considering the first finite element of the reactor as a CSTR is introduced here. In the case of CSTR, rates are evaluated at the output concentration of the reactor. The presence of hydrogen at the output of the CSTR solves the problem. Although this CSTR concept may introduce some error in the mathematical sense (as discussed below), it provides an engineering solution to this complex problem. 


\section{Consistency and Stability}

Before solving a problem using the finite difference approximation method, one needs to be sure that the finite difference representation is consistent and stable. Consistent forward finite difference approximation along the reactor axis and central finite difference approximation along the radial direction was used. Considering the whole range of the operating conditions of the present simulated SMR reactor, it was found that a grid number of higher than 1200 when $\Delta \bar{R}=0.095$ gives stable results. Thus, all the simulation results presented here are based on 1500 grids along the reactor length.

\section{Extent of Error in the First Element as a CSTR}

From a practical point of view, the assumption of a CSTR element to initiate the numerical integration of the membrane reactor model introduces a negligible amount of error. The reactor length is divided into 1500 equally spaced grids. Out of this 1500 only the first grid is considered as a CSTR (a non-membrane micro-reactor). At the inlet of this element without a membrane, for all practical purposes, there will be no concentration gradient in the radial direction. Whatever error it may incur may not have any effect on the numerical solution of the remaining 1499 elements. Thus, the error associated with the assumption of the first element as a non-membrane CSTR can be ignored for all engineering solutions.

\section{Problems in Solving the First Element of the Reactor as a CSTR}

Each of the three rate expressions contains a term showing the difference between forward and backward reactions. These negative signs make a trial error or iteration solution of these rate equations difficult. Without a good initial guess they may yield values that can lead to negative concentration(s) or partial pressure(s). A negative partial pressure of hydrogen is not acceptable even to calculate the rates hypothetically due to the fractional indices of partial pressure of hydrogen in the rate expressions. To initiate the solution, initially it requires guessing five of the six components' partial pressures. To solve this problem, a systematic and effective solution scheme is developed in the solution algorithm. The scheme is briefly discussed here.

One subroutine of the program performs a detailed search of the roots for possible conversion of methane from almost 0 to $100 \%$ with a small increment. It guesses the carbon monoxide 
conversion from 0 to $100 \%$ of the methane conversion guessed earlier with an increment. The difference between the conversion of methane and carbon monoxide conversion is the conversion of carbon dioxide. It calculates conversion of steam and yield of hydrogen from stoichiometry. For every combination of guessed values, errors are calculated. Error is calculated for each component in the reacting mixture for every combination of guessed values from the difference of the following two flow rates: (1) flow rate based on the guessed overall methane conversion and conversion of methane to carbon monoxide and (2) flow rate calculated from its reactions kinetic expressions and the design equation for the CSTR based on the above guessed conversions. The sets that give minimum error of each component and the minimum of sum of absolute errors are considered root regions. For each of these six root regions, the program takes three different approaches to obtain the solution: iteration, the Newton-Raphson method and a detailed search in a $\pm 5 \%$ range of the root in the root region. If any of these steps gives the result within a $10^{-5}$ error level, the result is accepted. If all these methods fail to get a set of solutions within the above-mentioned error level, the set with the minimum sum of error is considered as the required set of solutions.

\section{Gradient Check}

A negative partial pressure of hydrogen during the calculation may be obtained, if the amount of hydrogen present in the system is less than the amount of hydrogen the membrane can transport. To solve this problem, a subroutine for gradient check is called after every finite difference equation is solved at the wall of the membrane. If the gradient (the difference of partial pressure of hydrogen between reaction and permeate side) is positive, it does not take any action. If the gradient becomes negative, this subroutine keeps reducing the amount of diffused hydrogen through the membrane until it produces the gradient positive or above a certain limit.

\section{RESULTS AND DISCUSSIONS}

Pd-composite membrane on microporous stainless steel and ceramic substrates were prepared by conventional electroless deposition and also by combining osmotic pressure filed. Surface morphology and microstructure of the composite membranes were characterized by SEM and 
EDX. The separation behavior of the Pd composite membrane was investigated by conducting permeability experiments with pure hydrogen, nitrogen and helium gases.

\section{PD-Composite Membrane Characterization}

Pd-film deposited on the $0.2 \mu \mathrm{m}$ microporous ceramic substrates by conventional electroless deposition method were characterized by SEM and EDX. In Figure 6, SEM images of the Pdfilm surface and the $\mathrm{x}$-sectional view of a typical membrane are shown. Figure 6(a) provides a nice SEM of the Pd-film surface, while in Figure 6(b) we find the Pd-film does not have a good penetration through the pores. The EDX analysis of the film is given in Figure 6(c) which shows that the film is essentially composed of metallic palladium.

SEM and EDX analysis of another Pd-composite membrane on ceramic substrate prepared by conventional electroless deposition is shown in Figure 7. Although the surface morphology appears to be good as seen in Figure 7(a), the x-sectional image as seen in Figure 7(b) shows that the Pd-film is separated from the substrate surface due to poor penetration of Pd-film in the pores.

To improve the film penetration and adhesion to the substrate surface, we used a modified electroless deposition method that combines osmotic pressure field. Attempts to use the electroless plating bath formulation for ceramic substrate to stainless steel discs and tubes were not successful. The Pd-films obtained on porous stainless steel substrate were not even and pinholes were observed in the SEM study. By a series of trial and error formulation, a suitable reaction bath composition was developed (Table 2) that was able to deposit a good thin (13 $\mu \mathrm{m})$ palladium on a stainless steel substrate. The goodness of the Pd-film was concluded from the SEM study. In Figure 8, the SEM images of the stainless steel substrate surface and Pd-films deposited by modified electroless deposition method are shown at 100, 400, and 2000 times magnifications, respectively.

Figure 9 show SEM micrograph of the surface morphology of a as-deposited $\mathrm{Pd} / \mathrm{SS}$ composite membrane at 1000 magnification of $1000 \mathrm{X}$. From the SEM image, it can be seen that a dense palladium layer is formed on the substrate. It can also be seen that the deposited palladium particles are spherical and possess a range of particle size. Small particles were deposited among the large particles and hence minimized the formation of defects. Palladium film is composed of 
fine palladium grains and these grains are grown well together and form a dense palladium layer on the support.

The cross-sectional view SEM image of the Pd film is shown in Figure 10. From Figure 10, it is clearly visible that the palladium film coverage is almost uniform and firmly connected to the SS support and shows a uniform coating and deep penetration of the palladium into the support pores. These results demonstrate that a defect-free palladium composite membrane can be prepared by the electroless plating method combined with osmotic pressure field.

\section{Gas PeRmeation Study}

The transport of hydrogen through dense palladium film is described by Sievert's law (Eqn. 45). When diffusion through the bulk metal is the rate limiting step and hydrogen atoms form an ideal solution in the metal, Sievert's law predicts that $n$ equals to 0.5 . However, a value of $n$ greater than 0.5 may result when the surface processes influence the permeation rate or when Sievert's law is not followed.

To study the gas transport behavior the Pd-SS composite membrane in tubular configuration, we studied hydrogen, Nitrogen and helium gas transport thorough membrane at elevated temperatures and pressures. The membrane thickness was estimated by the weight gain method. In Figure 11, hydrogen flux data as function of indexed transmembrane pressure difference is shown for a $20 \mu \mathrm{m}$ thick Pd-film. The index, $n=0.765$ was obtained by non-linear least-square fit with regression coefficients values around 0.999 for all temperatures tested. A deviation of the hydrogen pressure exponent from the theoretical value of 0.5 suggests that the hydrogen flux depends not only on atomic diffusion through the Pd film, for which the pressure exponent should be 0.5 , but also on the surface processes of hydrogen chemisorption and dissolution.

Computed hydrogen permeance data as obtained from the slopes of the regressed line in Figure 11 for $20 \mu \mathrm{m}$ thick Pd-SS composite membrane are given at various temperatures with the corresponding regression coefficients in Table 5. To obtain the activation energy for hydrogen permeation through the membrane, Arrhenius plot based on equation, Eqn. (46) was used. The Arrhenius plot of the permeability data is shown in Figure 12. The activation energy for this composite membrane for hydrogen permeation is calculated as $16.58 \mathrm{~kJ} / \mathrm{mol}$. This value is in good agreement with those reported by other groups. For example, Mardilovich et al. (1998) 
reported a value of $16.38 \mathrm{~kJ} / \mathrm{mol}$ and similar activation energy of $15.7 \mathrm{~kJ} / \mathrm{mol}$ was reported by Shu et al. (1994). These authors fabricated Pd membranes using porous stainless steel as a substrate.

To compare the performance of Pd-SS membrane, we used selectivity of gases as a measure of its performance. Selectivity is defined as the ratio of the hydrogen flux to the flux of another less permeable gas at the same transmembrane pressure. In Figure 13, selectivity data of $\mathrm{H}_{2} / \mathrm{N}_{2}$ is given as a function of trans-membrane pressure difference in the temperature range of $335{ }^{\circ} \mathrm{C}$ to $450{ }^{\circ} \mathrm{C}$. The selectivity coefficients decreased with transmembrane pressure differences. High hydrogen/nitrogen permeation ratio of the Pd-SS composite membrane at higher temperature confirms that the composite membrane is suitable for high temperature hydrogen separation applications.

In Figure 14, the selectivity data for $\mathrm{He} / \mathrm{N}_{2}$ is shown at $450{ }^{\circ} \mathrm{C}$ as a function of transmembrane pressure difference. The selectivity range for the helium/nitrogen was found from about 2.15 to 3.5 at $450^{\circ} \mathrm{C}$ and decreased as the transmembrane pressure difference increased. The Knudsen diffusion selectivity for the helium/nitrogen system is about 2.6, which indicates that viscous flow was insignificant for gas flow through the membrane assembly and the flow of gases other than hydrogen through this membrane was via a mixed mode.

\section{MEMbRANE REACtOR MOdEL Simulation AND VALIDATION}

The effect of the major operating variables and design parameters on the performance of the simulated PBIMTR is examined here. In addition, the performance of the PBIMTR is compared with that in a PBR, as well as Equilibrium Conversion (EC), under identical operating conditions. The membrane reactor model is used to investigate the steam methane reforming process in a tubular reactor with the following parameters as reactor dimensions, catalyst properties, and membrane transport properties:

\section{Reactor Dimensions:}

Total reactor length, $l_{0}=0.1524 \mathrm{~m}$

Inner radius of inner tube, $r_{1}=3.175 \times 10^{-3} \mathrm{~m}$

Outer radius of inner tube, $r_{2}=4.7625 \times 10^{-3} \mathrm{~m}$ 
Inner radius of shell, $r_{3}=9.525 \times 10^{-3} \mathrm{~m}$

The shell space is the reaction side, and the tube volume is the permeate side.

\section{Catalyst Properties:}

Radius, $r_{P}=0.1125 \mathrm{~mm}$

Composition of $\mathrm{Ni}$ in the catalyst $=15.2 \%$

BET surface area $=58 \mathrm{~m}^{2}$

Catalyst surface area $=9.3 \mathrm{~m}^{2} / \mathrm{gm}_{\text {cat }}$ (fresh catalyst)

Void fraction, $\varepsilon=0.528$

\section{Membrane Characteristics:}

Permeation parameters used in this investigation are: [taken from Shu et al., 1994]

$\mathrm{Pd} / \mathrm{SS}$ membrane thickness, $H=20 \mu \mathrm{m}$

Power index, $n=0.5$

Hydrogen permeation activation energy, $E_{P}=15.7 \mathrm{KJ} / \mathrm{mol}$

Permeation pre-exponential factor, $Q_{o}=1.56 \times 10^{-8} \mathrm{~m}^{3} / \mathrm{m} . \mathrm{s} . \mathrm{Pa}^{0.5}$

Permeate side pressure, $P_{S}=1.0 \mathrm{~atm}$

\section{Effect of Reaction Temperature:}

Since the membrane reactor has the ability to remove one component selectively from a mixture of gaseous products, it can be used advantageously over the conventional reactor to enhance the conversion of an equilibrium-limited reversible reaction. In the steam methane reforming process, the use of the $\mathrm{Pd}$ membrane reactor leads to a significantly enhanced conversion by selective hydrogen removal at a temperature range of $350^{\circ} \mathrm{C}$ to $650^{\circ} \mathrm{C}$, which is evident from Figure 15. This increase in conversion takes place for both methane and steam. This figure compares the total methane and steam conversions for the membrane reactor with that in the non-membrane packed-bed reactor together with the equilibrium conversions of the shell feed gas. The packed-bed inert membrane reactor (PBIMTR) is superior to a conventional packed-bed reactor (PBR). Since the overall SMR process is endothermic in nature, it is thermodynamically favored by high temperatures. Hydrogen permeation rate through the $\mathrm{Pd}$ membrane is also temperature-dependent; therefore, high temperatures not only positively and directly affect the 
reaction equilibrium, but also the hydrogen permeation rate. The net effect is therefore the shifting of reaction equilibrium towards higher conversion. Both the methane and steam conversions with the permselective membrane are higher than those obtained at the equilibrium condition. The highest conversion can be more than twice the equilibrium value, which would be expected in the absence of the preferential separation of hydrogen.

Figure 16 shows the comparison of level of conversion for SMR reactions in the conventional non-membrane PBR with thermodynamic equilibrium conversion as a function of reaction temperature for $2 \mathrm{~atm}$ reaction pressure. From this figure it can be seen that in the non-membrane reactor the total conversion of methane, steam, and conversions of methane to carbon-monoxide and carbon dioxide are lower than the equilibrium conversion at the same temperature. Similarly, the packed-bed (shell feed side) inert membrane tubular reactor is compared to a conventional packed-bed reactor in Figure 17 for 2 atm reaction pressure. The result indicates that total conversion of methane, and steam, conversions of methane into $\mathrm{CO}$ and $\mathrm{CO}_{2}$ in PBIMTR are always higher than that in the PRR under the same operating conditions. Total conversion of methane increases with temperature. It also indicates that at higher temperatures the conversion of methane into $\mathrm{CO}$ is relatively high. Conversion of methane into carbon dioxide has a decreasing trend at higher temperatures.

\section{Effect of Reaction Pressure}

Since the steam methane reforming is accompanied by a volume expansion, lower reaction pressures are thermodynamically favored. The thermodynamic equilibrium conversions as well as conversions in the non-membrane plug-flow reactor decrease with increasing reaction pressure, as reported in Figure 18. In the non-membrane reactor the level of conversions (total methane conversion, steam conversion, and conversions of methane to $\mathrm{CO}$ and $\mathrm{CO}_{2}$ ) are lower than that of equilibrium values at any reaction pressure. The differences in performances between PBR and EC with pressure are higher at lower pressure. Conversion of methane into carbon monoxide has a decreasing trend at higher pressures.

In a conventional non-membrane reactor an increase of pressure leads to a decreased conversion of methane as well as steam conversion during the steam reforming reaction, in agreement with the equilibrium calculation as described. However, when the $\mathrm{Pd}$ composite membrane is 
employed, the conversion level increases with pressure, as shown in Figure 19. There are two determining factors those intricate balance determines the net effect of reactor pressure increase on the overall conversion in a membrane reactor. Increase in pressure has adverse effect on thermodynamic equilibrium, which is just described. Whereas the equilibrium shift towards the product side caused by enhanced hydrogen permeation due to higher transmembrane pressure difference is favorable. When the enhancement of hydrogen permeation flux through the membrane from reaction side to permeate side due to an increase in reaction pressure is sufficient enough to counterbalance the adverse effect on thermodynamic equilibrium, the net effect is an enhancement of the conversion. Therefore, the increased level of methane and steam conversions is mainly related to the increased rate of hydrogen permeation from the reaction side, as shown in Figure 19 (reaction conditions are described in the figure). An increasing variation in total methane, steam conversions, the production rates of $\mathrm{CO}$ and $\mathrm{CO}_{2}$ with the increase of reaction side pressure is shown in Figure 20 for a particular reaction condition.

However, in the case of a Pd- composite membrane, a decreasing variation in total methane, steam conversions, the production rates of $\mathrm{CO}$ and $\mathrm{CO}_{2}$ with the increase of reaction side pressure is also observed, as shown in Figure 21. In this case keeping all other reaction parameters constant, almost a fifteen times lower sweep ratio than that used in Figure 20 is used. Here, the adverse effect on thermodynamic equilibrium dominates over the increased rate of the sweep gas brings in a direct increase of methane conversion with the pressure. This behavior of the membrane reactor with pressure is in harmony with the reported literature results of Shu et al. (1994); Uemiya et al. (1991); Adris et al. (1994). Shu et al. (1994) experimentally found a decrease methane conversion with increasing reaction pressure in their experimental conditions where they used a sweep ratio of approximately 0.25 . However, in their simulation study of membrane reactor, they found an increase of methane conversion with increasing reaction pressure. During their simulation study, they increased the sweep ratio to $\sim 0.86$ and $\sim 1.23$. Uemiya et al. (1991) experimentally found an increase in methane conversion in a packed bed catalytic membrane reaction with increasing reaction pressure by using a high sweep ratio of 4.0. From these results, it can be concluded that the behavior of methane conversion in a hydrogen perm-selective Pd membrane reactor depends on the operating conditions of the reactor. 


\section{Yield of Hydrogen}

Yield of hydrogen can be defined in two ways: yield with respect to molar feed rate of methane and yield of hydrogen with respect to methane reacted. Thus, the yield of hydrogen with respect to methane feed methane is defined as:

$$
Y_{m f}=\frac{\mathrm{H}_{2} \text { production rate }}{\mathrm{CH}_{4} \text { feed rate }}
$$

The yield of hydrogen with respect to methane reacted is defined as:

$$
Y_{m r}=\frac{\mathrm{H}_{2} \text { production rate }}{\mathrm{CH}_{4} \text { depletion rate }}
$$

Yield with respect to feed methane is the amount of hydrogen production per mole of feed methane. Yield with respect to methane reacted can only signify the extent of the reaction, Eqn. (6) in comparison to the reaction, Eqn. (8). If the only rate of the second reaction is greater or equal to the rate of the first reaction, the product will be carbon monoxide free. It can be viewed as only the third reaction is taking place in the reactor. In this case $Y_{m r}$ is 4.0 or $400 \%$. If only the first reaction takes place in the reactor, $Y_{m r}$ will be 300. Therefore, a 300 value of $Y_{m r}$ indicates that no carbon dioxide is present in the output and a value of 400 shows that no carbon monoxide is present in the output.

Hydrogen yields as a function of reaction temperature in both PBIMTR and PBR, as well as the thermodynamic equilibrium yield, are plotted in Figure 22 for a reaction pressure of $2 \mathrm{~atm}$. The hydrogen permeation rate is also plotted on the same figure. The figure clearly shows that the yield of hydrogen in a non-membrane reactor is much lower than that of thermodynamic equilibrium values achievable in a closed system, and PBIMTR always outperforms the conventional reactor. From this figure it is obvious that the yield increases greatly at higher temperatures. Increase rate is greater in the membrane reactor because of the higher permeation rate through the membrane at higher temperatures, which is obvious from the figure.

Figure 23 shows the effect of reaction side pressure on the yield of hydrogen with respect to. methane feed rate. It indicates that at a particular temperature, a lower reactor pressure favors a higher yield in a conventional reactor but in a membrane reactor it behaves conversely at the 
reaction conditions mentioned in the figure. Similarly, increase in the yield of hydrogen with respect to methane feed rate is because of the higher hydrogen permeation rate through the $\mathrm{Pd}$ membrane at higher reaction pressure.

Hydrogen yield with respect to feed rate of methane in PBIMTR is plotted in Figure 24 for different sweep ratios. Yield at a fixed temperature increases with the increase in sweep ratio. At a particular temperature, as the sweep ratio increases, the driving force for hydrogen permeation also increases, which in turn increases the yield of hydrogen.

Yield of hydrogen with respect to methane reacted is presented in Figure 25. A sharp fall of the yield at higher temperatures indicates that at lower temperatures, the extent of carbon monooxide production is very small and at higher temperatures carbon mono-oxide production is severe. It also shows that the higher pressure is favorable for a lower carbon mono-oxide production.

\section{Effect of Steam to Methane Molar Feed Ratio}

In order to prevent the carbon deposition over the catalyst surface and to enhance conversion, steam methane reforming reaction usually conducts in the presence of an excess amount of steam. The conversion of methane increases and the conversion of steam decreases with the steam to methane molar feed ratio for both membrane and non-membrane reactors as shown in Figure 26. In the case of palladium membrane, a constant sweep gas flow rate is maintained. Thermodynamically, lowering the partial pressure of methane is favorable to its catalytic reforming accompanied by volume expansion. By increasing the steam to methane molar ratio

for a constant flow of methane, partial pressure of methane is reduced along the length of the reactor, which is shown in Figure 27. For example at these reaction conditions mentioned in the Figure 26, the conversion of methane in the non-membrane PBR is $5.64 \%$ and $14.29 \%$ at a steam to methane molar feed ratio of 2 and 8 respectively. This increase in methane conversion is due to the reduced methane partial pressure in the reactor. However, in the membrane reactor when maintaining constant flow of methane, for a constant flow rate of sweep gas, an increase in the molar ratio of steam to methane results in decreasing the hydrogen flux through the membrane, as shown in Figure 27. The effect of the second factor is compensated by the first factor in this 
case for all the ratios studied and hence there is an increase in overall methane conversion in the membrane reactor.

\section{$\underline{\text { Effect of Space Time }}$}

Space time $\left(\mathrm{W} / \mathrm{F}_{\mathrm{CH}_{4}}^{o}\right)$ can be defined as the weight of catalyst in the bed, W (gm), divided by the molar feed flow rate of methane, $F_{\mathrm{CH}_{4}}^{o}(\mathrm{~mol} / \mathrm{hr})$. The effect of space time on the performance of the co-current PBIMTR compared to a conventional PBR can be seen in Figure 28. The methane conversion for the membrane reactor is higher than that for the PBR and the equilibrium conversion. The effect of space time on membrane reactor performance is generated by changing the reaction side inlet flow rates while maintaining a constant inlet sweep ratio of 1.0. Since the thermodynamic equilibrium conversion does not depend on residence time, it remains constant. However, the conversion increases with the space time for both PBIMTR and PBR. As the mean residence time of feed gas in the reactor increases, the overall methane conversion increases slightly in the PBR, but in the membrane reactor, the conversion of methane increases significantly. At sufficiently higher contact times, the conversions in the membrane reactor are higher than the equilibrium value because product hydrogen has diffused to the permeate side. As the space time of feed gas in the shell side of the membrane reactor increases, the mean residence time of hydrogen of the reaction side increases, which allows more hydrogen to permeate through the membrane wall, as shown in the same figure and thereupon conversion increases. At very short space time, methane conversion in PBIMTR is lower than that of equilibrium values because the mean residence time of methane in the reactor is too short to shift the thermodynamic equilibrium towards an increased level of methane conversion.

\section{Effect of Temperature and Pressure on Hydrogen Permeation}

Figure 29 shows the effect of reaction pressure on hydrogen permeation rate through the $\mathrm{Pd}$ composite membrane for different reactor temperatures. Separation side total pressure is assuming $1 \mathrm{~atm}$ in all the cases. The figure shows that with an increasing reaction side total pressure increases the hydrogen permeation rate through the membrane. An increase in the driving force causes this increased efficiency of the membrane. During the steam methane reforming process the reaction temperature can affect not only the rate of hydrogen production 
but also the hydrogen permeation flux through the membrane wall. As the temperature increases, the rate of hydrogen production increases for the same sweep gas flow rate because of the positive effect of temperature on the steam methane reforming reaction, which in turn increases the partial pressure of hydrogen in the reaction side. Simultaneously, the hydrogen permeation coefficient, which is a temperature dependent, increases the hydrogen permeation flux with the increase in reaction temperature. Therefore, PBIMTR exhibits pronounced hydrogen permeability at high temperature because of this combined effect.

\section{Effect of Sweep Ratio}

The conversion of methane increases with increasing sweep gas flow rate in the permeate side of the membrane reactor. An increase in the flow rate of sweep gas reduces the partial pressure of hydrogen in the permeate side, which results in an increase in the difference in hydrogen pressure between the reaction side and the permeate side. Therefore, increase in sweep ratio increases the hydrogen permeation flux from the reaction side to permeate side through the Pd membrane. This enhanced hydrogen permeation flux in turn shifted the chemical equilibrium towards the product side and thus greatly enhances the conversion level. This effect is examined in the $\mathrm{Pd} / \mathrm{SS}$ membrane system, as shown in Figures 30 and 31 . At $600{ }^{\circ} \mathrm{C}$, methane conversion is slightly increased with raising the sweep gas flow rate while the shell-side space time is maintained constant.

\section{$\underline{\text { Average Partial Pressure Profiles }}$}

Figure 32 shows the partial pressure profiles of reaction side components along the length of the reactor. This plot indicates that changes in partial pressures are higher near the inlet of the reactor. They become almost horizontal near the outlet of the reactor.

Figure 33 illustrates the partial pressures of hydrogen along the radial direction of the reactor for both feed and permeate sides together. The partial pressures of hydrogen at the reaction and separation sides approach the same level at the end of the reactor.

Hydrogen diffusion through the membrane causes all the components in the reaction system to diffuse in the radial direction. For example, Figure 34 shows the variation of partial pressures of $\mathrm{CH}_{4}$ in the radial direction with axial position as a parameter for a particular reaction condition. 
The left hand side vertical line of the figure represents the membrane and the vertical line at the right hand side represents the shell wall of the reactor. Partial pressure of $\mathrm{CH}_{4}$ at the membrane wall are higher compared to that at any other radial position, but for $\mathrm{H}_{2}$ (as shown in Figure 33) the situation is the opposite because of hydrogen permeation through the composite membrane wall, which means hydrogen has a positive partial pressure gradient along the radial direction. From these figures it is also clear that the rate of change of partial pressures of all components in the radial direction of the reactor is steeper near the membrane wall. Since the difference of partial pressure of hydrogen on the reaction and permeate side decreases along the reactor coordinate, the change of the partial pressures of all components on the reaction side in the radial direction becomes flat near the outlet of the reactor.

\section{Model Validation}

Here the calculated numerical results are compared with experimental data available in the literature, namely, those by Shu et al. (1994). The research team studied the steam methane reforming process in a conventional reactor and in a catalytic membrane reactor, using a stainless steel supported palladium membrane. The reactor used by Shu et al. (1994) to investigate the steam methane reforming process had the following parameters as reactor dimensions, catalyst properties, and membrane transport properties:

\section{Reactor dimensions:}

Total reactor length, $l_{o}=3.6 \mathrm{~cm}$

Outer diameter of inner tube, $d_{2}=0.95 \mathrm{~cm}$

Inner diameter of shell, $d_{3}=1.7 \mathrm{~cm}$

Shell volume is used as reaction side and tube volume as permeate side.

\section{Catalyst properties:}

Amount of $\mathrm{Ni} / \mathrm{Al}_{2} \mathrm{O}_{3}$ catalyst $=11.0 \mathrm{gm}$

Catalyst pellets size $=18-30$ mesh size

Permeation parameters used in this investigation:

$\mathrm{Pd} / \mathrm{SS}$ membrane thickness, $H=20 \mu \mathrm{m}$

Power index, $n=0.5$

Hydrogen permeation activation energy, $E_{P}=15.7 \mathrm{KJ} / \mathrm{mol}$ 
Permeation pre-exponential factor, $Q_{o}=1.56 \times 10^{-8} \mathrm{~m}^{3} / \mathrm{m} \cdot \mathrm{s} \cdot \mathrm{Pa}^{0.5}$

The first comparison of the results of this model with experimental data is made for a conventional packed-bed reactor. In Figure 35 total methane conversion is reported for various reaction temperatures. In this figure it is possible to observe a reasonable agreement between the experimental data and the simulation results. The predicted simulation results are slightly lower than the experimental values. The variation between the experimental and simulation results could be possible by the simplified assumptions made during the models development.

Figure 36 shows the experimental total conversion of methane and the methane conversion calculated with the present model against temperature for the Pd-membrane reactor. It is found that the experimental data is somehow higher than the predicted values from the model.

The effect of reaction pressure on the steam methane reforming conversion is compared with experimental data for the conventional non-membrane PBR in Figure 37. As expected, in the case of the non-membrane system, the methane conversion decreased with increasing total reaction pressure, in agreement with the equilibrium calculation. Model agreement with experimental data is good especially at low reaction pressure but at high pressure the model somehow over-predicts the experimental data.

In Figure 38 total methane conversion in the $\mathrm{Pd} / \mathrm{SS}$ membrane reactor system is plotted against the sweep gas flow rate while maintaining the permeate side at a fixed pressure of $1 \mathrm{~atm}$. An increasing variation in the methane conversion with the increase of sweep gas flow rate is observed. At low to moderate sweep gas flow rates agreement is good. At higher sweep gas flow rates the deviation from the model predicted values is high. This could be caused by the cooling effect of the purge gas stream as well as poorer separation efficiency of the membrane at the high purge rate.

\section{CONCLUSIONS}

To overcome the limitations of conventional electroless plating to deposit thin metal film in porous substrate, we have used osmotic pressure field to induce deep penetration of target metal into pore structures. Using this novel method, we deposited thin Pd-film on the inside of microporous stainless steel tube and the deposited film appears to be robust and defect free. 
From limited permeability tests, it was found that the new membrane has excellent selectivity for hydrogen. Both the permeability and selectivity increase with increasing temperature. This property makes the new membrane attractive for high temperature $\mathrm{H}_{2}$-separation applications.

A two-dimensional pseudo-homogeneous reactor model with parallel-flow configuration was developed for steam methane reforming process. The shell volume was taken as the feed and sweep gas was fed to the inside of the membrane tube. Radial diffusion was taken into account for concentration gradient in the radial direction due to hydrogen permeation through the membrane. With appropriate reaction rate expressions, a set of partial differential equations was derived using the continuity equation for the reaction system and then solved by finite difference method with appropriate boundary and initial conditions.

At the inlet of the reactor, if there is no hydrogen present, it is impossible to evaluate the rate expressions because of singularity. To overcome this problem, in the numerical solution, the first element of the reactor was considered as a CSTR. Iteration or trial and error solution of the complex rate expressions of the reactions under consideration is difficult. The program contains an effective root search scheme and three alternative approaches to solve the equations. If one approach fails, it automatically switches to the next approach. These approaches and schemes help the computer program to solve the problem effectively for all practical, feasible operating conditions.

Membrane reactor performance was compared to that in a conventional non-membrane packedbed reactor. Their performances were also compared with thermodynamic equilibrium values achievable in a closed system. Numerical results of the models show that the methane conversions in the PBIMTR are always higher than that in the PBR, as well as thermodynamic equilibrium conversions. Models showed reasonable agreement with experimental data of Shu et al. (1994) for both membrane and non-membrane reactors. From the analysis of the model results, it is obvious that the membrane reactor performance can be optimized with respect to conversion or yield through the selection of appropriate operating and design parameters of the reactor. 


\section{REFERENCES}

Adris, A.M., A Fluidized Bed Membrane Reactor for Steam Methane Reforming: Experimental Verification and Model Validation, PhD. Dissertation, 1994, The University of British Columbia, Vancouver, Canada.

Barrer, R.M., Diffusion in and Through Solids, Cambridge University Press, London, 1951.

Cheng, Y.S., and Yeung, K.L., J. Memb. Sci., 182, 195 (2001).

Collins, J.P., and Way, J.D., Ind. Eng. Chem. Res., 32, 3006 (1993).

Elnashaie, S.S.E.H., Adris, A.M., Al-Ubaid, A.S., and Soliman, M.A., Chem. Eng. Sci., 45, 491 (1990).

Hirschenhofer, J. H., Stauffer, D.B., Engleman, R. R., and Kjlett, M. G., Fuel Cell Handbook, $4^{\text {th }}$ edition, U.S. DOE, Oak Ridge, Tennessee (1999).

Hsieh, H. P., Inorganic Membranes for Separation and Reaction, Membrane Science Technology Series, Volume 3, Elsevier, 1996.

Itoh, N., Xu, W.C., and Haraya, K., Ind. Eng. Chem. Res., 33, 197 (1994).

Li, A., Liang, W., and Hughes, R., J. Memb. Sci., 149, 259 (1998).

Sato, K., Kaguku kogaku, 1, 43 (1953).

Shu, J., Grandjean, B.P.A., and Kaliaguine, S., Appl. Catal. A: General, 119, 305 (1994).

Uemiya,S., Sato, N., Ando, H., Matsuda, T., and Kikuchi, E., Appl. Catal., 67, 223 (1991).

Wen, C. Y. and Fan, L.T., Models for Flow Systems and Chemical Reactors. Dekker, New York, 1975.

Wilke, C. R., J. Chem. Phys. 18, 517 (1950).

Xu, J. and Froment, G.F., AIChE J., 35, 88 (1989).

Yeoung, K.L., Christiansen, S.C., and Varma, A., J. Meb. Sci., 159, 107 (1999).

\section{ACKNOWLEDGMENTS}

This research was sponsored by the Pittsburgh Energy Technology Center, U.S. Department of Energy, under Award No. DE-FG26-01NT41361. Mr. Donald Krastman, NETL, Pittsburgh is the DOE Project Officer. However, any opinions, findings, and conclusions, or recommendations expressed herein are those of the author and do not necessarily reflect the views of the DOE. Analytical support from the Center for Advanced Materials and Smart Structures (CAMSS) of North Carolina A\&T State University is gratefully acknowledged with special thanks to Drs. Jag Sankar and Zhigang $\mathrm{Xu}$. 
Table 1. Composition of Sensitization and Activation Solutions

\begin{tabular}{|l|l|l|}
\hline & Activation & Sensitization \\
\hline Solute & $\mathrm{PdCl}_{2}$ & $\mathrm{SnCl}_{2}$ \\
\hline Solute Concentration & $0.09 \mathrm{~g} / \mathrm{L}$ & $1.19 \mathrm{~g} / \mathrm{L}$ \\
\hline Solvent & $0.2 \mathrm{~N} \mathrm{HCl}$ & $0.2 \mathrm{~N} \mathrm{HCl}$ \\
\hline Temperature & $25^{\circ} \mathrm{C}$ & $25^{\circ} \mathrm{C}$ \\
\hline
\end{tabular}

Table 2. Typical Pd-electroless Plating Bath Composition

\begin{tabular}{|l|l|}
\hline Component & Concentration \\
\hline $\begin{array}{l}\mathrm{Pd}\left(\mathrm{NH}_{3}\right)_{4}\left(\mathrm{NO}_{3}\right)_{2} \\
(15-\mathrm{wt} \% \text { solution, Pd content } 5 \% \text { max. })\end{array}$ & $16.2 \mathrm{ml} / \mathrm{L}$ \\
\hline $\mathrm{Na}_{2} \mathrm{EDTA}$ & $40.1 \mathrm{~g} / \mathrm{L}$ \\
\hline $\mathrm{NH}_{4} \mathrm{OH}(28 \mathrm{wt} \%)$ & $198 \mathrm{ml} / \mathrm{L}$ \\
\hline $\mathrm{N}_{2} \mathrm{H}_{4}(35 \mathrm{wt} \%$ solution $)$ & $0.59 \mathrm{ml} / \mathrm{L}$ \\
\hline $\mathrm{pH}$ & 10.5 \\
\hline Temperature & $60^{\circ} \mathrm{C}$ \\
\hline
\end{tabular}

Table 3. Kinetic parameters used to calculate rates of three reactions involved in steam methane reforming process

\begin{tabular}{|c|c|c|}
\hline Reaction No.,i & $\boldsymbol{k}_{\boldsymbol{i}, T_{r}}$ & $\boldsymbol{E}_{\boldsymbol{i}}[\mathbf{k J} / \mathbf{m o l}]$ \\
\hline 1 & $1.842 \times 10^{-4}\left[\mathrm{kmol} \cdot \mathrm{bar}^{1 / 2} / \mathrm{kg}_{\mathrm{cat}} \cdot \mathrm{hr}\right]$ & 240.1 \\
2 & $7.558\left[\mathrm{kmol} / \mathrm{kg}_{\mathrm{cat}} \cdot \mathrm{hr} \cdot \mathrm{bar}\right]$ & 67.13 \\
3 & $2.193 \times 10^{-5}\left[\mathrm{kmol} \cdot \mathrm{bar}^{1 / 2} / \mathrm{kg}_{\mathrm{cat}} \cdot \mathrm{hr}\right]$ & 244.9 \\
\hline
\end{tabular}


Table 4. Parameters used to calculate adsorption constants of the species involved in the steam methane reforming process

\begin{tabular}{|c|c|c|}
\hline Species, $\boldsymbol{j}$ & $\boldsymbol{k}_{\boldsymbol{j}, T_{\boldsymbol{r}}}$ & $\Delta \boldsymbol{H}_{\boldsymbol{j}}[\mathbf{k J} / \mathbf{m o l}]$ \\
\hline$C$ & $40.91\left[\mathrm{bar}^{-1}\right]$ & -70.65 \\
$H$ & $0.0296\left[\mathrm{bar}^{-1}\right]$ & -82.90 \\
$M$ & $0.1791\left[\mathrm{bar}^{-1}\right]$ & -38.28 \\
$S$ & 0.4152 & 88.68 \\
\hline
\end{tabular}

Table 5. Hydrogen permeabilities and regression coefficient values for the composite membrane $(\mathrm{H}=20 \mu \mathrm{m})$ for $\mathrm{n}=0.765$

\begin{tabular}{|c|c|c|}
\hline $\begin{array}{c}\text { Temperature, } \mathrm{T} \\
\left({ }^{\circ} \mathrm{C}\right)\end{array}$ & $\begin{array}{c}\text { Regression } \\
\text { coefficient, } \mathrm{R}^{2}\end{array}$ & $\begin{array}{c}\text { Hydrogen Permeance, } \mathrm{Q}_{\mathrm{H}} / \mathrm{t} \\
\left(\mathrm{mol} / \mathrm{m}^{2} / \mathrm{S} / \mathrm{Pa}^{0.765}\right)\end{array}$ \\
\hline 450 & 0.9997 & $3.01990 \times 10^{-5}$ \\
\hline 425 & 0.9997 & $2.72348 \times 10^{-5}$ \\
\hline 400 & 0.9993 & $2.48330 \times 10^{-5}$ \\
\hline 375 & 0.9994 & $2.09843 \times 10^{-5}$ \\
\hline 325 & 0.9996 & $1.71346 \times 10^{-5}$ \\
\hline
\end{tabular}




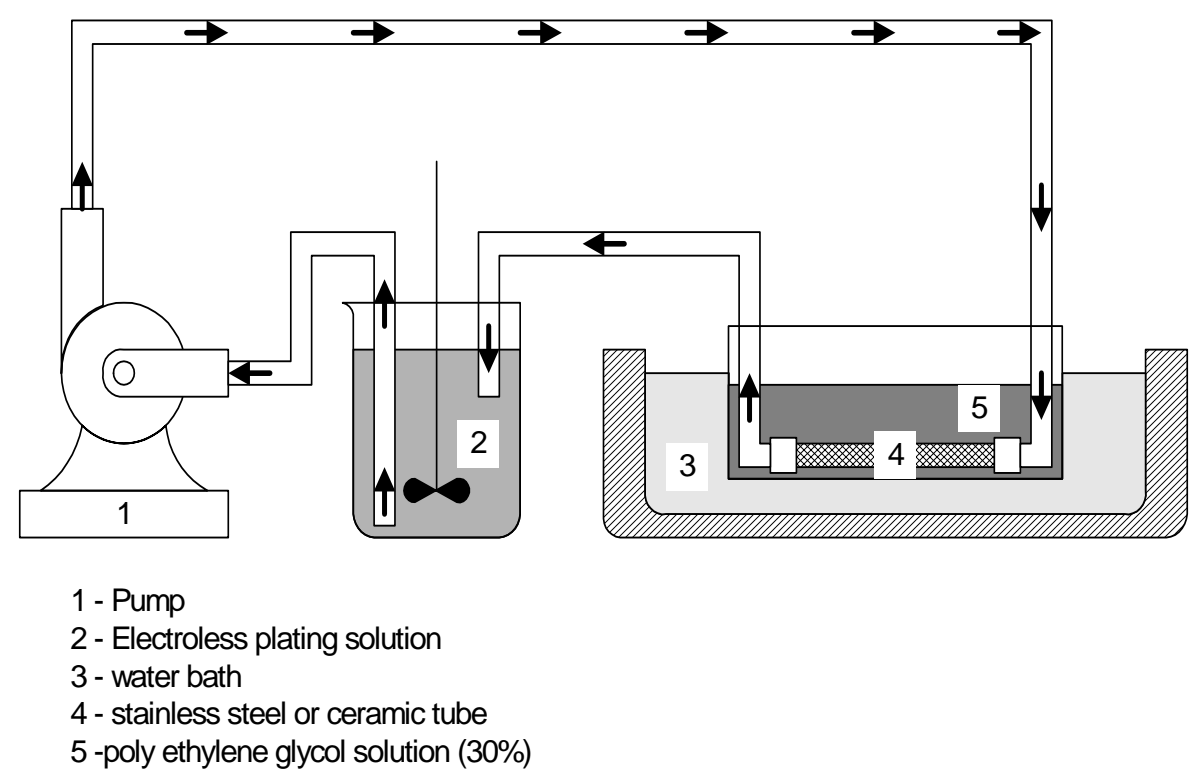

Figure 1. Experimental Setup for Electroless Plating with Osmotic Pressure Field 


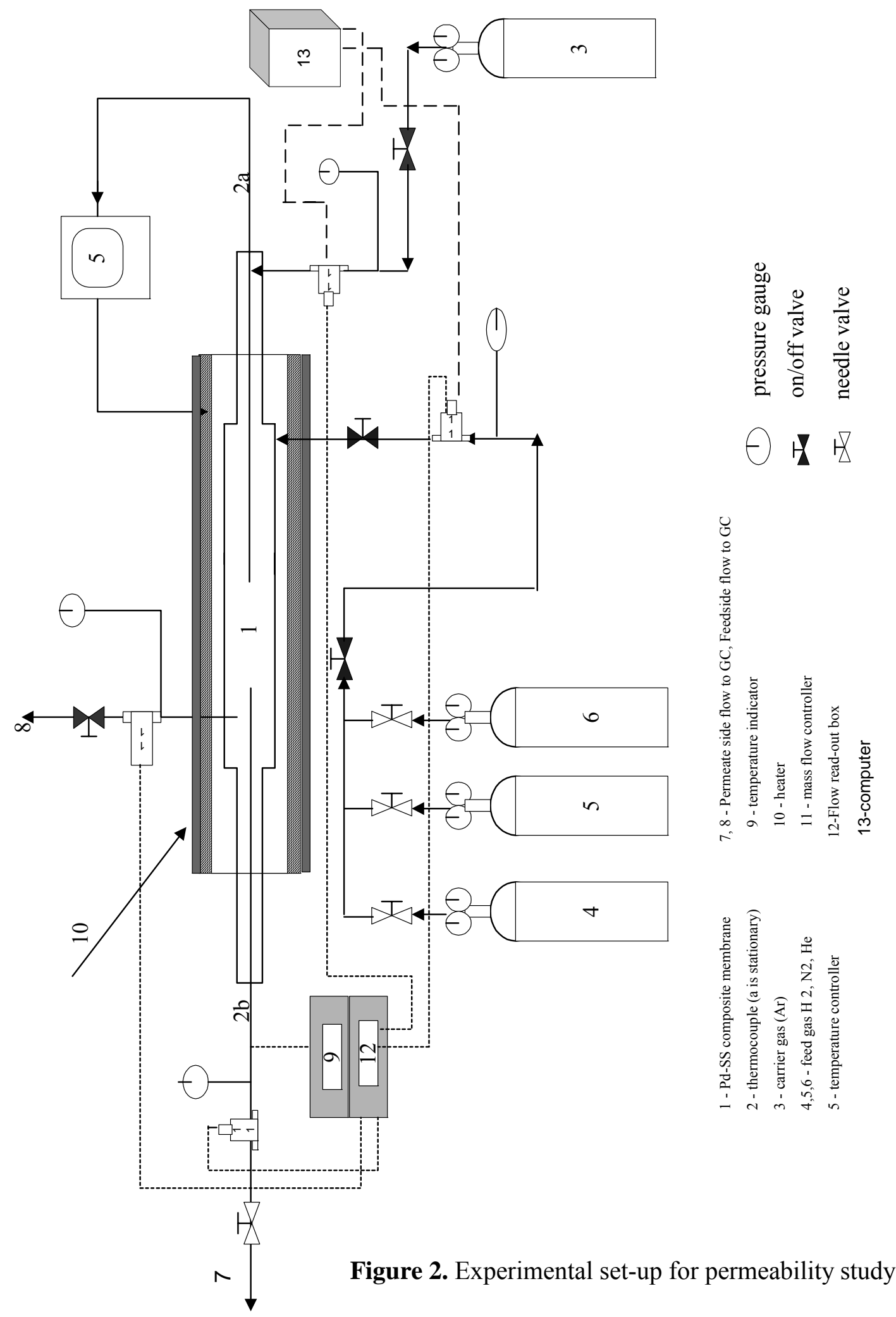




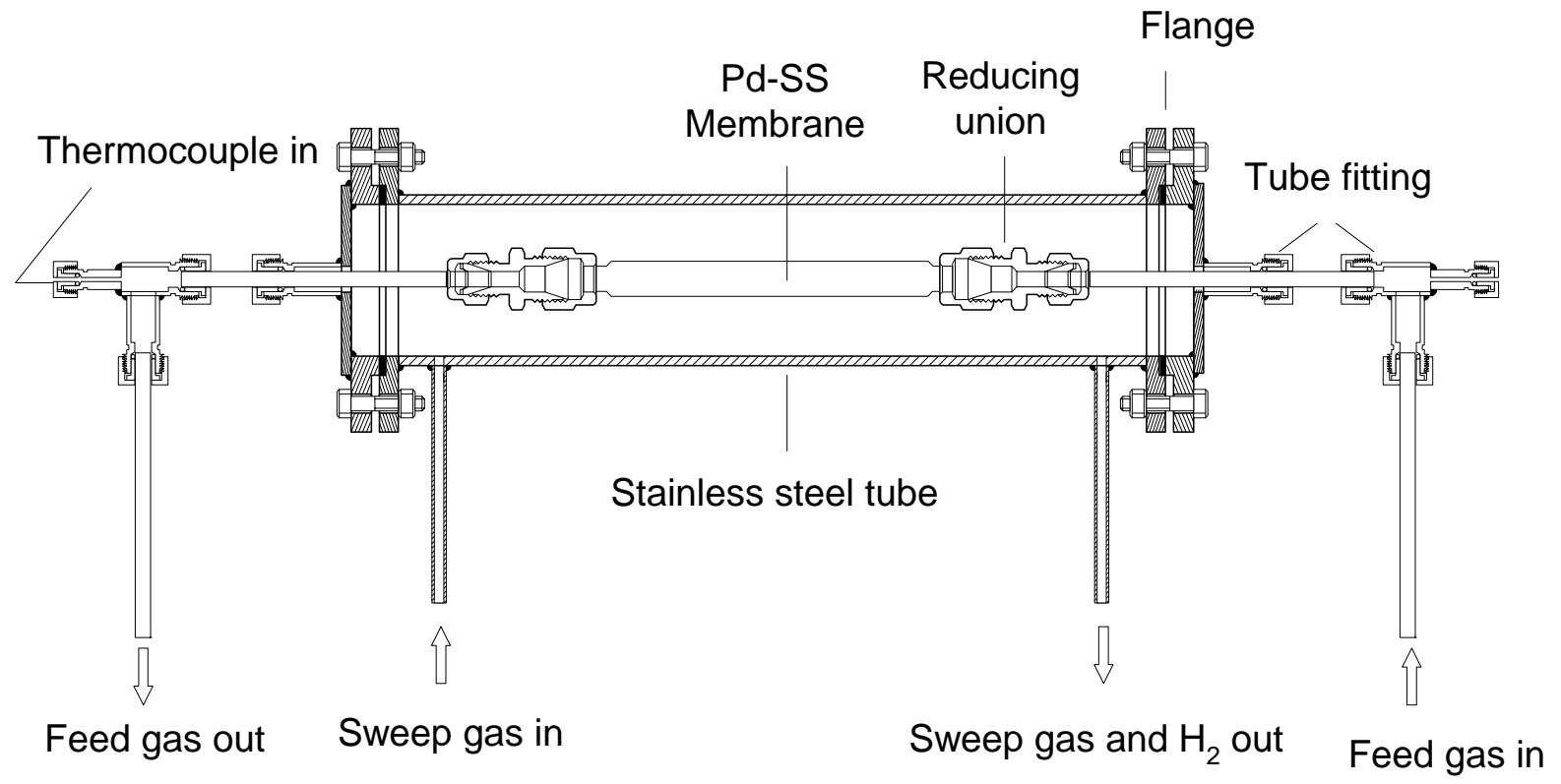

Figure 3. Permeator/Reactor Setup 


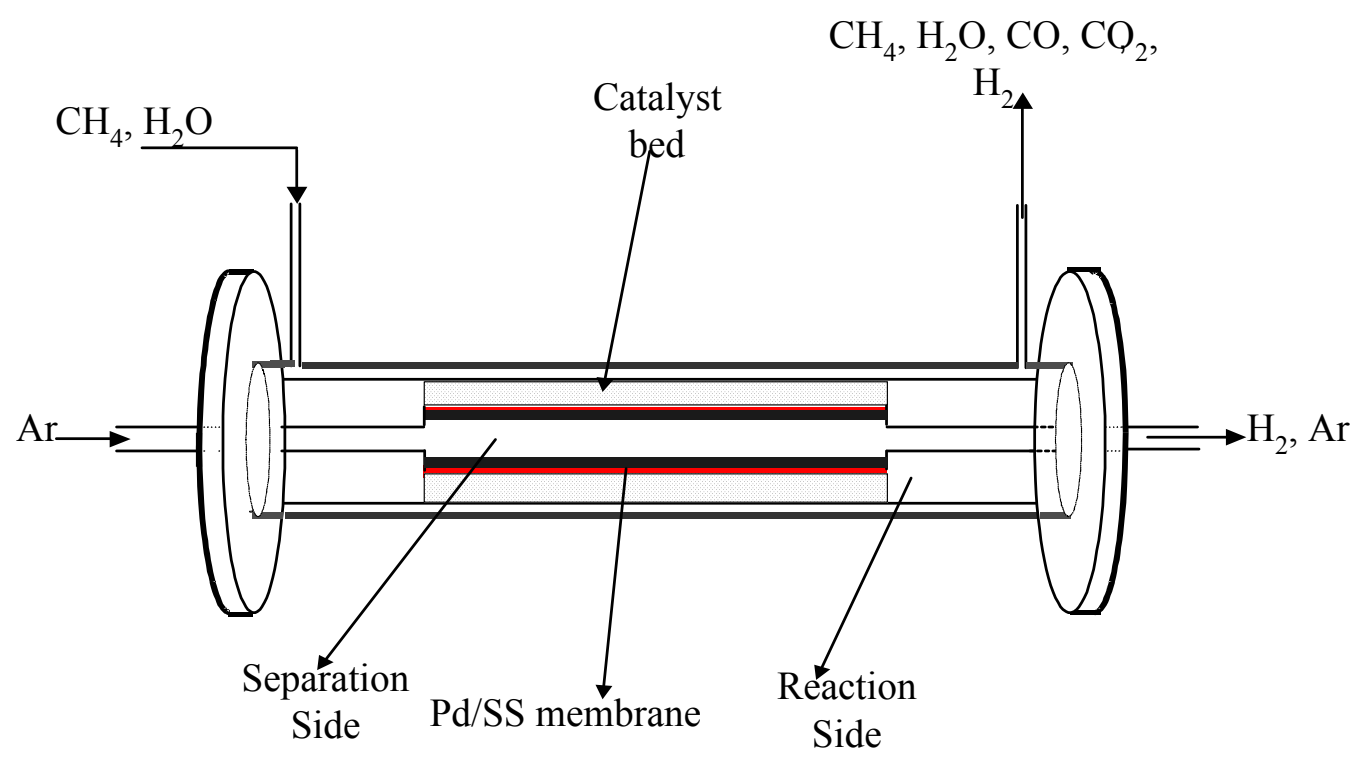

Figure 4. Schematic diagram of the membrane reactor configuration

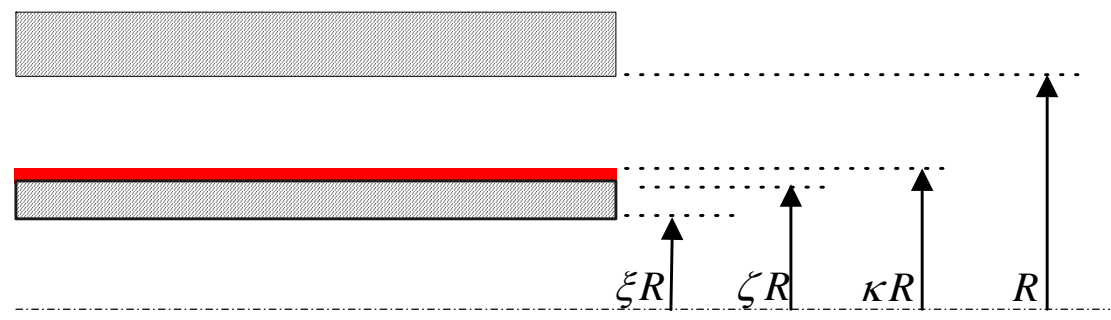

Figure 5. Various radial dimensions of the reactor used during problem formulation (not drawn to scale) 


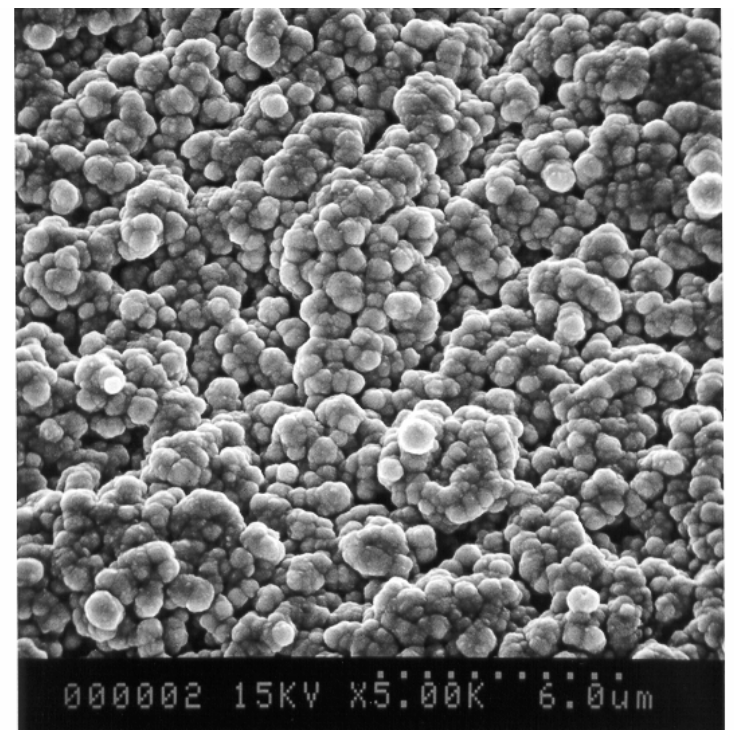

(a) Pd-film on ceramic substrate cps

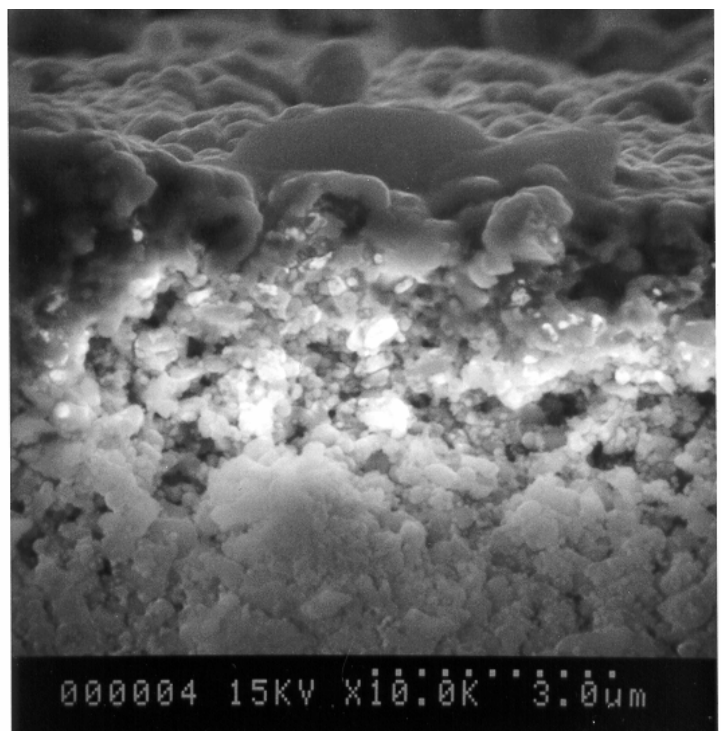

(b) Penetration of Pd-film through Pores

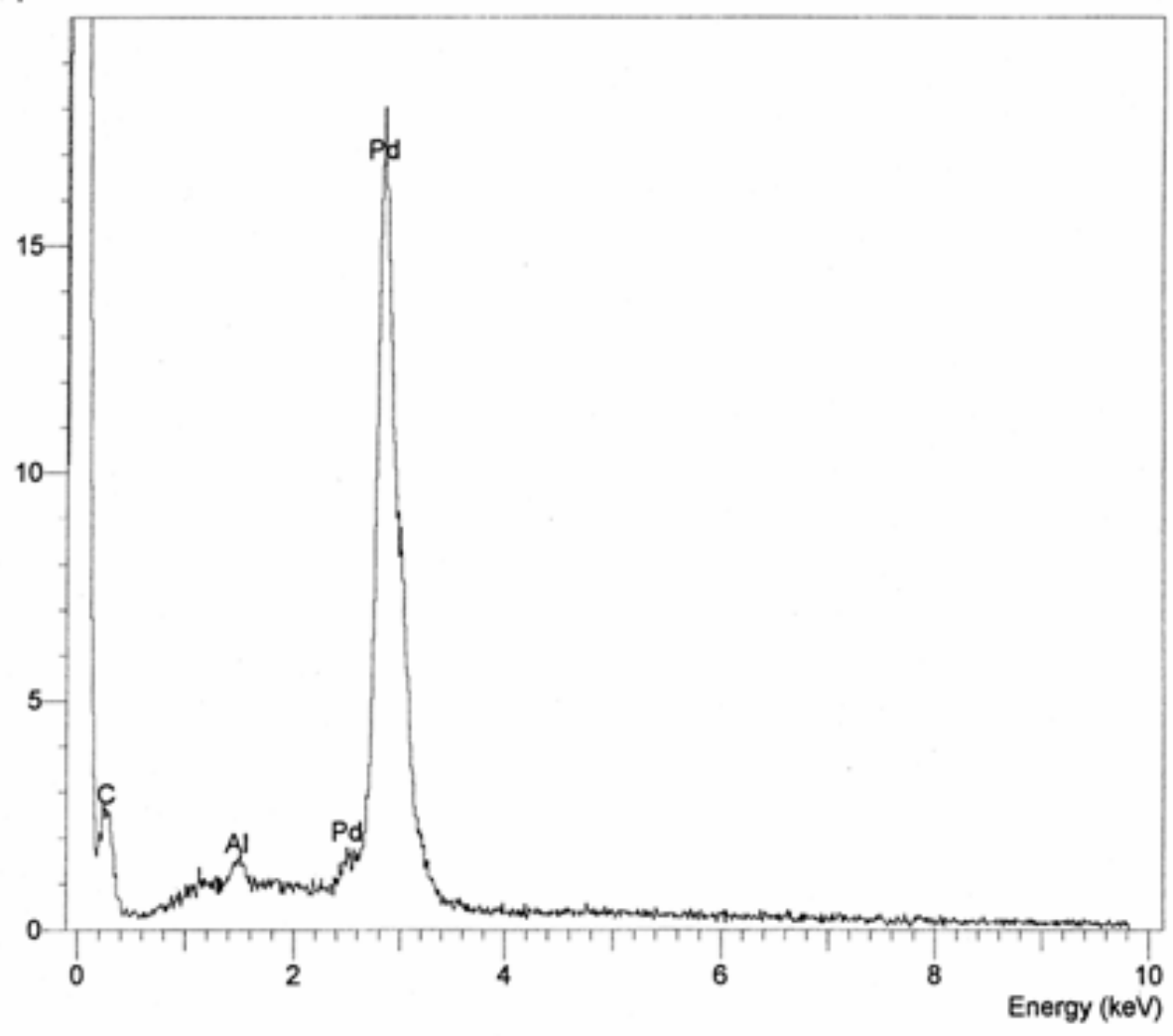

(c) EDX analysis of analysis of electroless deposited Pd-film on ceramic substrate

Figure 6. SEM and EDX analysis of Pd-film on $0.2 \mu \mathrm{m}$ microporous ceramic substrate: (a) SEM of Pd-film surface; (b) Penetration of Pd-film across the thickness; and (c) EDX analysis of Pdfilm. 


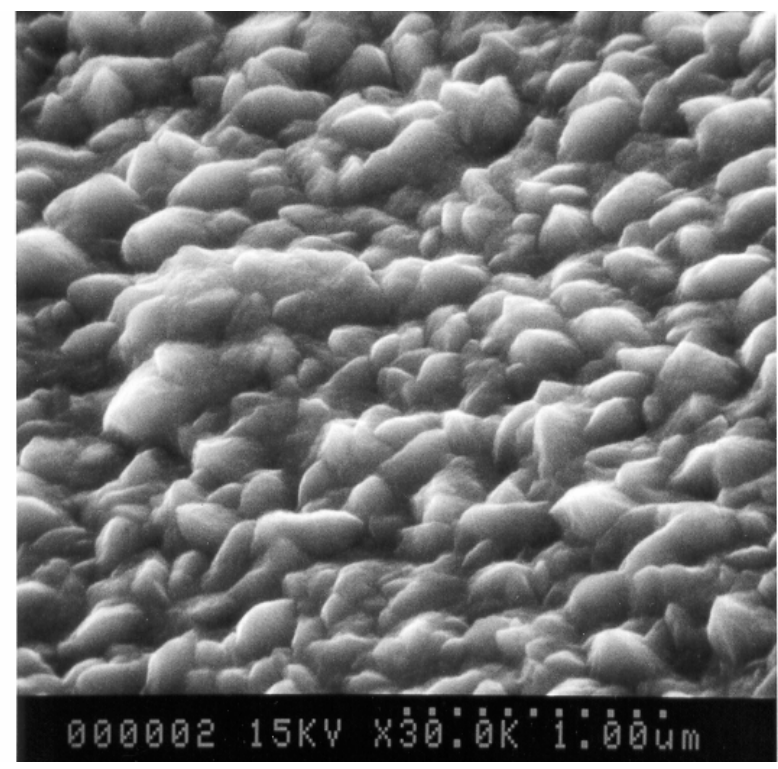

(a) Pd-film on ceramic substrate

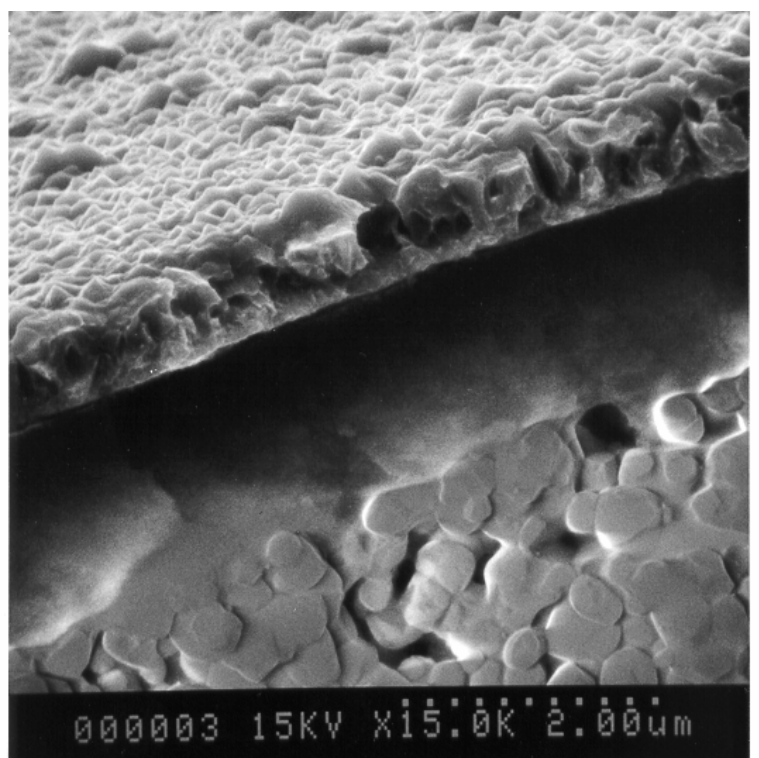

(b) Penetration of Pd-film through Pores

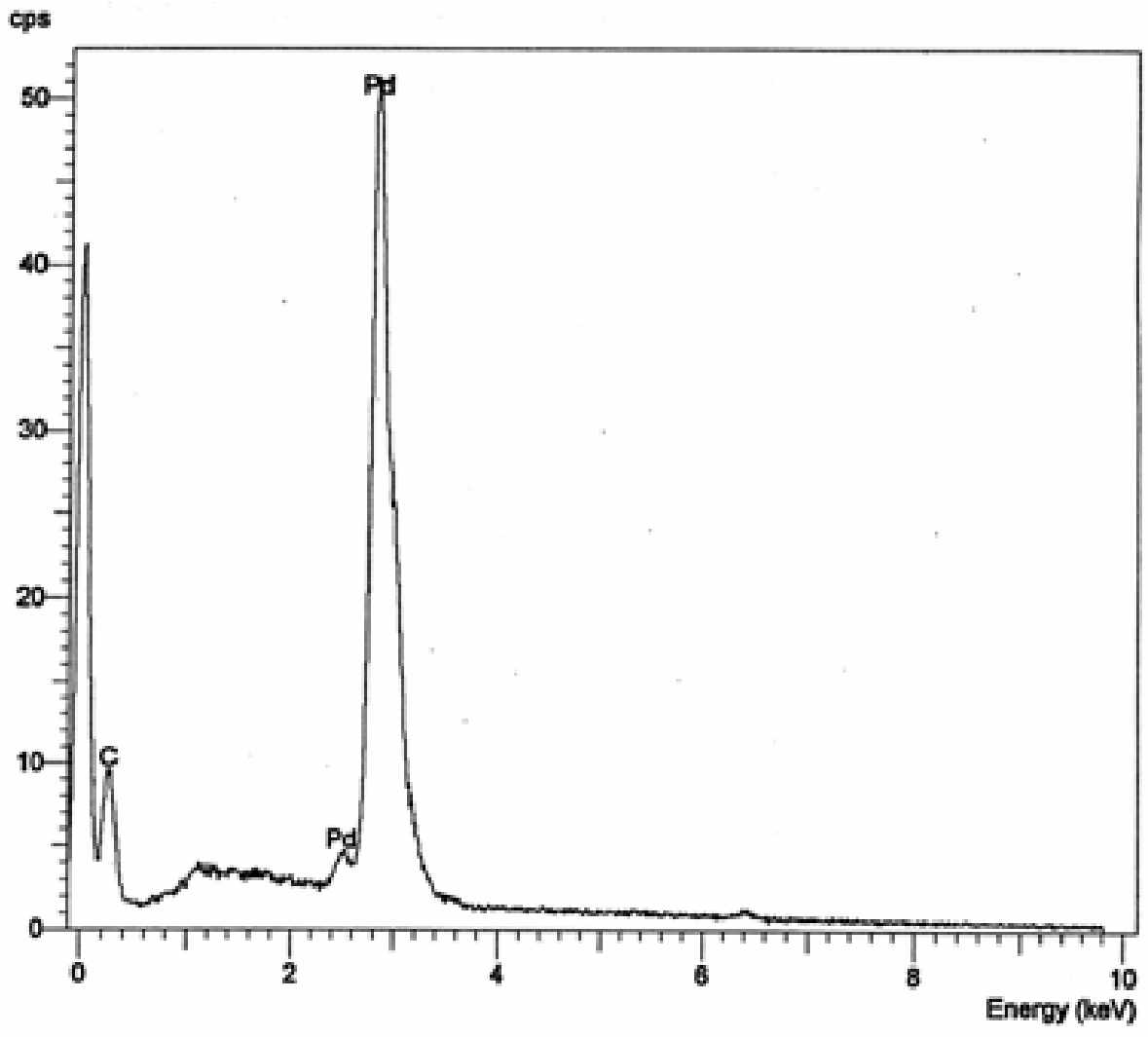

Figure 7. SEM and EDX analysis of Pd-film on $0.2 \mu \mathrm{m}$ microporous ceramic substrate: (a) SEM of Pd-film surface; (b) Penetration of Pd-film across the thickness (film separated from the support); and (c) EDX analysis of Pd-film. 


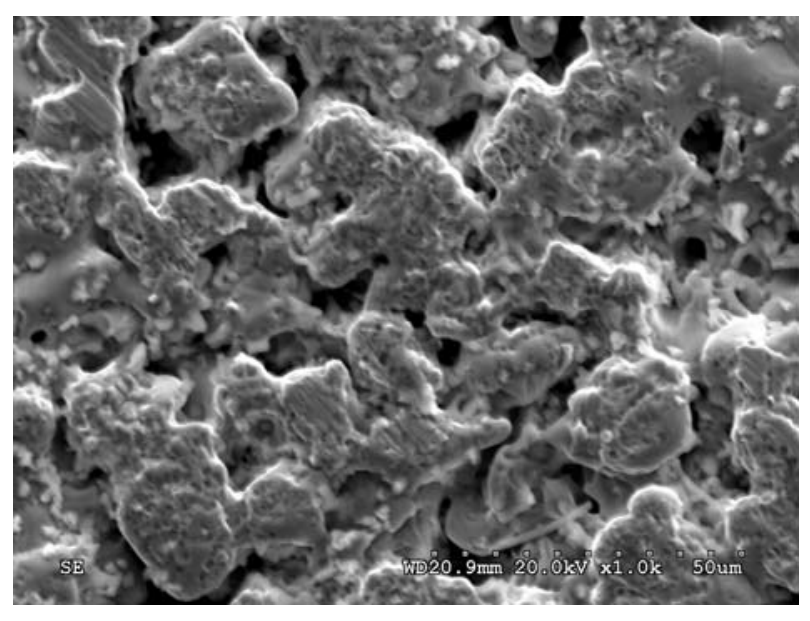

(a) $0.2 \mu \mathrm{m}$ porous $\mathrm{SS}$ surface at $1000 \mathrm{X}$

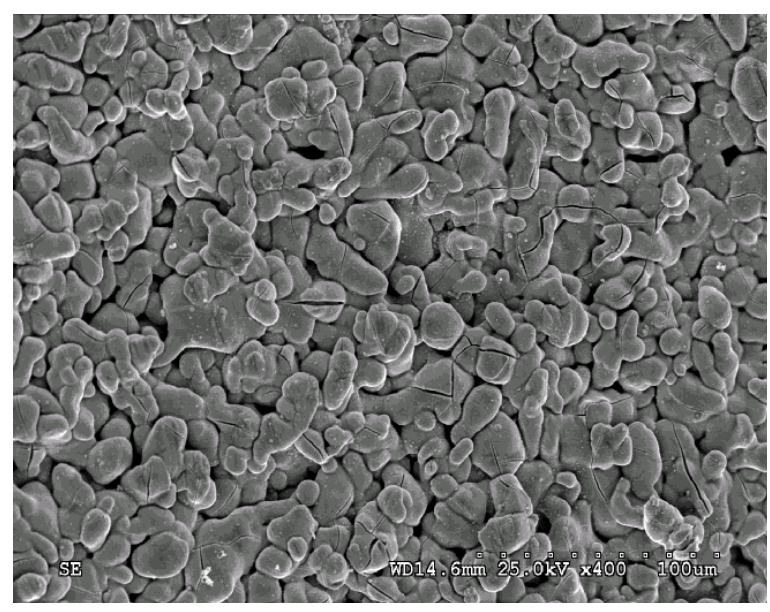

(c) Pd-film on SS surface at $400 \mathrm{X}$

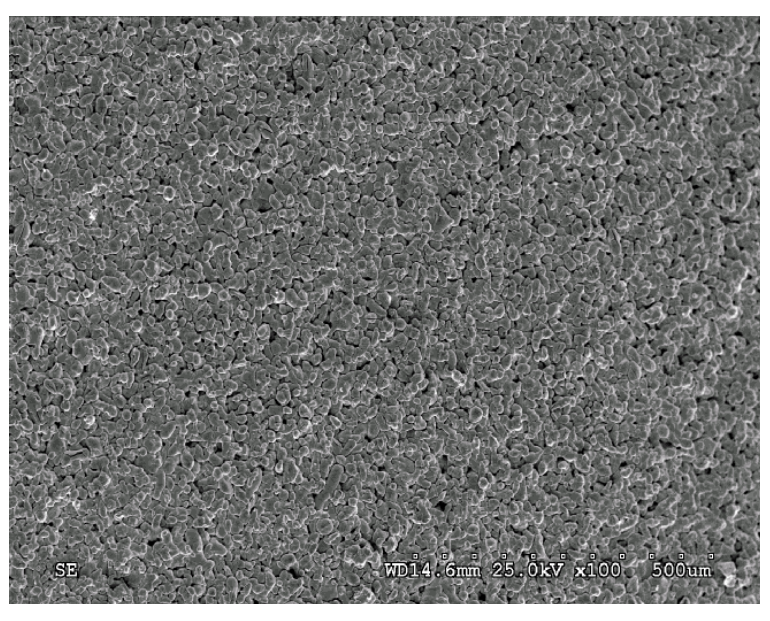

(b) Pd-film on SS surface at 100X

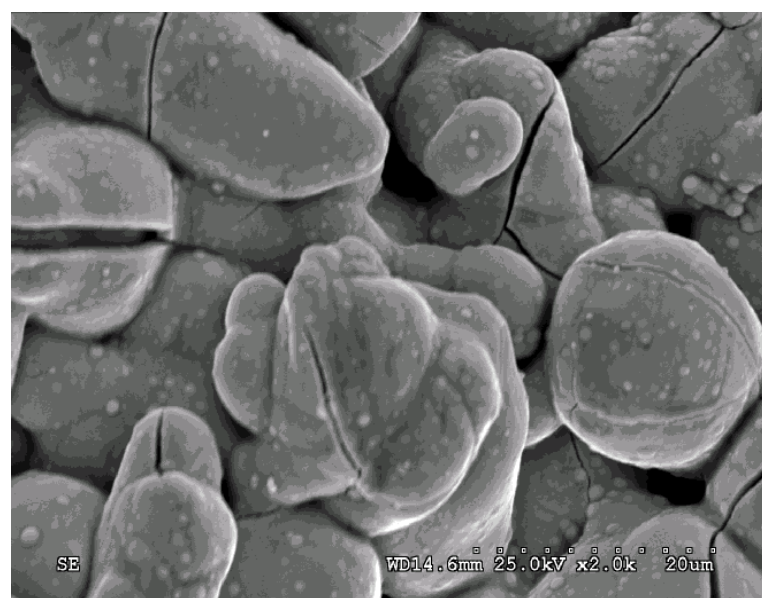

(d) Pd-film on SS surface at 2000X

Figure 8. SEM Micrographs of 0.2 micron pore size stainless steel tube: (a) Substrate surface at 1000 magnification; (b) Pd-film at 100 magnification; (c) Pd-film at 400 magnification and (d) Pd-film at 2000 magnification. 


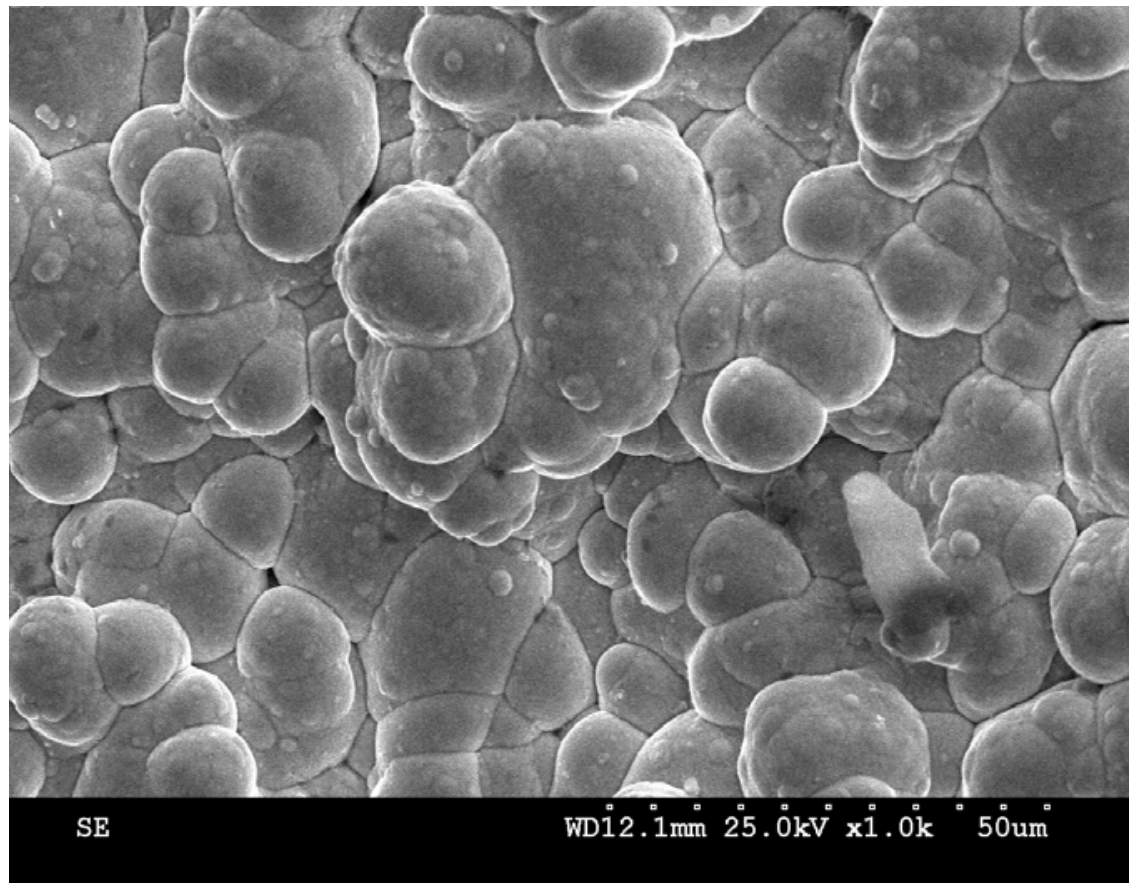

Figure 9. Scanning electron micrograph of deposited Pd on the porous SS substrate at 1000 times magnification

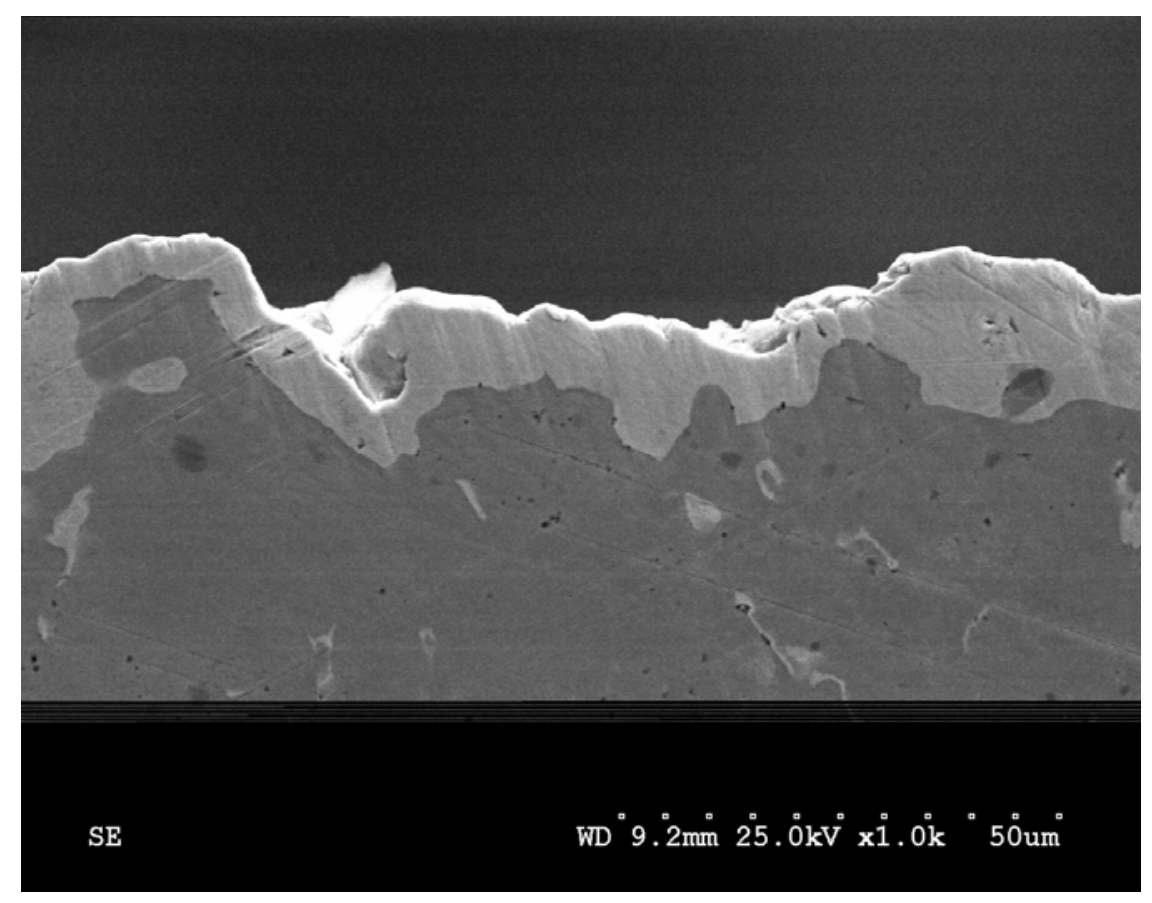

Figure 10. SEM of the cross-section of Pd-SS composite membrane showing a uniform deposition on the substrate 


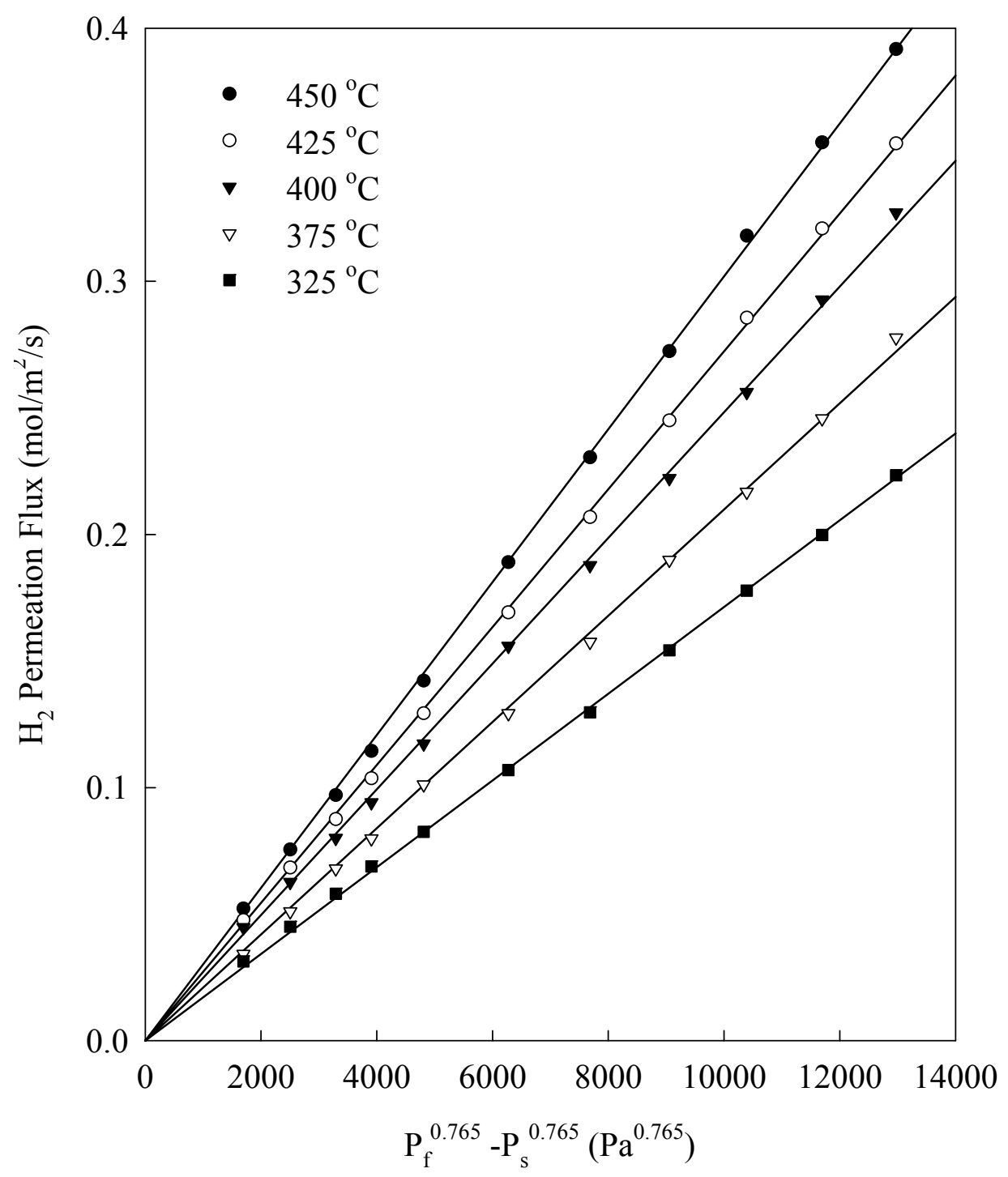

Figure 11. Hydrogen flux through Pd-SS composite membrane as a function of indexed pressure difference. Temperature was decreased from $450{ }^{\circ} \mathrm{C}$ to $325^{\circ} \mathrm{C}$. 


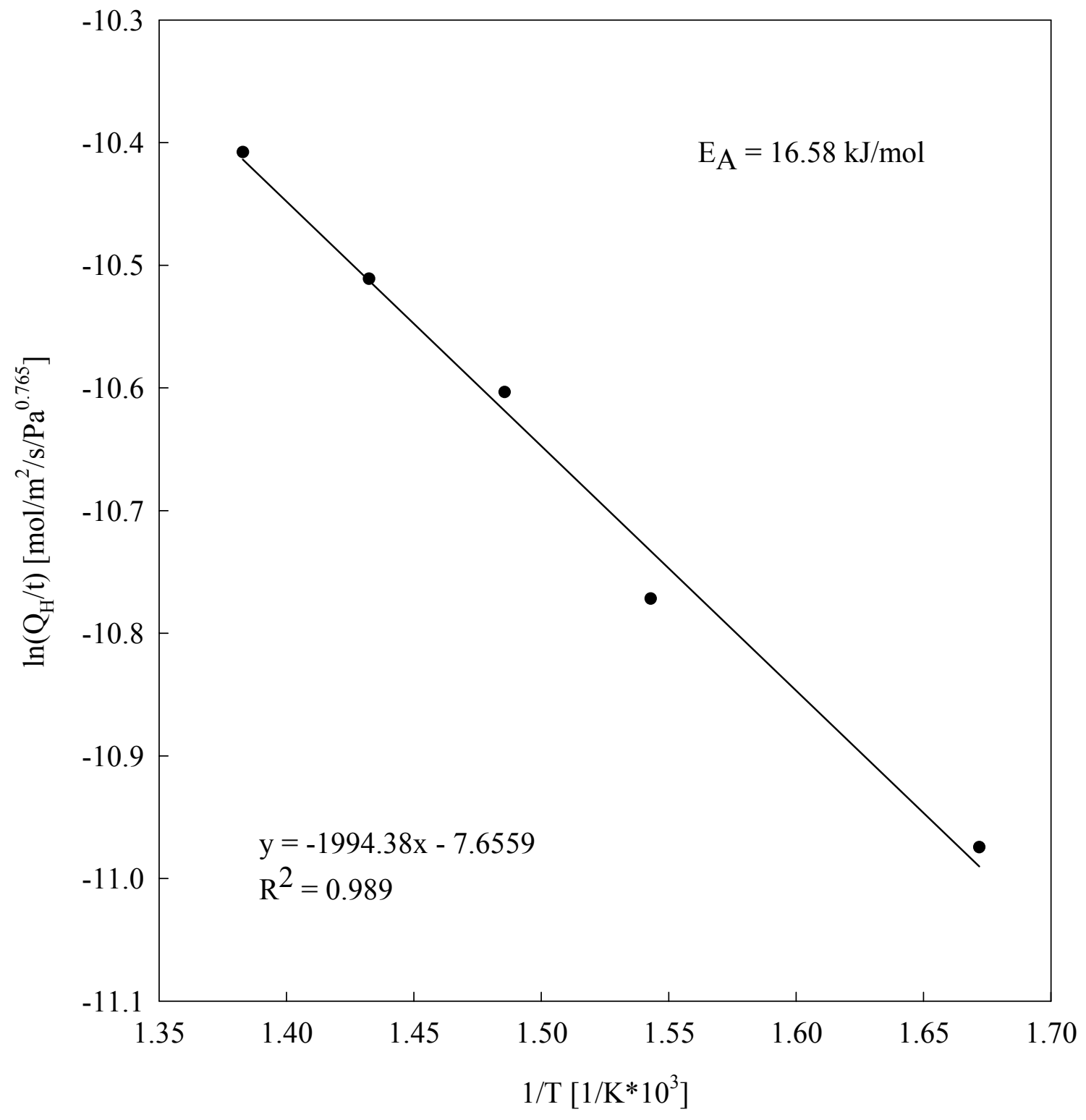

Figure 12. Arrhenius plot of the hydrogen permeance of the $20 \mu \mathrm{m}$ thick Pd-SS composite membrane as a function of inverse of absolute temperature. 


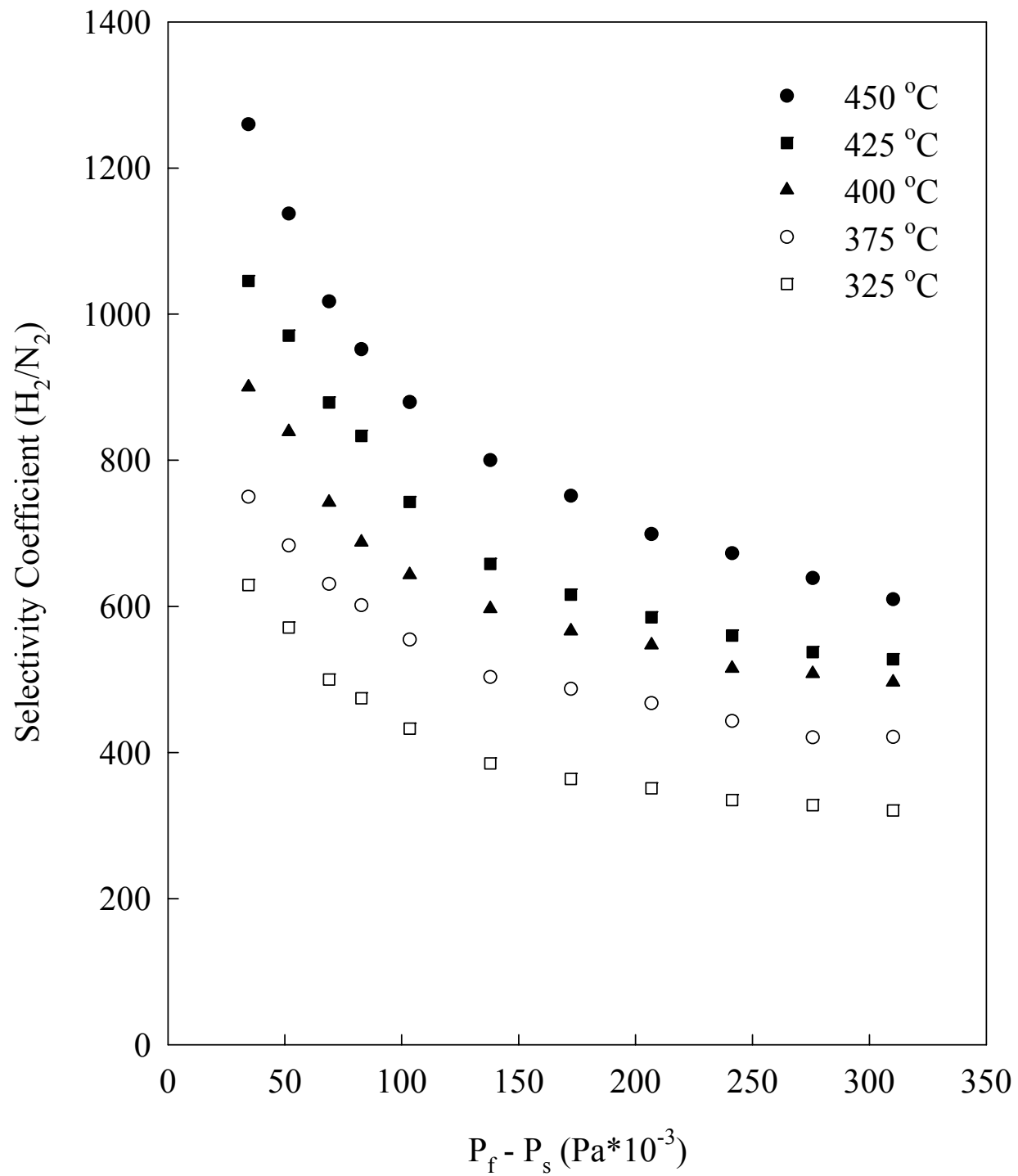

Figure 13. Plot of Hydrogen/Nitrogen $\left(\mathrm{H}_{2} / \mathrm{N}_{2}\right)$ selectivity coefficient as a function of transmembrane pressure difference at various temperatures $(20 \mu \mathrm{m}$ thick Pd-SS composite membrane). 


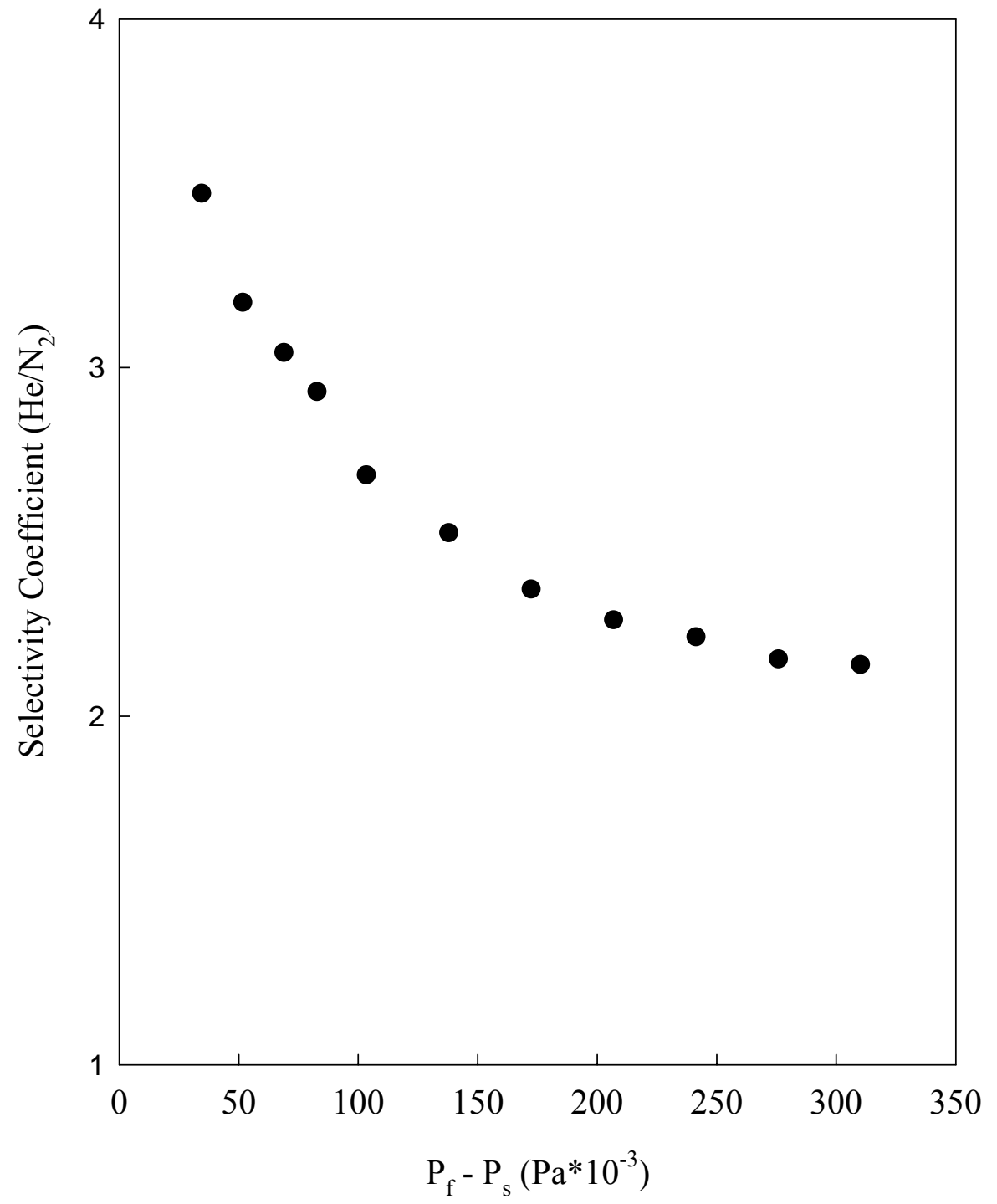

Figure 14. He/ $\mathrm{N}_{2}$ selectivity coefficient as a function of transmembrane pressure difference at $450{ }^{\circ} \mathrm{C}(20 \mu \mathrm{m}$ thick Pd-SS composite membrane). 


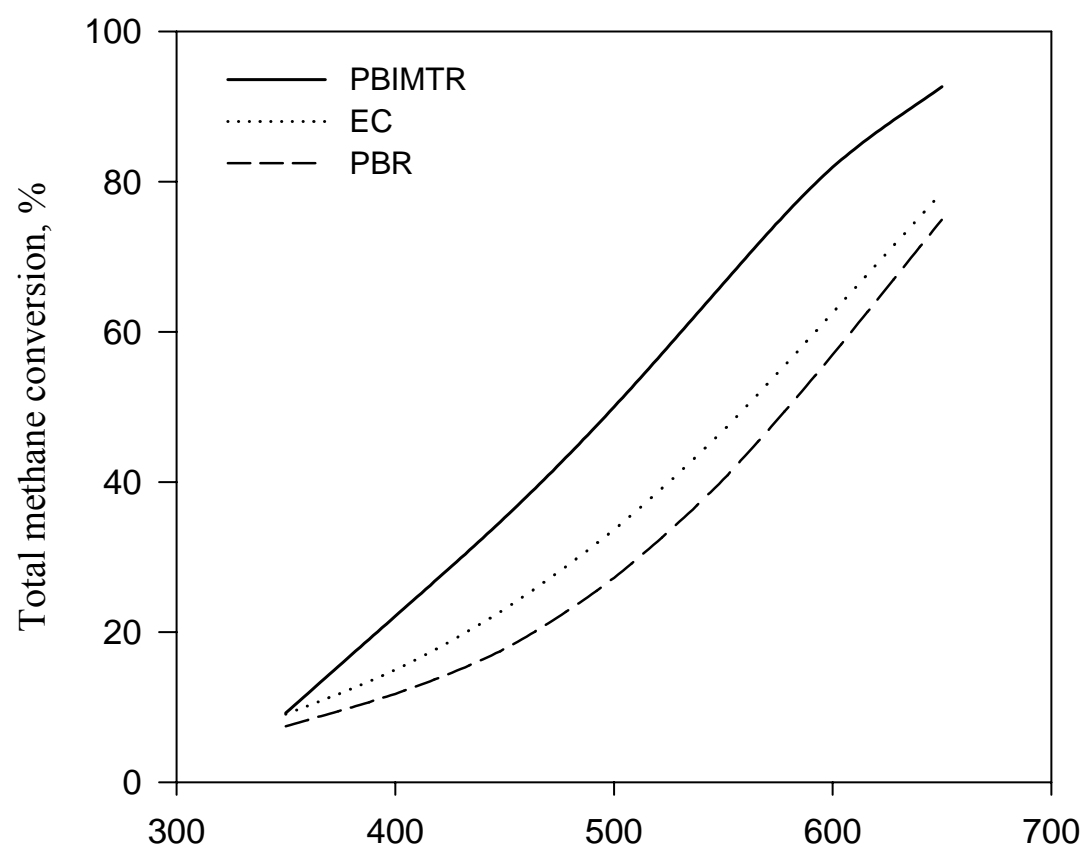

Temperature, ${ }^{\circ} \mathrm{C}$

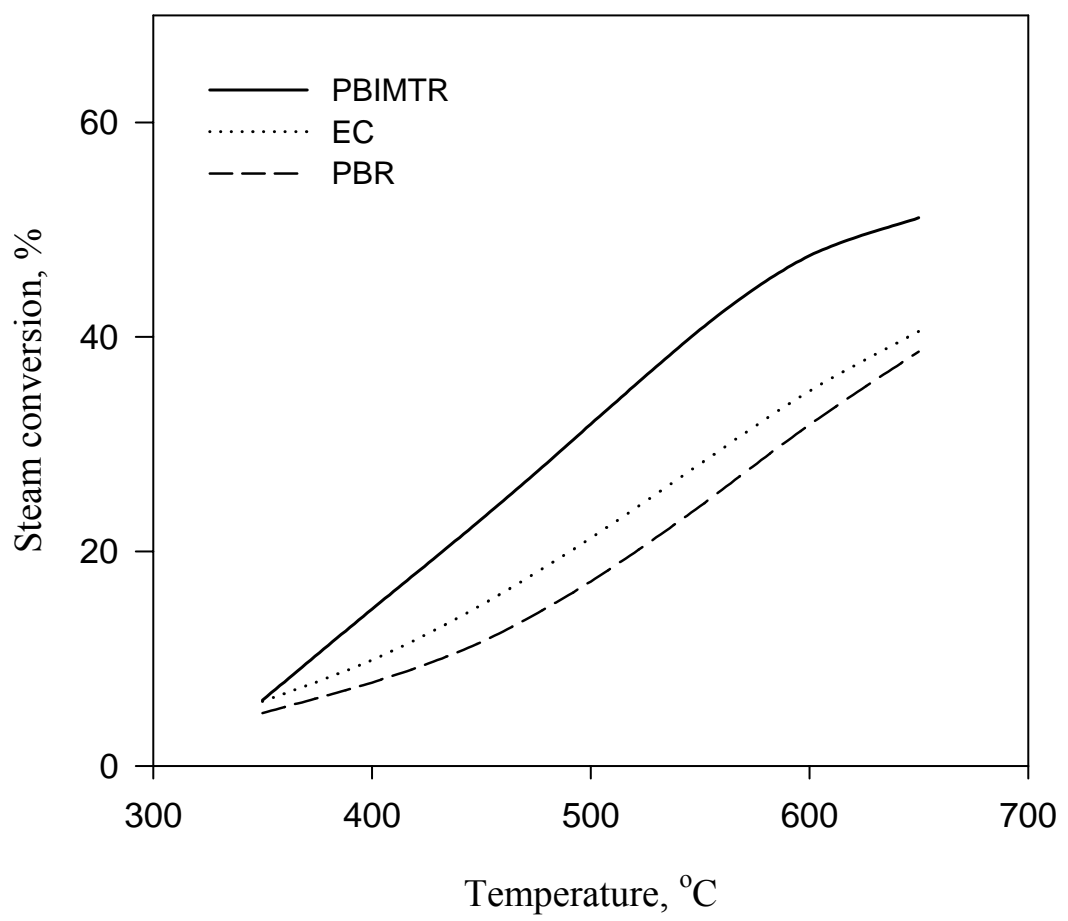

Figure 15. Comparison of conversions in a PBIMTR as a function of the operating temperature with that in a conventional PBR, as well as thermodynamic equilibrium conversion achievable in a closed system at $2 \mathrm{~atm}$ (Space velocity $=900 / 16 \mathrm{SCCM} / \mathrm{gm}_{\text {cat }}$, Steam to methane molar ratio $=$ 3.0 , and Sweep ratio $=1.25$ ). 


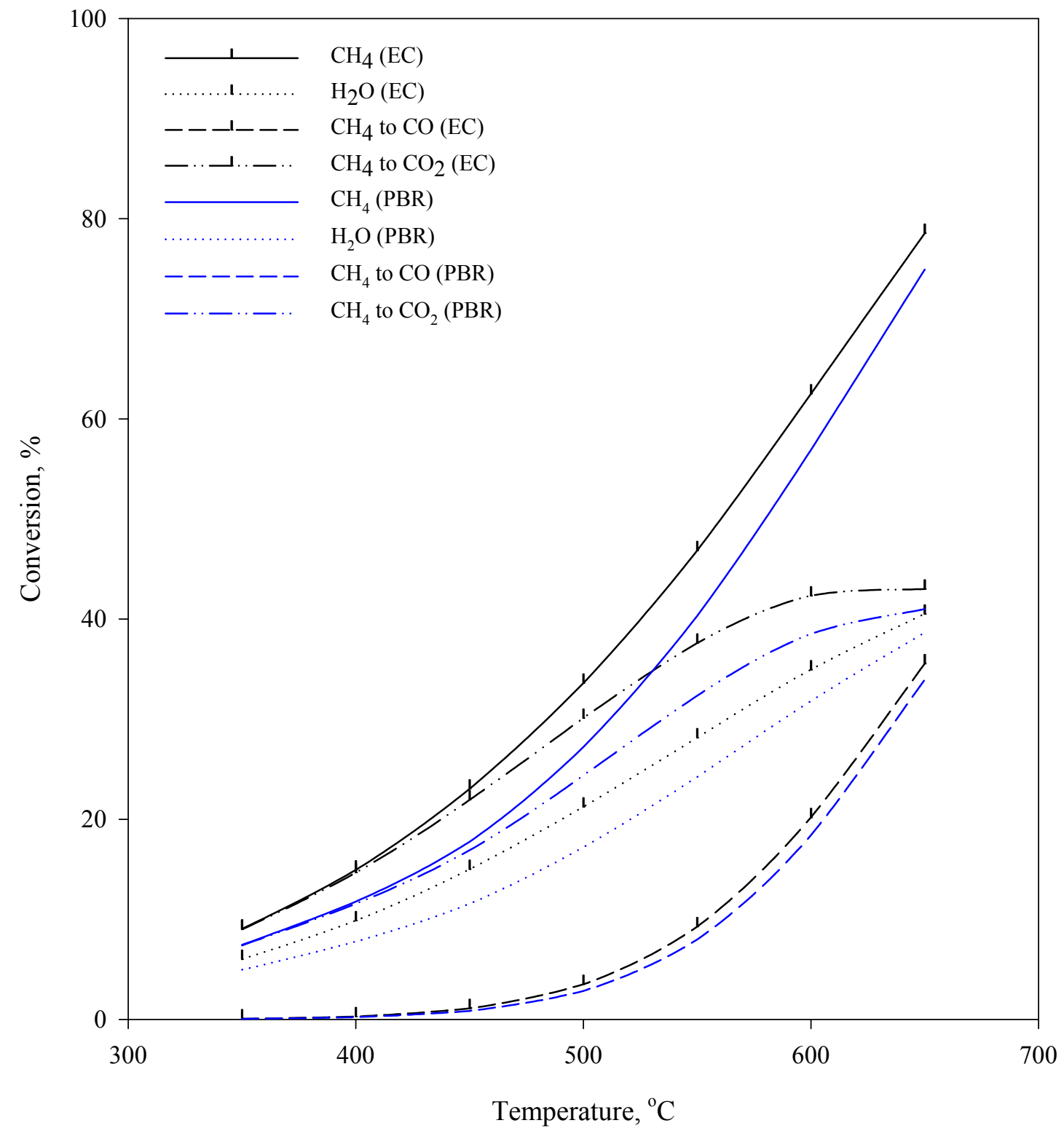

Figure 16. Comparison of the performance of the PBR with thermodynamic equilibrium conversion as a function of the operating temperature at 2 atm (Space velocity $=900 / 16$ $\mathrm{SCCM} / \mathrm{gm}_{\text {cat }}$, and Steam to methane molar ratio $=3.0$ ). 


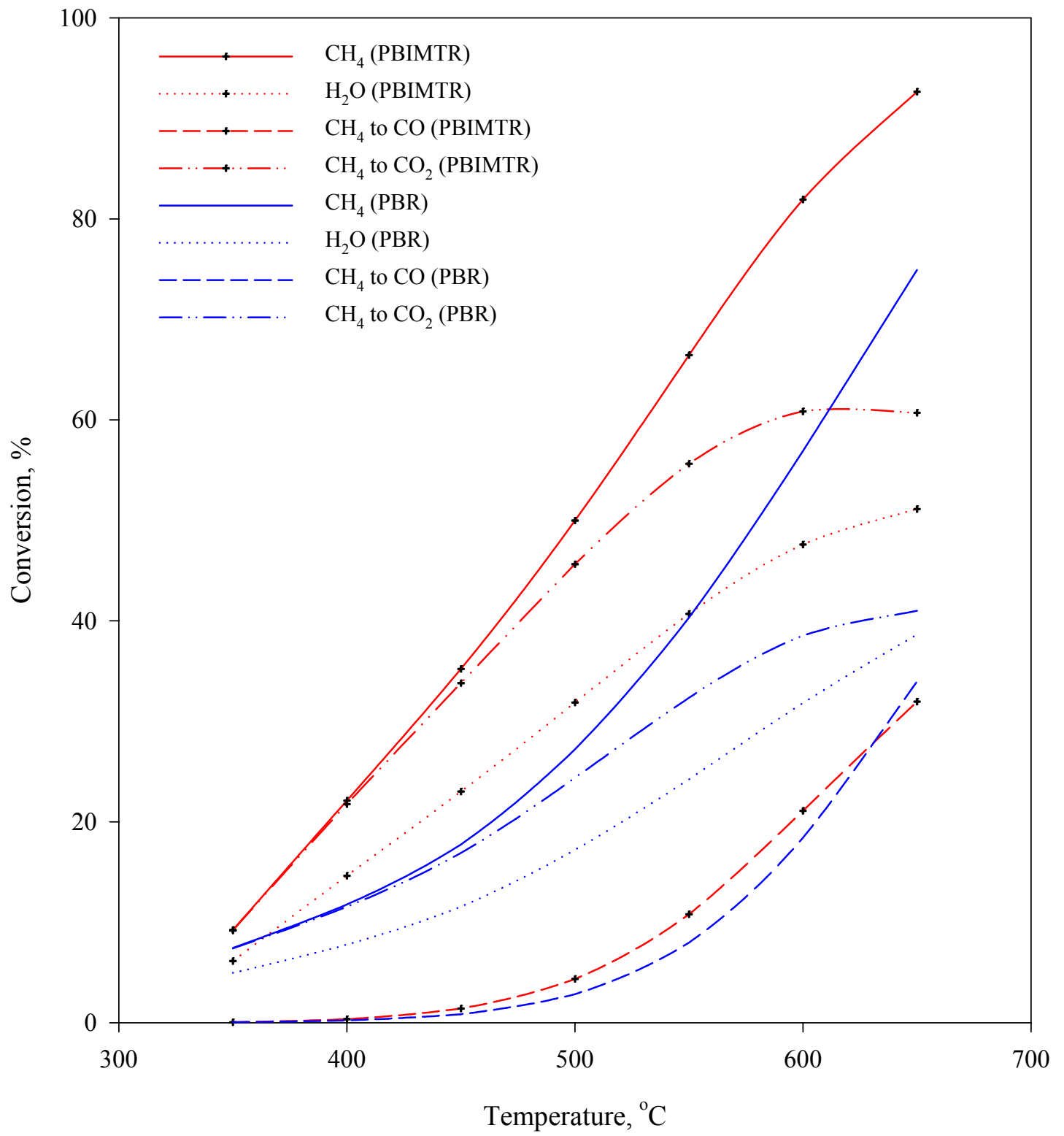

Figure 17. Comparison of the performance of PBIMTR with PBR as a function of operating temperature at $2 \mathrm{~atm}\left(\left(\right.\right.$ Space velocity $=900 / 16 \mathrm{SCCM} / \mathrm{gm}_{\text {cat }}$, Steam to methane molar ratio $=$ 3.0 , and Sweep ratio $=1.25)$. 


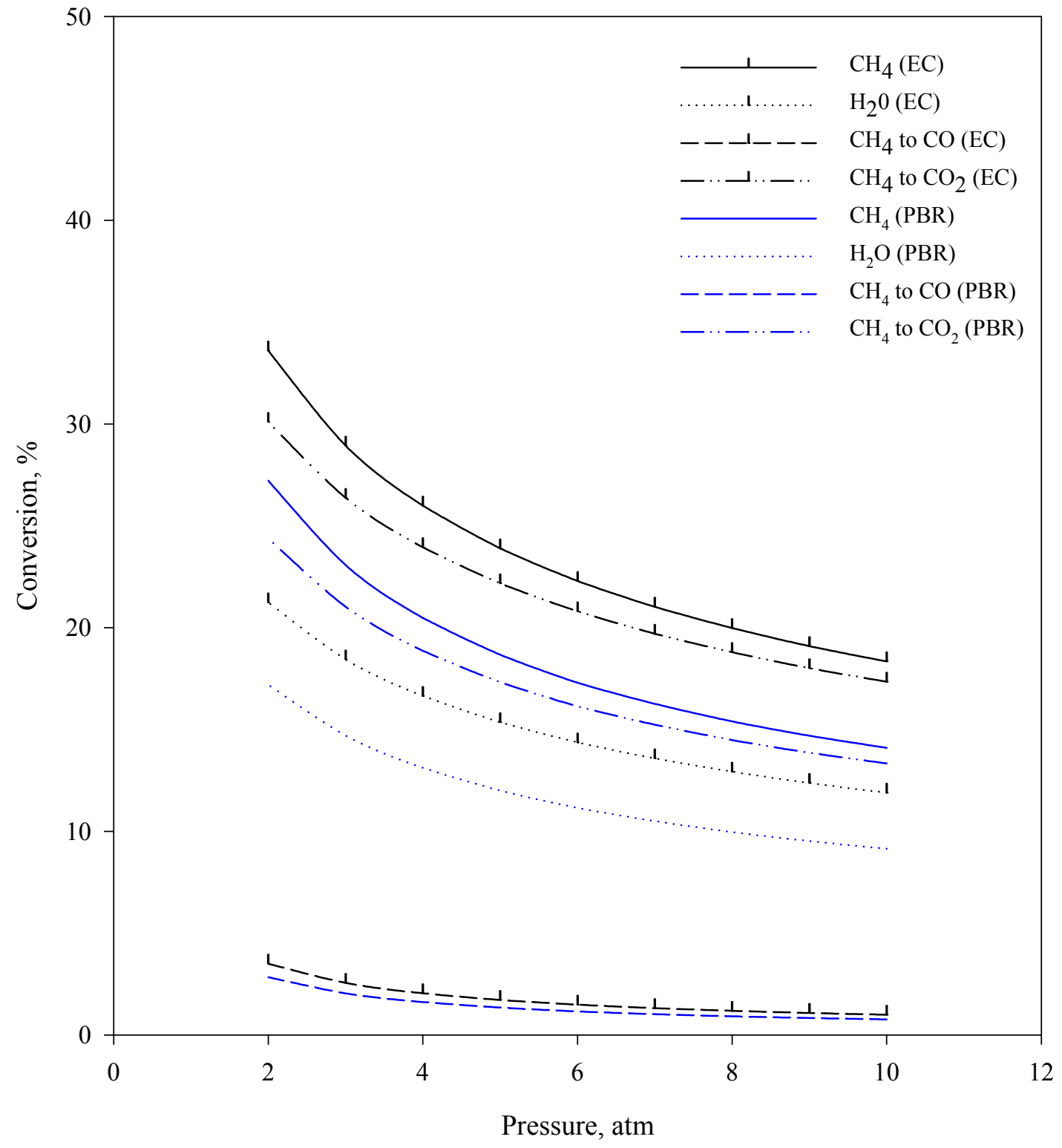

Figure 18. Effect of pressure on conversion in the PBR compared with the equilibrium conversion at $500{ }^{\circ} \mathrm{C}\left(\left(\right.\right.$ Space velocity $=900 / 16 \mathrm{SCCM} / \mathrm{gm}_{\text {cat }}$, Steam to methane molar ratio $=$ 3.0, and Sweep ratio $=1.25)$. 



Figure 19. Influence of pressure on methane and steam conversions at $500{ }^{\circ} \mathrm{C}$ (Space velocity $=$ $900 / 16 \mathrm{SCCM} / \mathrm{gm}_{\text {cat }}$ Steam to methane molar ratio $=3.0$, and Sweep ratio $\left.=0.28\right)$. 


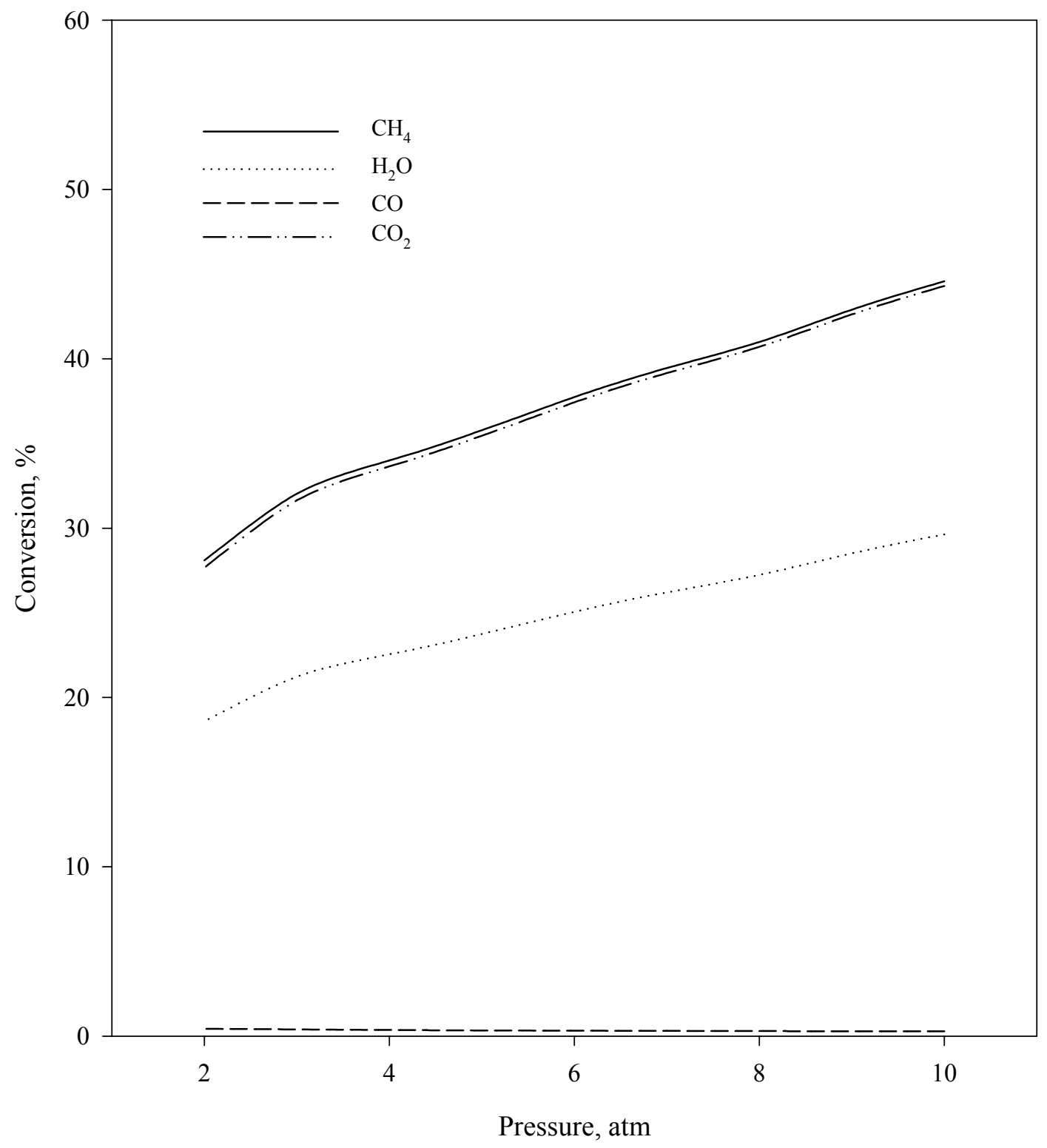

Figure 20. Effect of reactor pressure on conversion in the PBIMTR at $400{ }^{\circ} \mathrm{C}$ (Space velocity $=$ $900 / 16 \mathrm{SCCM} / \mathrm{gm}_{\text {cat }}$, Steam to methane molar ratio $=3.0$, and Sweep ratio $\left.=1.25\right)$. 


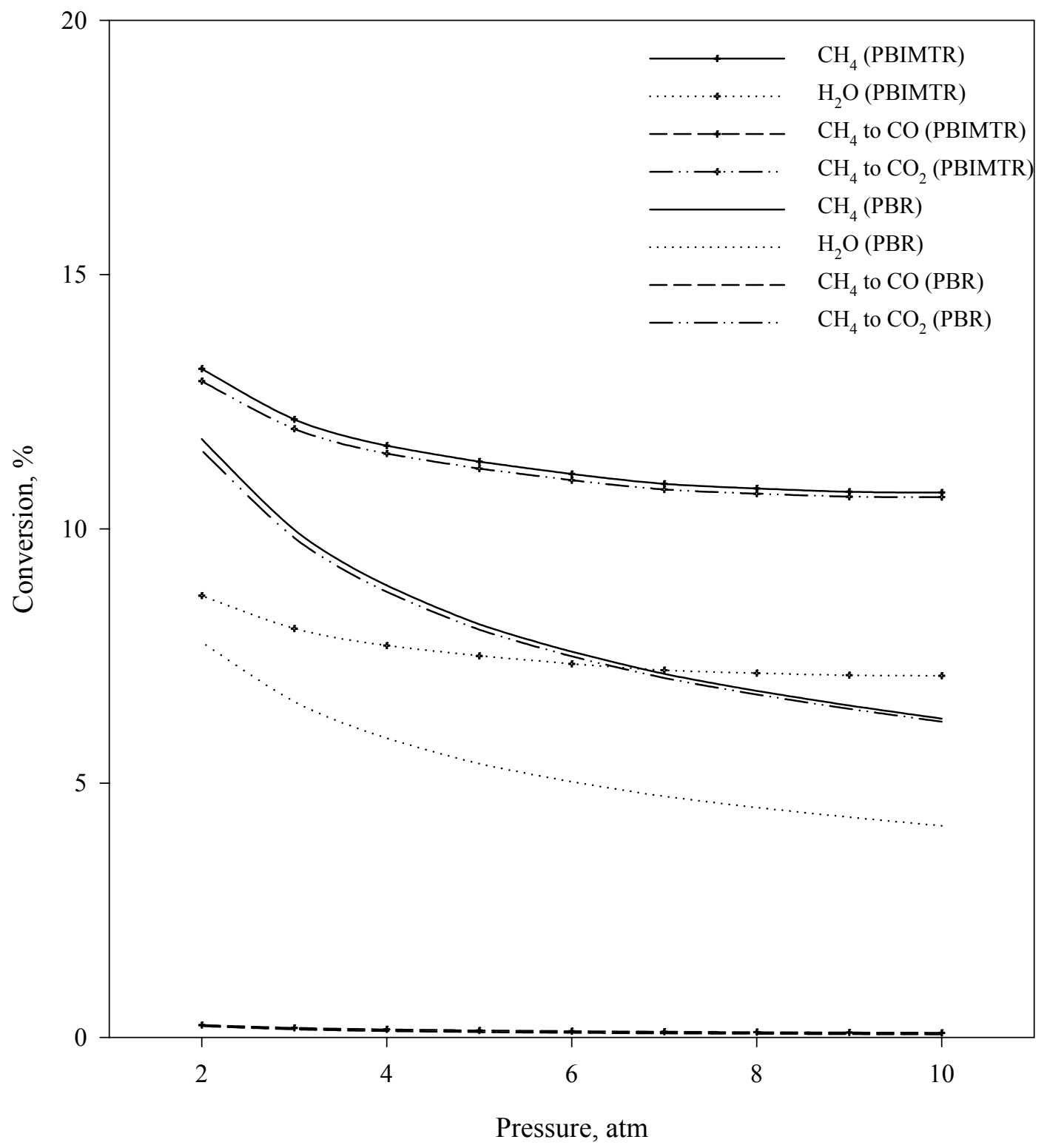

Figure 21. Comparison of conversion in the PBIMTR with conventional PBR (Space velocity = $900 / 16 \mathrm{SCCM} / \mathrm{gm}_{\text {cat }}$, Steam to methane molar ratio $=3.0$, and Sweep ratio $=0.08$ ). 


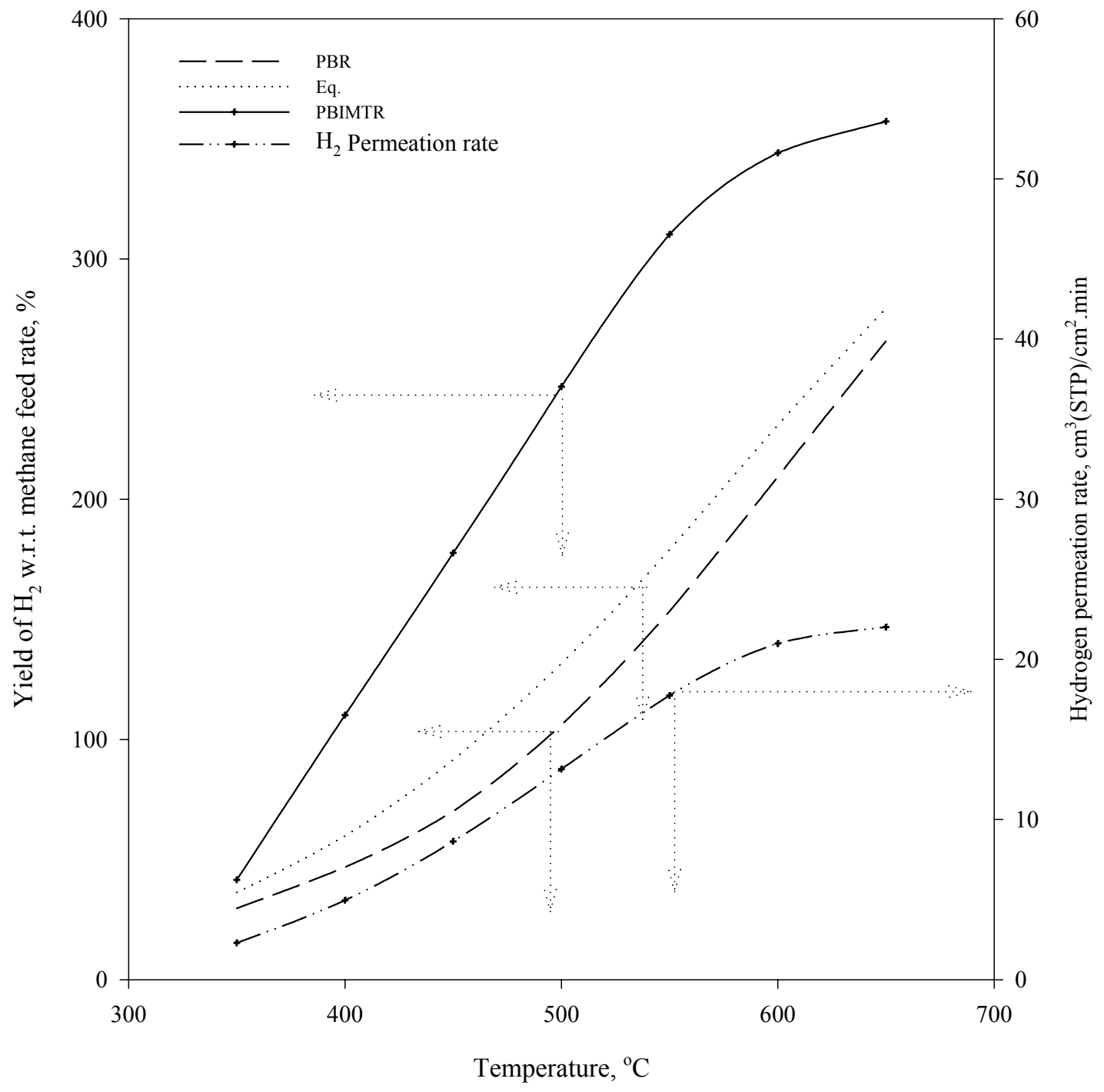

Figure 22. Influence on temperature on yield of hydrogen with respect to methane feed rate for 2 atm $\left(\right.$ Space velocity $=900 / 16 \mathrm{SCCM} / \mathrm{gm}_{\text {cat }}$, and Sweep ratio $\left.=1.25\right)$. 


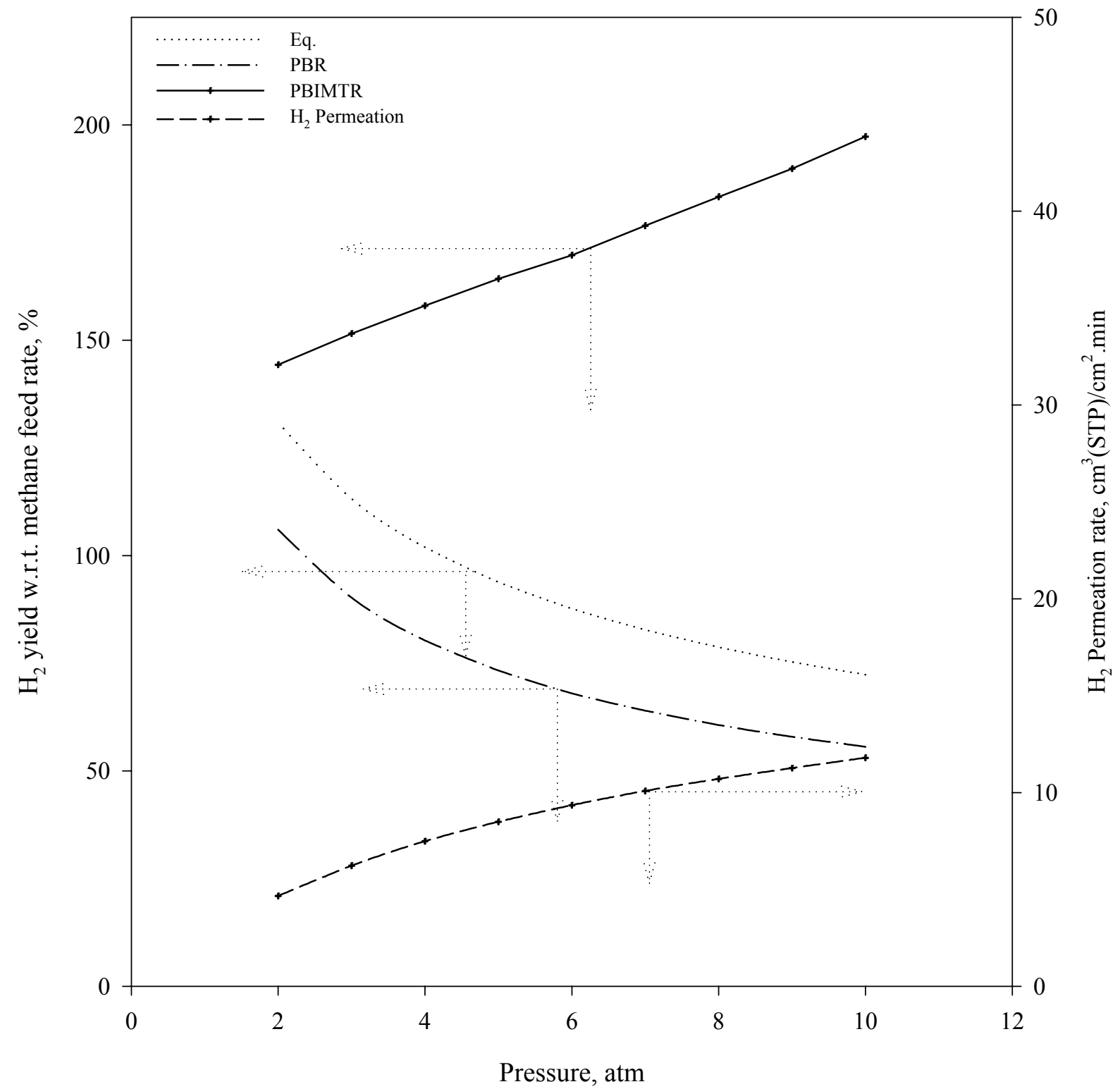

Figure 23. Effect of total pressure on the yield of hydrogen with respect to methane feed rate at $500{ }^{\circ} \mathrm{C}\left(\right.$ Space velocity $=900 / 16 \mathrm{SCCM} / \mathrm{gm}_{\text {cat }}$, Steam to methane molar ratio $=3.0$, and Sweep ratio $=0.28)$. 


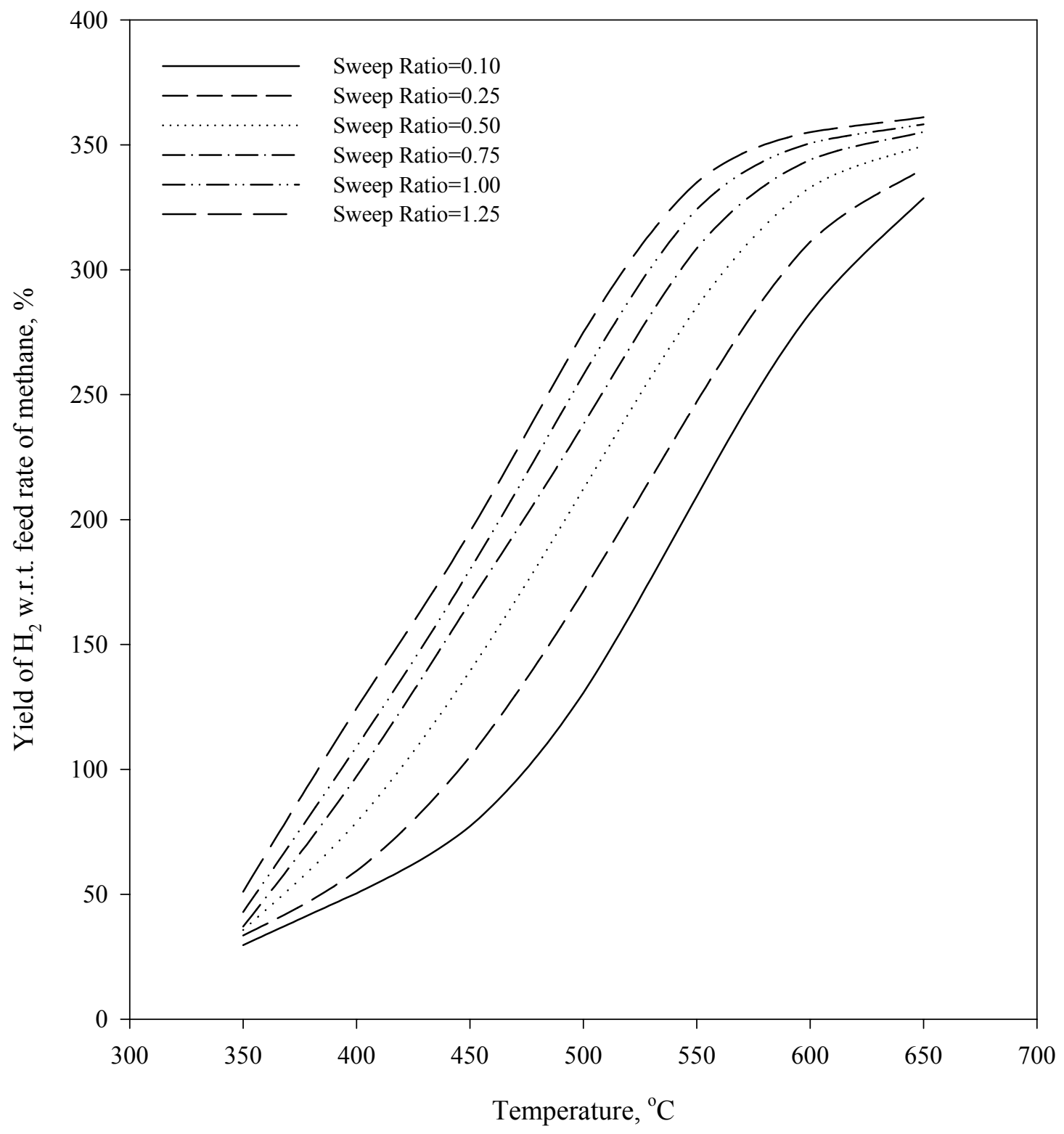

Figure 24. Effect of temperature on the yield of hydrogen with respect to feed ratio of methane in the PBIMTR for different sweep ratio at $3 \mathrm{~atm}$ (Space velocity $=900 / 16 \mathrm{SCCM} / \mathrm{gm}_{\text {cat }}$, and Steam to methane molar ratio $=3.0$ ). 


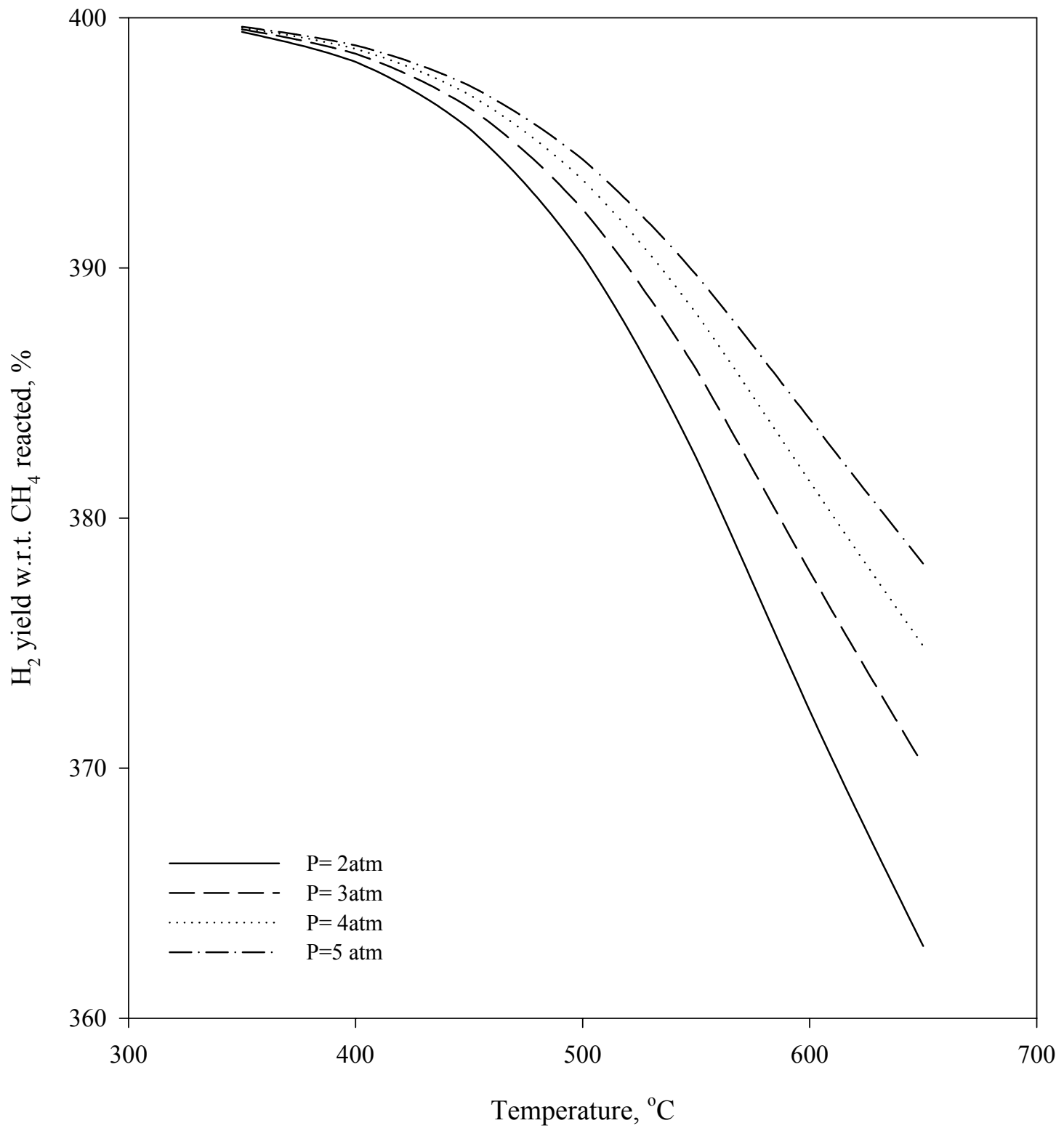

Figure 25. Predicted yield of hydrogen with respect to methane reacted in the PBIMTR as a function of reaction temperature with total reactor pressure as a parameter (Space velocity $=$ $900 / 16 \mathrm{SCCM} / \mathrm{gm}_{\text {cat }}$, Sweep ratio $=0.25$, and Steam to methane molar ratio $=3.0$ ). 


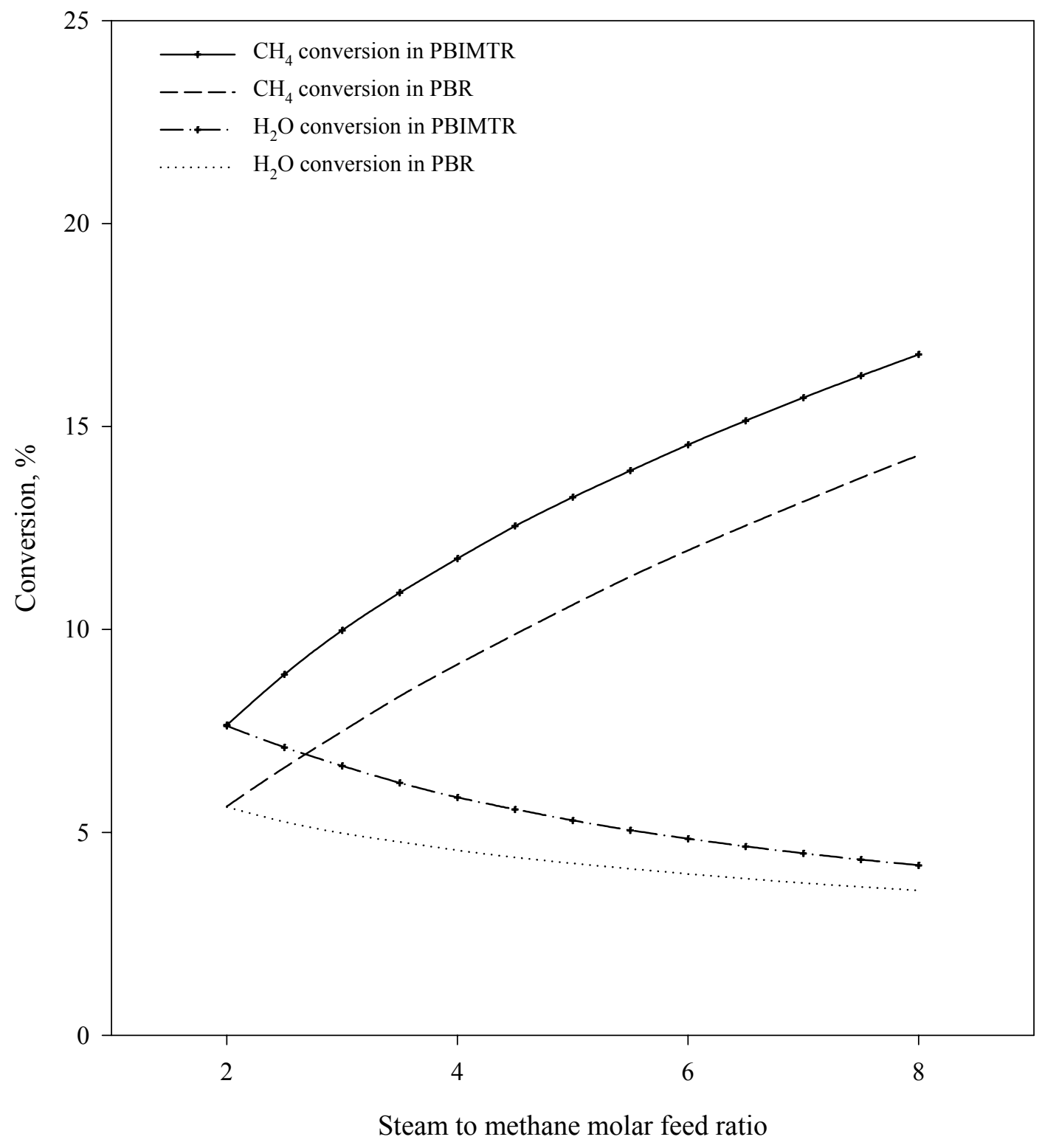

Figure 26. Effect of steam to methane molar feed ratio on the methane and steam conversion at $350{ }^{\circ} \mathrm{C}$ and $2 \mathrm{~atm}$ (Space velocity $=900 / 16 \mathrm{SCCM} / \mathrm{gm}_{\text {cat }}$, and Sweep ratio $=0.75$ ). 


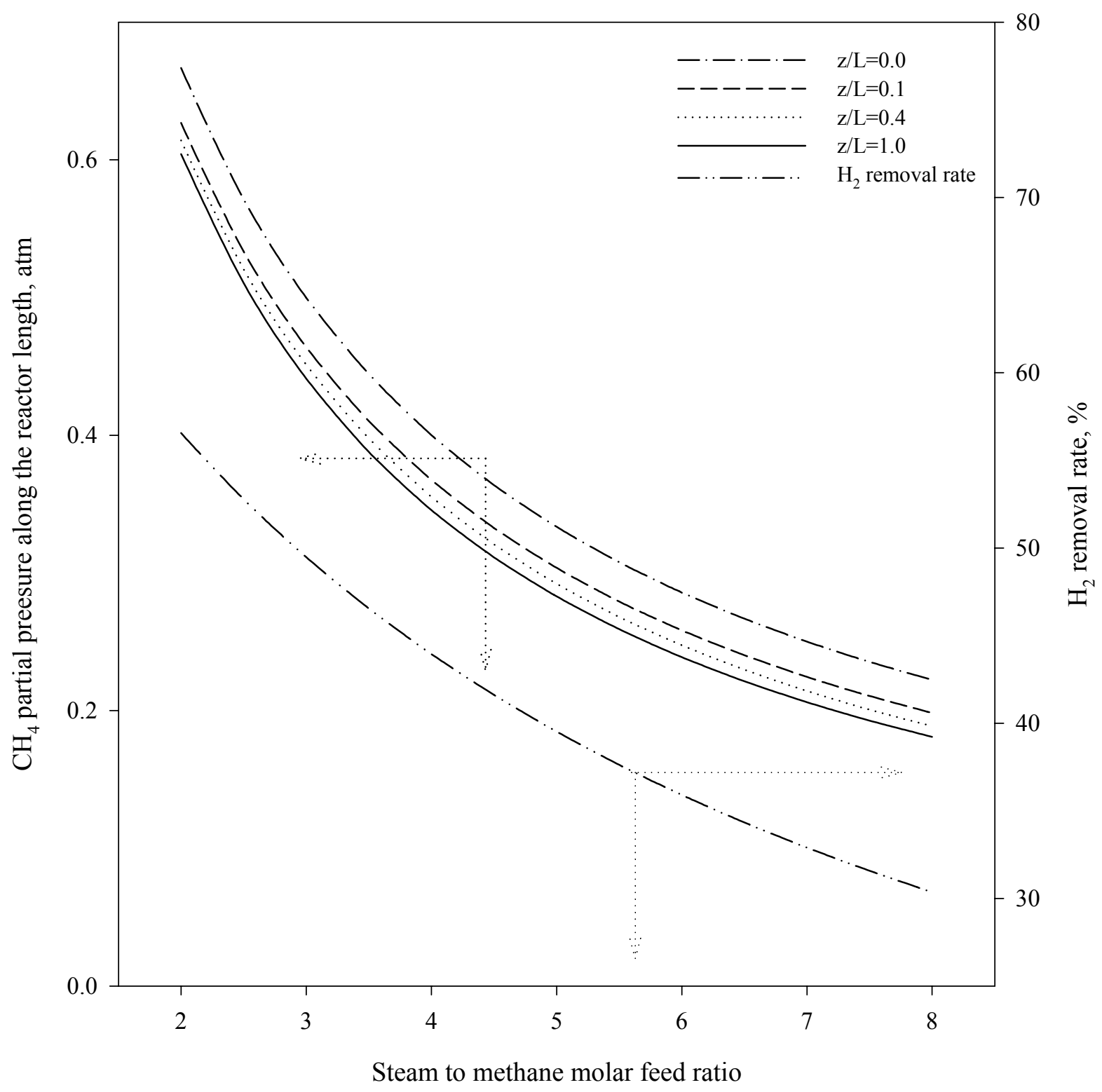

Figure 27. Effect of steam to methane molar feed ration on methane partial pressure at various locations along the length of the reactor and hydrogen removal rate in the PBIMTR (Space velocity $=900 / 16 \mathrm{SCCM} / \mathrm{gm}_{\text {cat }}$, and Sweep ratio $=0.75$ ). 


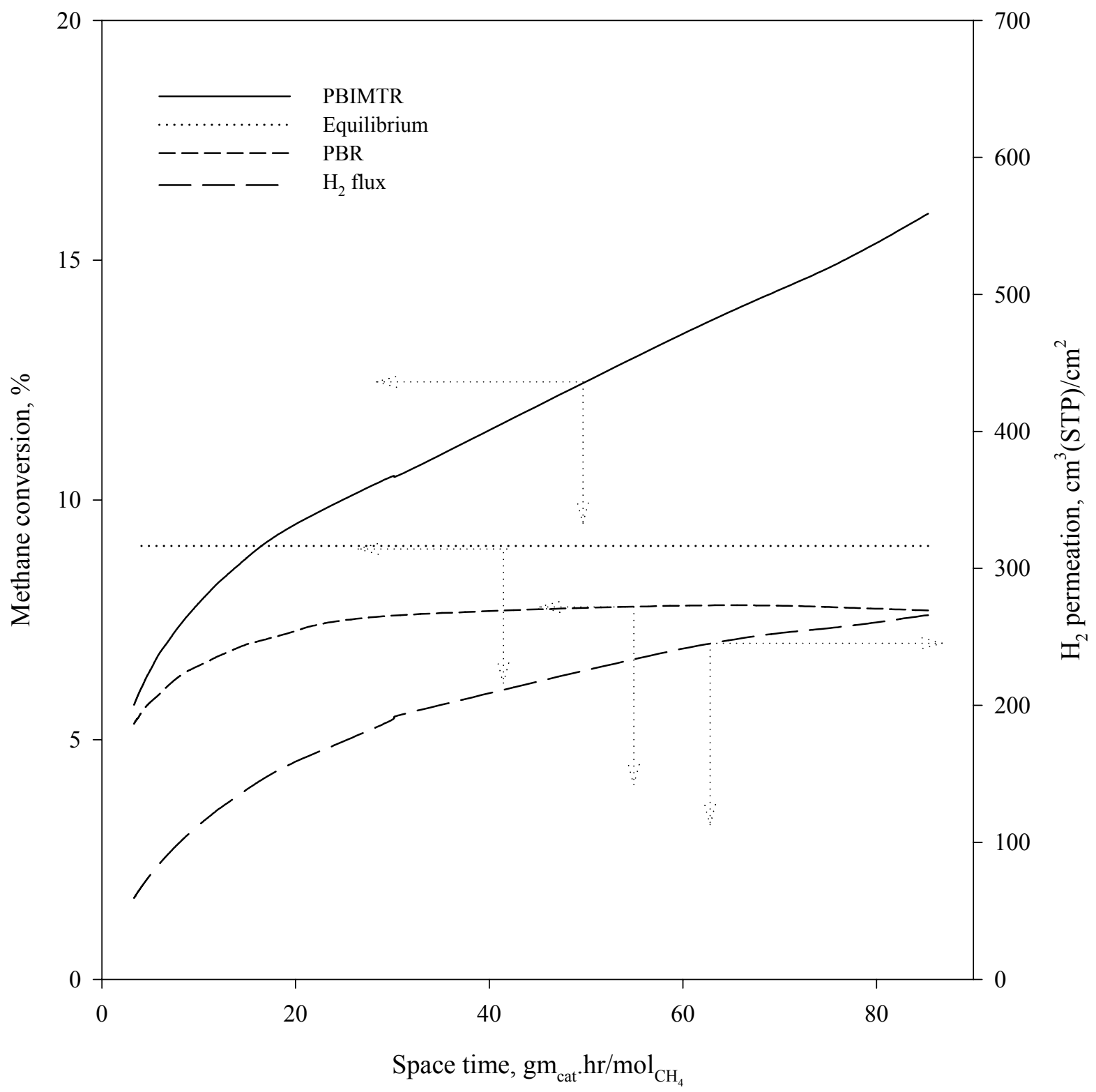

Figure 28. Influence of space time on the overall methane conversion at $300{ }^{\circ} \mathrm{C}$ and 2 atm $\left(\right.$ Steam to methane molar ratio $=3.0, \mathrm{Ni} / \mathrm{Al}_{2} \mathrm{O}_{3}$ catalyst loading $=16 \mathrm{gm}$, and Sweep ratio $=1.0$ ). 


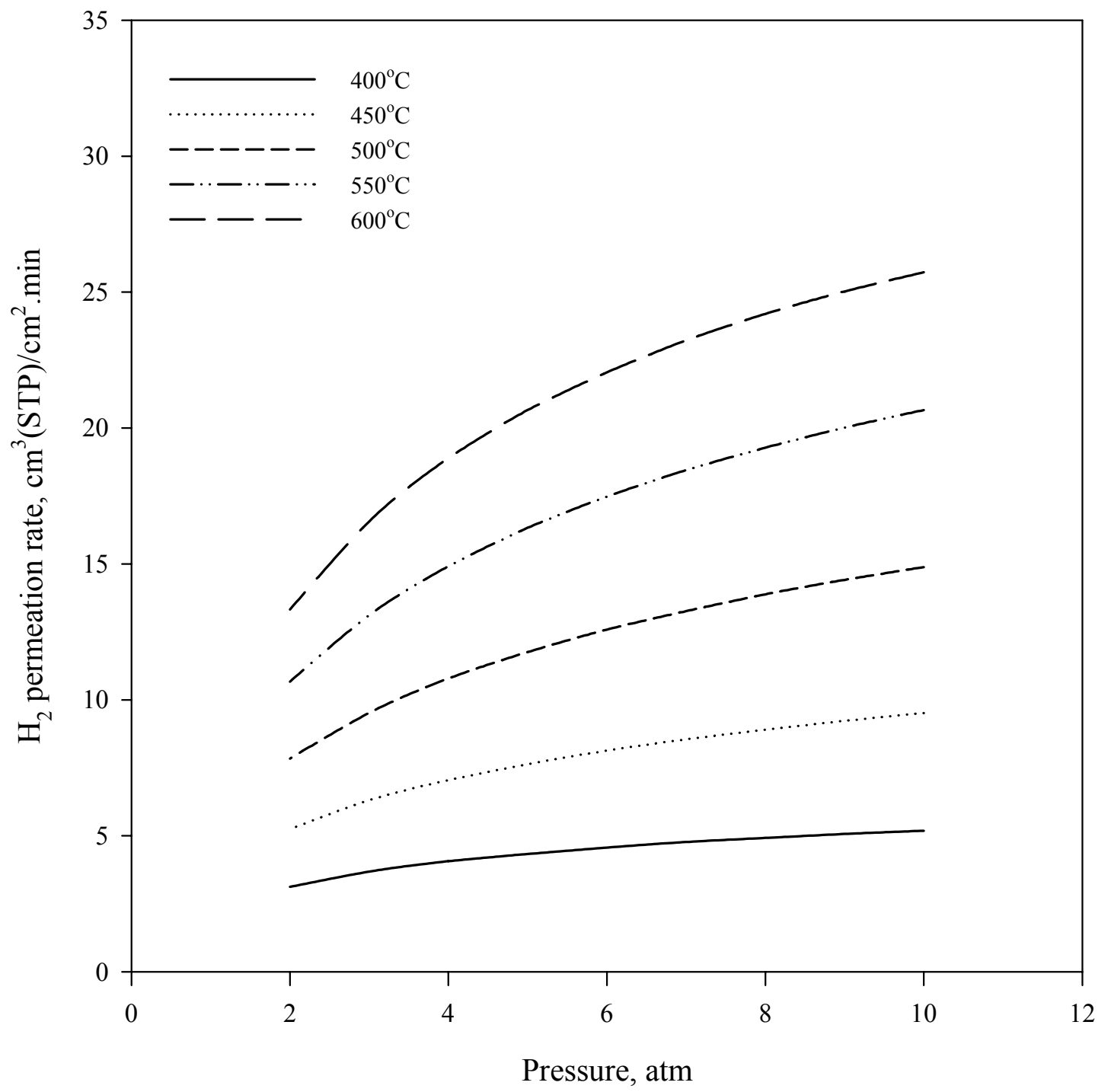

Figure 29. Effect of reaction pressure on hydrogen permeation rate in the PBIMTR with reaction temperature as a parameter (Space velocity $=900 / 16 \mathrm{SCCM} / \mathrm{gm}_{\text {cat }}$, Steam to methane molar feed ratio $=3.0$, and Sweep ratio $=0.75)$. 


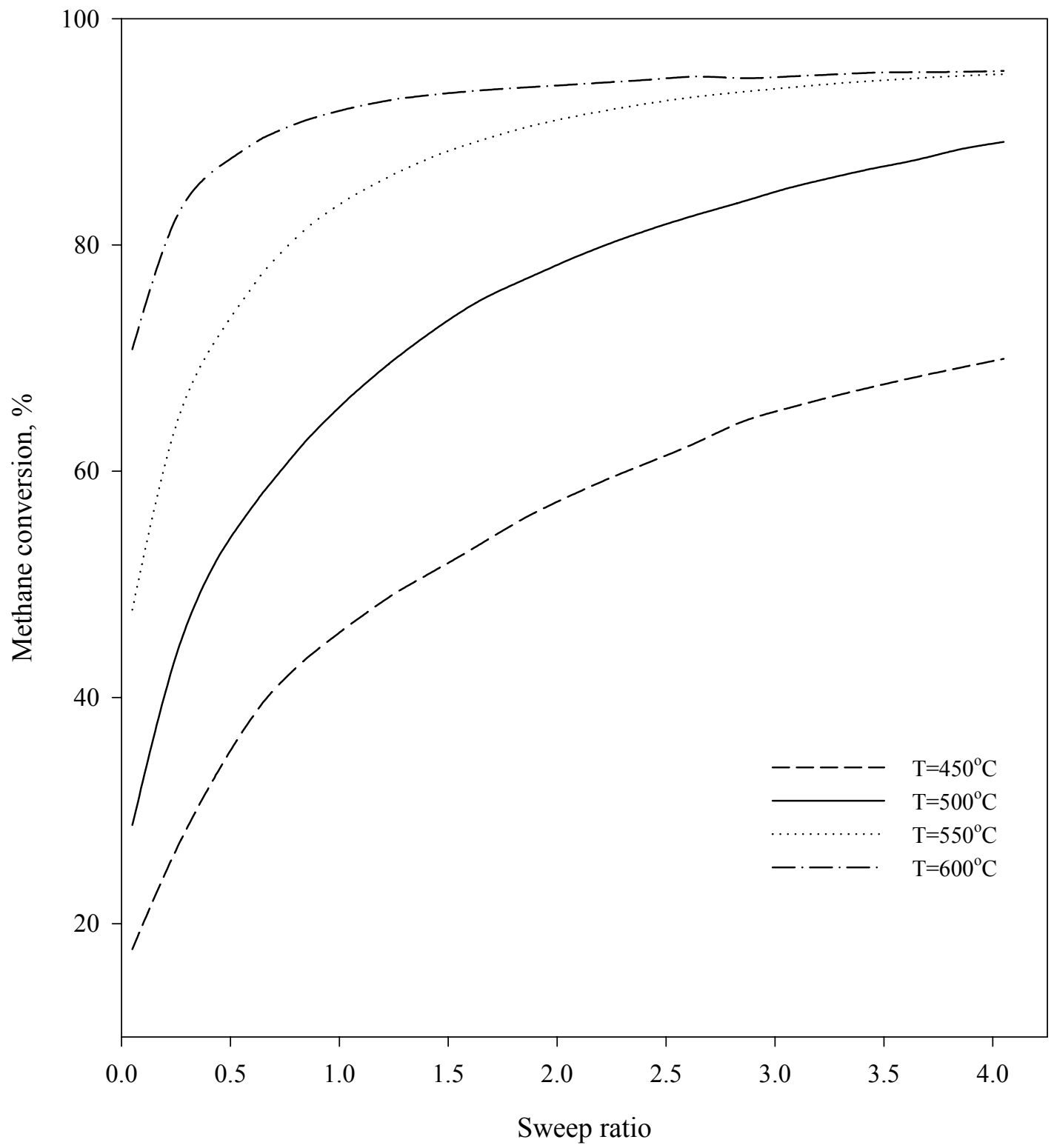

Figure 30. Effect of sweep ratio on the overall methane conversion in PBIMTR with reaction temperature as a parameter at $3 \mathrm{~atm}$ (Space velocity $=900 / 16 \mathrm{SCCM} / \mathrm{gm}_{\text {cat }}$, and Steam to methane molar feed ratio $=3.0$ ). 


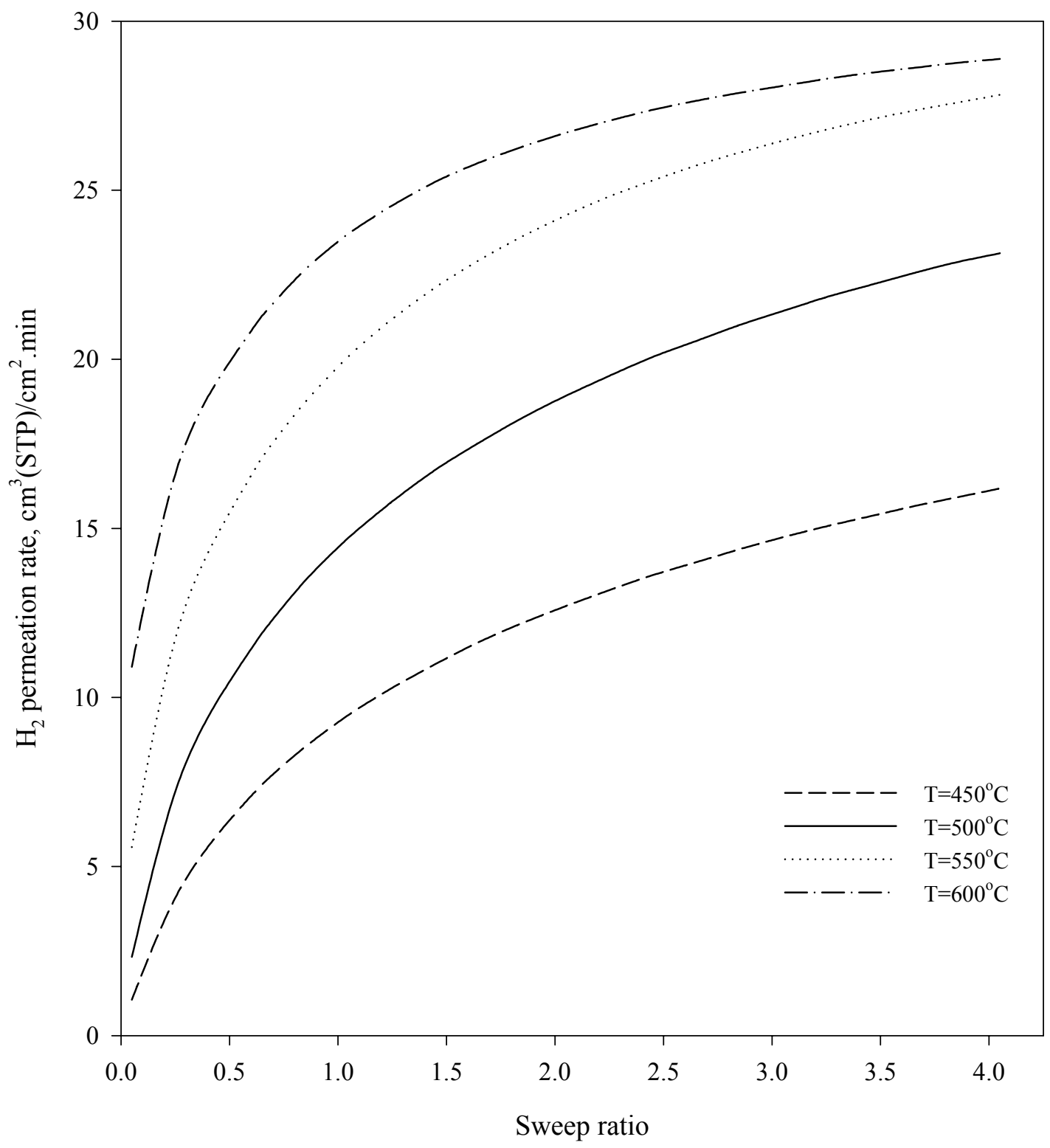

Figure 31. Effect of sweep ratio on hydrogen permeation rate in the PBIMTR with reaction temperature as a parameter (Space velocity $=900 / 16 \mathrm{SCCM} / \mathrm{gm}_{\text {cat }}$, and Steam to methane molar feed ratio $=3.0$ ). 


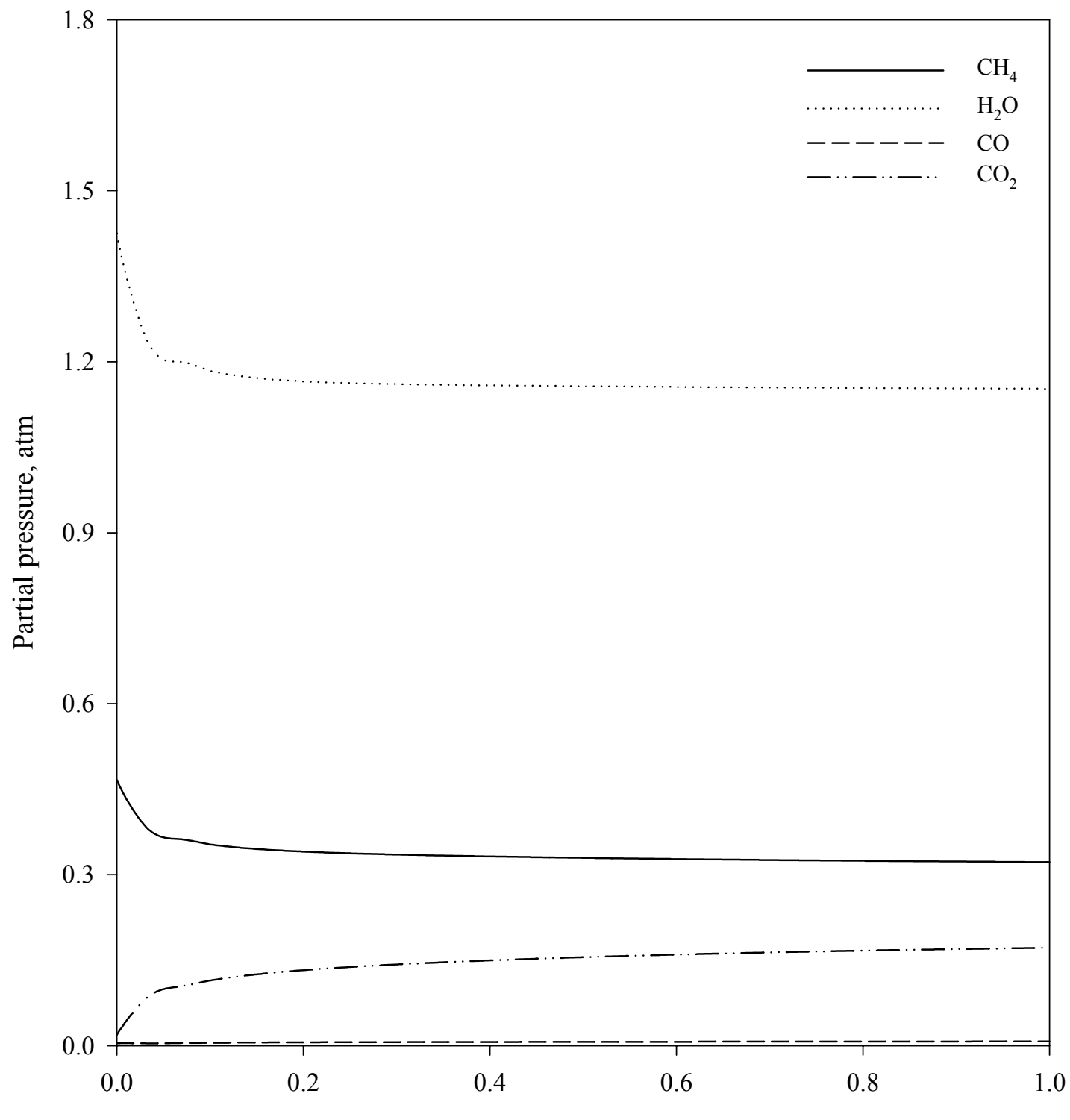

Dimensionless reactor length, $\mathrm{z} / \mathrm{L}$

Figure 32. Partial pressure profiles along the length of the PBIMTR at $450{ }^{\circ} \mathrm{C}$ and 2 atm (Space velocity $=900 / 16 \mathrm{SCCM} / \mathrm{gm}_{\text {cat }}$, Steam to methane molar feed ratio $=3.0$, and Sweep ratio $=$ $0.75)$. 


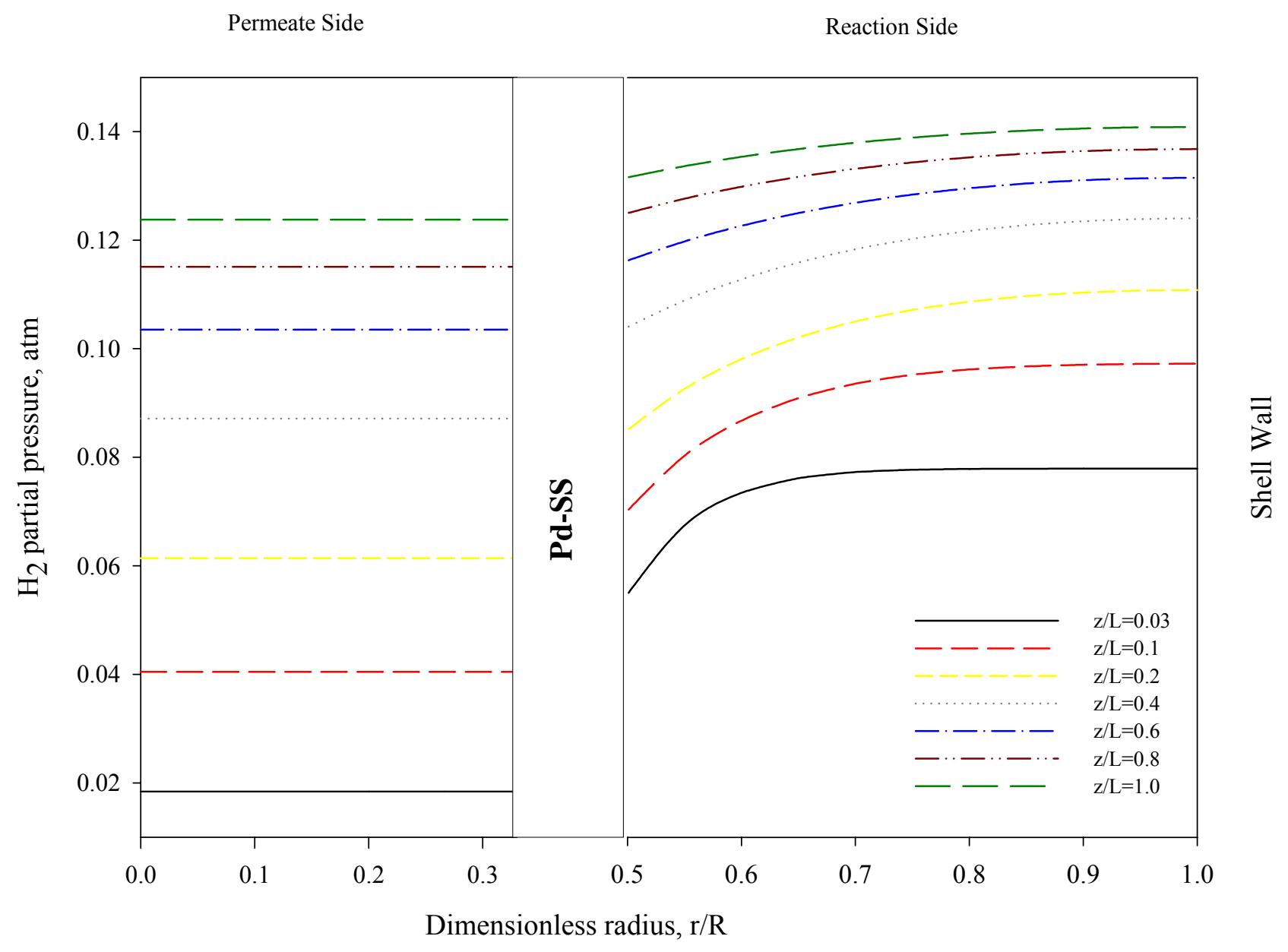

Figure 33. Hydrogen partial pressure radial profiles on both permeate and reaction sides at different axial positions in the reactor at $350{ }^{\circ} \mathrm{C}$ and $2 \mathrm{~atm}$ (Space velocity $=900 / 16$ $\mathrm{SCCM} / \mathrm{gm}_{\text {cat }}$, Steam to methane molar feed ratio $=3.0$, and Sweep ratio $=0.3$ ). 


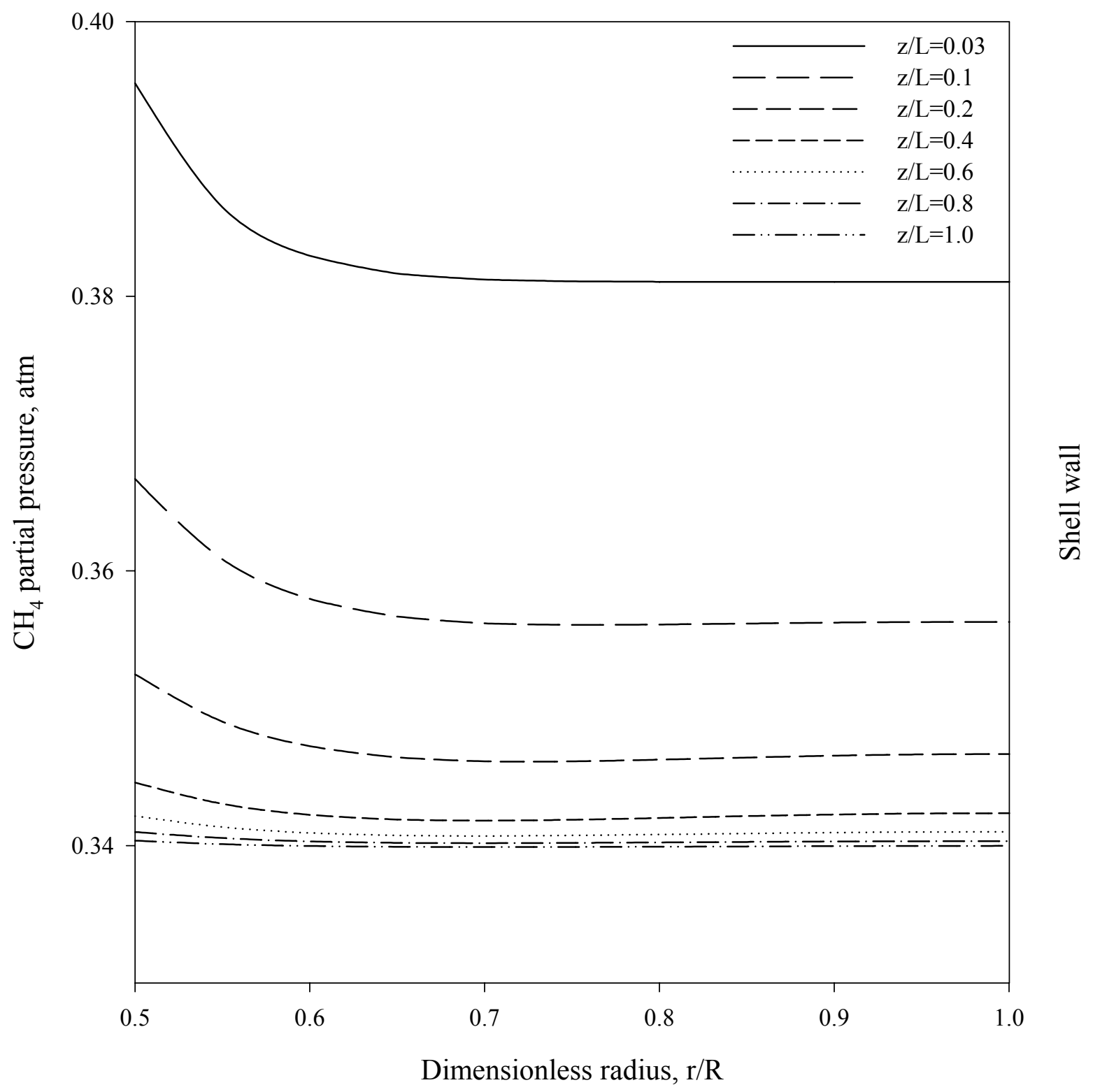

Figure 34. Methane partial pressure radial profiles on the reaction side at different axial positions at $450{ }^{\circ} \mathrm{C}$ and $2 \mathrm{~atm}$ (Space velocity $=900 / 16 \mathrm{SCCM} / \mathrm{gm}_{\text {cat }}$, Steam to methane molar feed ratio $=3.0$, and Sweep ratio $=0.15$ ). 


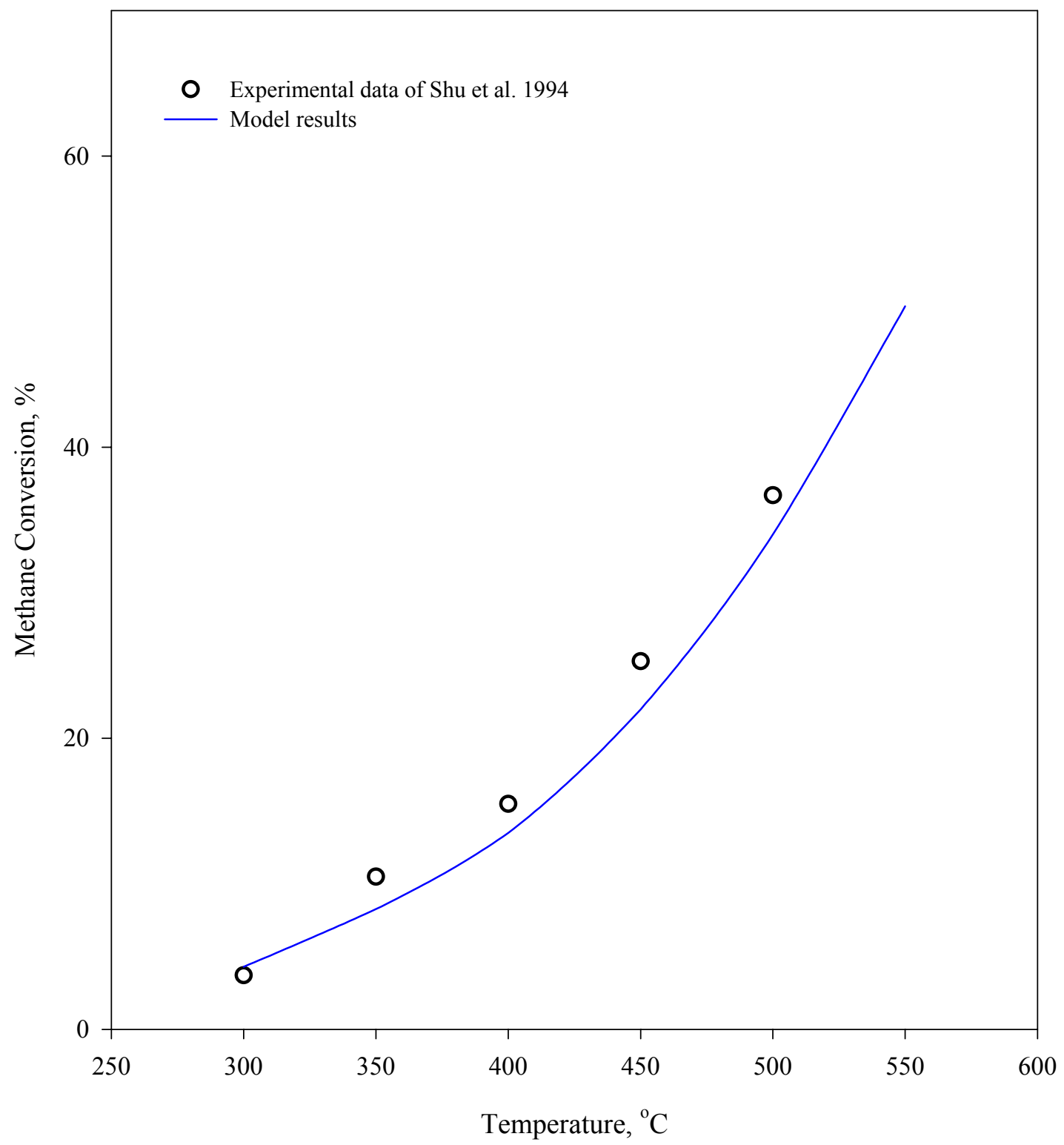

Figure 35. Total conversion of methane in the conventional PBR as a function of temperature at $136 \mathrm{kPa}\left(\right.$ Space velocity $=162 / 11 \mathrm{SCCM} / \mathrm{gm}_{\text {cat }}$, and Steam to methane molar feed ratio = 3.0). 


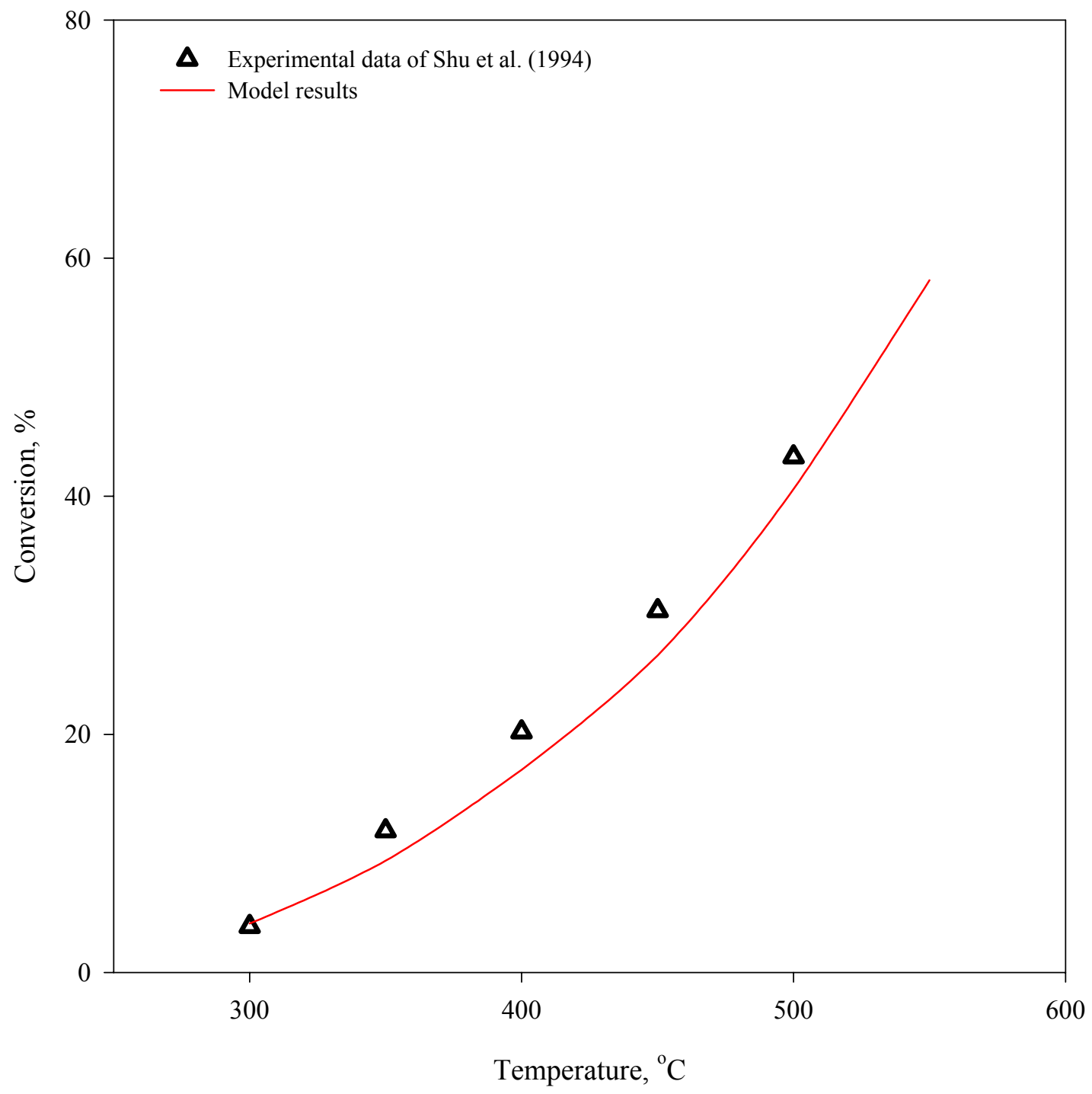

Figure 36. Total conversion of methane in the membrane reactor as a function of temperature at $136 \mathrm{kPa}$ (Space velocity $=162 / 11 \mathrm{SCCM} / \mathrm{gm}_{\text {cat }}$, Sweep flow rate $=40 \mathrm{SCCM}$, and Steam to methane molar feed ratio $=3.0$ ). 


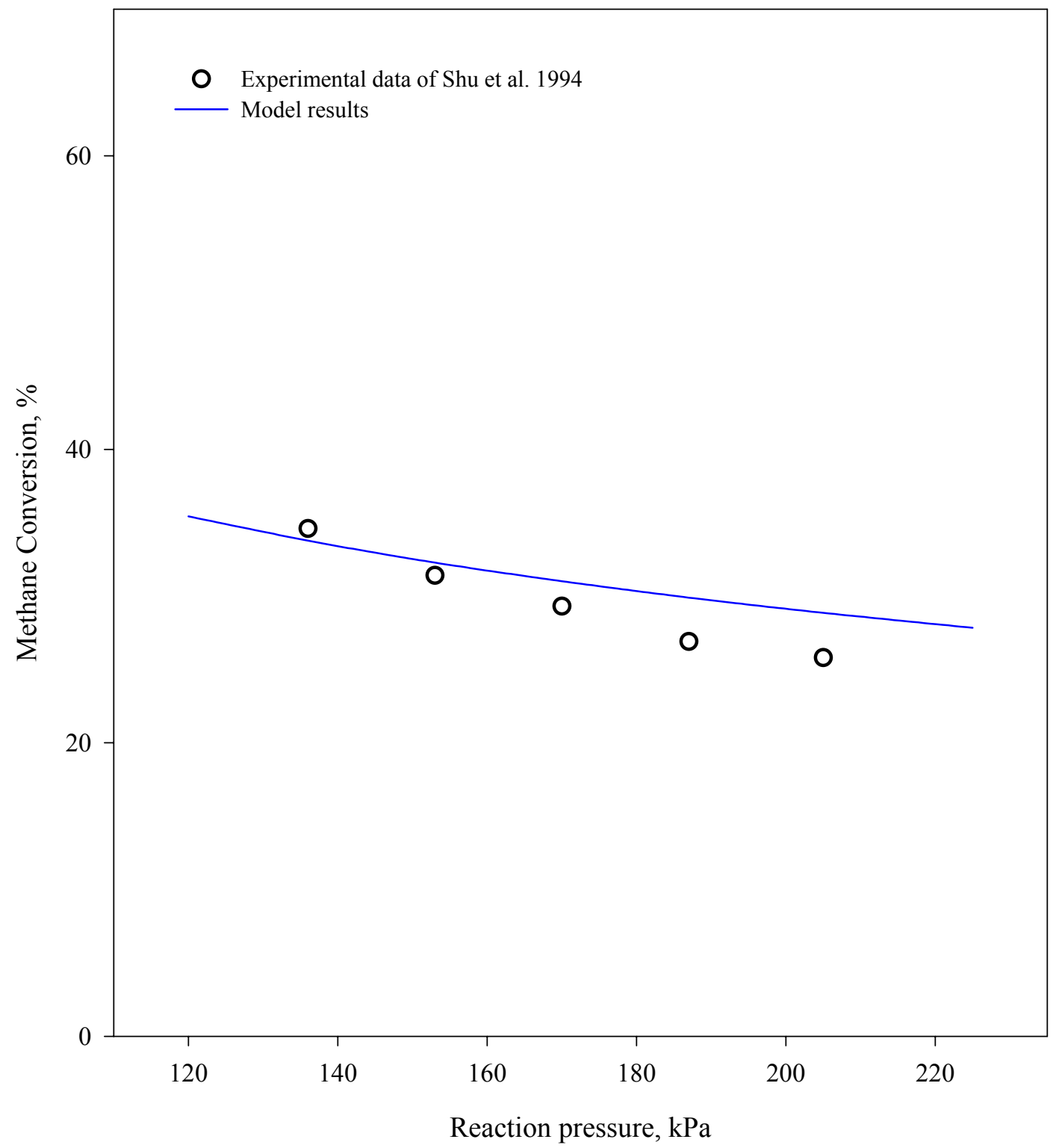

Figure 37. Pressure effect on methane conversion in the non-membrane PBR at $500{ }^{\circ} \mathrm{C}$ (Space velocity $=162 / 11 \mathrm{SCCM} / \mathrm{gm}_{\text {cat }}$, and Steam to methane molar feed ratio $=3.0$ ). 


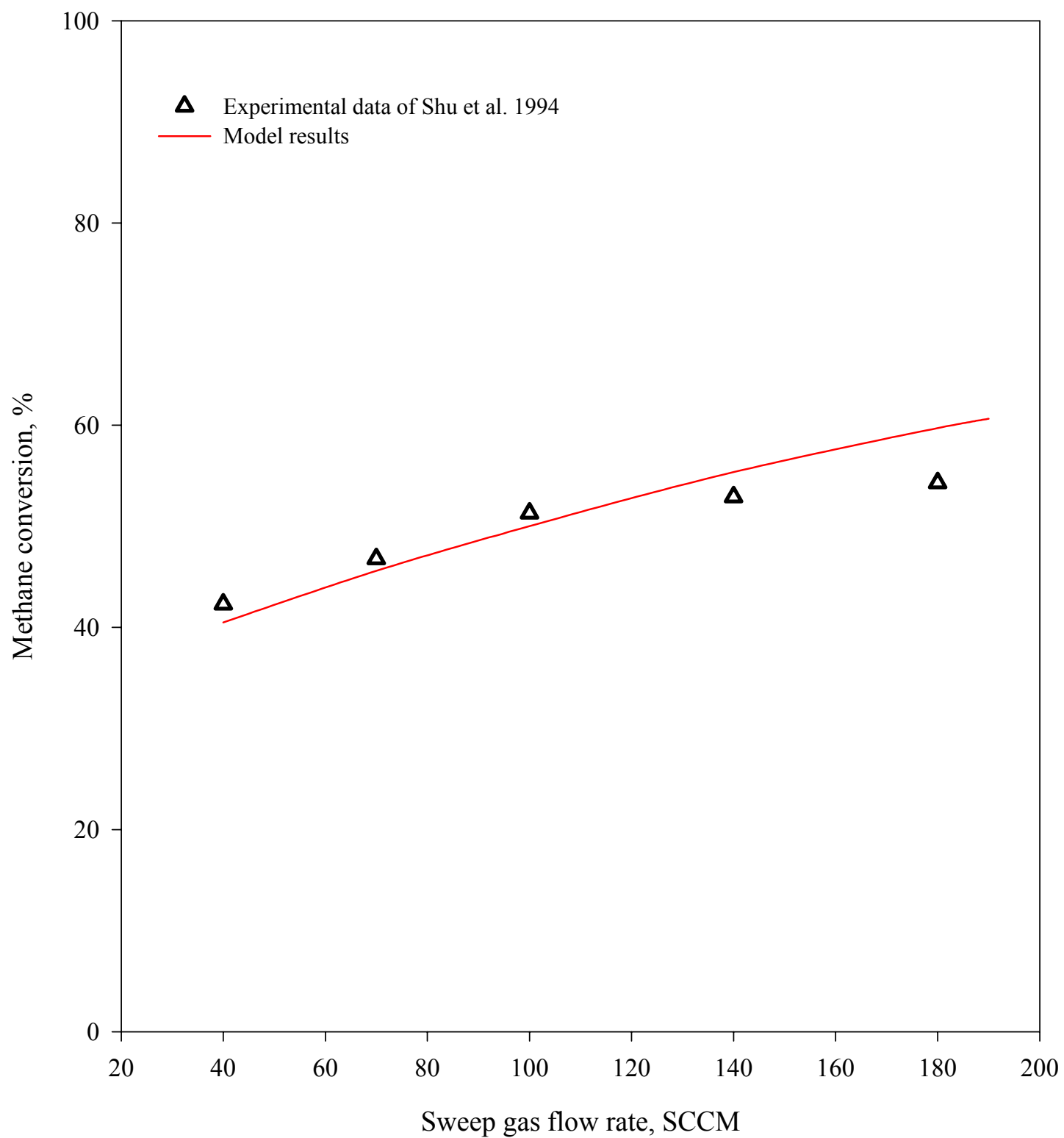

Figure 38. Effect of purge flow rate on total methane conversion in the membrane reactor at 500 ${ }^{\circ} \mathrm{C}$ and $136 \mathrm{kPa}$ (Space velocity $=162 / 11 \mathrm{SCCM} / \mathrm{gm}_{\text {cat }}$, and Steam to methane molar feed ratio $=$ $3.0)$. 